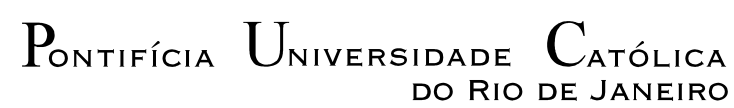

Érica Telles Carlos

\title{
Alocação de Custos pelo Uso do Sistema de Transmissão via Otimização Binível
}

Tese de Doutorado

Tese apresentada ao Programa de Pós-Graduação em Engenharia Elétrica da PUC-Rio como requisito parcial para obtenção do grau de Doutor em Engenharia Elétrica.

Orientador: Prof. Delberis Araujo Lima 


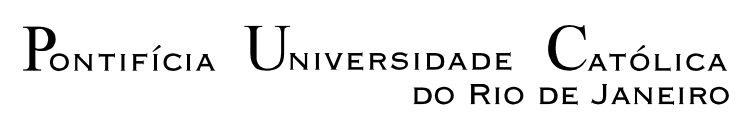

Érica Telles Carlos

\section{Alocação de Custos pelo Uso do Sistema de Transmissão via Otimização Binível}

Tese apresentada como requisito parcial para obtenção do grau de Doutor pelo Programa de Pós-Graduação em Engenharia Elétrica da PUC-Rio. Aprovada pela Comissão Examinadora abaixo assinada.

Prof. Delberis Araujo Lima

Orientador

Departamento de Engenharia Elétrica - PUC-Rio

Prof. Armando Martins Leite da Silva Departamento de Engenharia Elétrica - PUC-Rio

Prof. Reinaldo Castro Souza

Departamento de Engenharia Elétrica - PUC-Rio

Prof. Antonio Padilha Feltrin

Universidade Estadual Paulista Julio de Mesquita Filho

Profa. Carmen Lucia Tancredo Borges

UFRJ

Prof. Márcio da Silveira Carvalho

Coordenador Setorial do Centro

Técnico Científico - PUC-Rio

Rio de Janeiro, 28 de abril de 2016 
Todos os direitos reservados. É proibida a reprodução total ou parcial do trabalho sem autorização da autora, do orientador e da universidade.

\section{Érica Telles Carlos}

Obteve o título de mestre em engenharia elétrica pela PUCRio (Pontifícia Universidade Católica do Rio de Janeiro) em 2012. Graduou-se em Engenharia Elétrica pela mesma universidade em 2009. Sua área de pesquisa envolve alocação de tarifas de transmissão/distribuição, mercados de energia elétrica, e otimização.

Ficha Catalográfica

Carlos, Érica Telles

Alocação de custos pelo uso do sistema de transmissão via otimização binível / Érica Telles Carlos; orientador: Delberis Araujo Lima. - 2016.

117 f.: il. color. ; $29,7 \mathrm{~cm}$

Tese (doutorado)-Pontifícia Universidade Católica do Rio de Janeiro, Departamento de Engenharia Elétrica, 2016.

Inclui bibliografia.

1. Engenharia Elétrica - Teses. 2. Alocação de tarifas de transmissão. 3. Otimização binível. 4. Custos marginais de longo prazo. 5. Geração renovável. I. Lima, Delberis Araujo. II. Pontifícia Universidade Católica do Rio de Janeiro. Departamento de Engenharia Elétrica. III. Título.

CDD: 621.3 


\section{Agradecimentos}

À Pontifícia Universidade Católica do Rio de Janeiro (PUC-Rio) e aos seus profissionais e professores pela excelência no ensino, e por toda a estrutura e oportunidades a mim fornecidas que possibilitaram a conclusão dos cursos de graduação e pós-graduação.

Ao meu orientador Prof. Delberis Araujo Lima por toda a dedicação a este trabalho, e pela parceria e incentivo que sempre estiveram presentes.

Aos professores Natalia Alguacil e Javier Contreras por me receberem na Universidad de Castilla La-Mancha (UCLM) e pela importante contribuição para o aprimoramento e finalização deste trabalho. ¡Muchas gracias!

À minha família e ao Fernando por todo o suporte, paciência, compreensão e torcida constante pelo meu sucesso.

A todos os amigos que direta ou indiretamente participaram e me ajudaram para a conclusão do doutorado.

Ao CNPq, à FAPERJ e à CAPES pelos auxílios concedidos, sem os quais este trabalho não poderia ter sido realizado. 


\section{Resumo}

Carlos, Érica Telles; Lima, Delberis Araujo. Alocação de Custos pelo Uso do Sistema de Transmissão via Otimização Binível. Rio de Janeiro, 2016. 117p. Tese de Doutorado - Departamento de Engenharia Elétrica, Pontifícia Universidade Católica do Rio de Janeiro.

O trabalho "Alocação de Custos pelo Uso do Sistema de Transmissão via Otimização Binível" propõe uma nova abordagem para o problema de alocação de custos do sistema de transmissão, combinando os problemas de fluxo de potência e de cálculo das tarifas de transmissão, usualmente resolvidos separadamente, em um modelo de otimização binível. A proposta se baseia na multiplicidade de soluções viáveis para a alocação de custos através das componentes de fluxo. Tal conjunto viável de soluções existe devido às diferentes hipóteses que podem ser assumidas para calcular o caso base de fluxo de potência e para decompor os fluxos obtidos, atribuindo as componentes resultantes a geradores e demandas. Diante da diversidade de soluções, é proposto que seja escolhida àquela que atende de maneira ótima aos objetivos almejados pelo regulador e pelos usuários do sistema no que diz respeito à alocação de custos de transmissão. Devido à interdependência entre os problemas mencionados, tais objetivos são inseridos em um problema de otimização binível no qual o nível superior define o resultado de fluxo de potência, tendo como restrição o nível inferior que define o resultado de decomposição de fluxos e consequentemente de alocação de custos através de tarifas de transmissão. Neste trabalho, os objetivos representados no modelo de otimização proposto incluem dois pontos principais. O primeiro consiste em obter uma alocação que reflita os custos marginais de longo prazo (CMLP) do sistema. Assim, no nível superior, um modelo de fluxo de potência de pior caso maximiza os fluxos nas linhas de transmissão com o intuito de caracterizar a maior necessidade de investimentos na rede, e de refletir o CMLP. Já o segundo consiste em suavizar o valor das elevadas tarifas alocadas a usuários localizados em pontos desfavoráveis do sistema, e que não possuem flexibilidade para escolher seu ponto de instalação. É o caso, entre outros, dos geradores renováveis de grande porte do sistema brasileiro, instalados em pontos distantes dos grandes centros de demanda devido à disponibilidade geográfica do recurso renovável. Desta forma, no nível inferior, minimiza-se a amplitude tarifária do sistema, considerando restrições que 
mantém a coerência locacional da sinalização econômica das tarifas. O modelo proposto admite ainda limites máximo e mínimo de tarifas para garantir a suavização tarifária desejada, caso esta seja viável. De acordo com tais limites, a solução ótima do modelo binível proposto pode gerar três situações distintas: (i) os limites são restritos ao ponto tornar o problema inviável, (ii) os limites são tais que os dois níveis do problema são acoplados, ou (iii) os limites são menos restritos, e o resultado ótimo equivale à prática usual de resolver os dois níveis sequencialmente. Resultados numéricos são apresentados para um sistema didático de 6 barras e para o sistema IEEE 118 barras em diferentes configurações de demanda.

\section{Palavras-chave}

Alocação de tarifas de transmissão; otimização binível; custos marginais de longo prazo; geração renovável. 


\section{Abstract}

Carlos, Érica Telles; Lima, Delberis Araujo. (advisor). Transmission Costs Allocation via Bilevel Optimization. Rio de Janeiro, 2016. 117p. $\mathrm{PhD}$. Thesis - Departamento de Engenharia Elétrica, Pontifícia Universidade Católica do Rio de Janeiro.

The thesis "Transmission Cost Allocation via Bilevel Optimization" proposes a new approach to the transmission usage cost allocation problem, combining the power flow and tariff computation problems, usually solved separately, in a bilevel optimization model. The proposal is based on the multiplicity of feasible solutions to allocate costs by power flow components. Such a feasible set exists because of the different hypothesis that can be assumed to calculate the base case power flow, and to decompose the obtained power flows, assigning its components to generators and demands. Given the diversity of solutions, it is proposed that the chosen one should optimally meet the objectives specified by the system regulator and users concerning the costs allocation. Because of the interdependence between the mentioned problems, such objectives are inserted into a bilevel optimization problem in which the upper level defines the power flow results, having the lower level as a constraint that gives the power flow decomposition solution and, as a consequence, the cost allocation through tariffs assigned to generators and demands. In this work, the objectives represented in the optimization model include two main aspects. The first one is to obtain a cost allocation that reflects the system's long run marginal costs (LRMC). Thus, in the upper level, a worst-case power flow model maximizes the lines' flows in order to characterize the base case that causes the greatest need for transmission investments, and reflects the LRMC. The second consists in smooth out the high tariffs assigned to users located at unfavorable regions of the system and that do not have the freedom to choose their location. This is the case, among others, of the renewable generators in the Brazilian transmission system that are part of the system expansion planning, and are placed far away from the load centers due to the geographic availability of the renewable resource. Hence, in the lower level, the transmission tariff amplitude is minimized considering constraints that ensure the locational coherence of the tariffs economic signals. Additionally, the proposed model 
admits upper and lower tariff bounds to ensure the desired tariff smooth, if it is feasible. Given these bounds in, the optimal solution of the proposed bilevel model can provide three different situations: (i) the limits are restricted to the point that the problem is infeasible, (ii) the limits are such that the levels are coupled, or (iii) the limits are less restricted, and the optimal solution is equivalent to the common practice of solve both levels sequentially. Numerical results are presented to a 6-bus didactic system and to the IEEE 118-bus system under different demand configurations.

\section{Keywords}

Transmission tariff allocation; bilevel optimization; long run marginal cost; renewable plants. 


\section{Sumário}

1 Introdução

1.1. Multiplicidade de soluções na alocação de tarifas de transmissão

1.2. Fluxo de potência e decomposição de fluxos via modelos de otimização

1.3. Alocação de tarifas de transmissão via otimização binível 22

1.4. Organização do documento 28

2 Revisão bibliográfica

30

3 Modelo de despacho de geração de pior caso 38

4 Modelo de tarifação de mínima amplitude

4.1. Método Nodal

4.2. Método de Tarifação de Mínima Amplitude

45

4.2.1. Decomposição de fluxos via fatores de intercâmbio nodal 45

4.2.2. Formulação da tarifa de transmissão

4.2.3. Modelo de otimização TMA

5 Alocação binível de tarifas de transmissão

5.1. Modelo de otimização ABTT

5.2. Análise de soluções

6 Resultados

6.1. Sistema de 6 barras

62

6.2. Sistema de 118 barras

65

6.2.1. Avaliação do método proposto

6.2.2. Comparação com o método Nodal

6.2.3. Comparação com outros métodos de alocação de tarifas de 
transmissão

6.2.4. Desempenho computacional 78

7 Conclusões $\quad 84$

8 Trabalhos futuros $\quad 87$

8.1. Aplicação da alocação binível de tarifas de transmissão em sistemas multiárea

8.2. Utilização do sinal locacional ótimo para decisões de planejamento do sistema

9 Referências bibliográficas

Apêndice A Matriz de sensibilidade de fluxos

B.1. Pro rata 100

B.2. Zbus 101

B.3. Equivalent Bilateral Exchanges 103

Apêndice C Linearização do modelo ABTT via expansão binária 106

Apêndice D Dados de Simulação 111

D.1. Sistema 6 barras 111

D.2. Sistema 118 barras 111 


\section{Lista de figuras}

Figura 1.1. Ilustração da multiplicidade de soluções da decomposição de fluxo 21

Figura 1.2. Estrutura geral da alocação de tarifas de transmissão via otimização binível

Figura 1.3. Localização das regiões de maior consumo e maios expansão de geração no Brasil

Figura 1.4. Ilustração do objetivo de tarifas de mínima amplitude 26

Figura 1.5. Método de alocação binível de tarifas de transmissão 27

Figura 4.1. Metodologia de minimização da amplitude tarifária 49

Figura 5.1. Estresse máximo do sistema $y_{A B T T}^{*}$ como função de $z^{M A X}$ com $w^{M I N}$ fixo

Figura 5.2. Processo de alocação das tarifas de transmissão 60

Figura 6.1. Sistema de 6 barras $\quad 62$

Figura 6.2. Sistema de 118 barras $\quad 65$

Figura 6.3. Máximo estresse do sistema em função do limite tarifário $Z^{M A X}\left(\operatorname{com} w^{M I N}=0\right)$ no sistema de 118 barras

Figura 6.4. Despachos de geração do sistema de 118 barras com demanda original para diferentes valores de $z^{M A X}$ e $w^{M I N}=0$

Figura 6.5. Despachos de geração do sistema de 118 barras com incremento para diferentes valores de $z^{M A X}$ e $w^{M I N}=0$

Figura 6.6. Tarifas locacionais de geradores do sistema de 118 barras com demanda original para diferentes valores de $z^{M A X}$ e $w^{M I N}=0$

Figura 6.7. Tarifas locacionais de geradores do sistema de 118 barras

com incremento de demanda para diferentes valores de $z^{M A X}$ e $w^{M I N}=0$

Figura 6.8. Tarifas finais para geradores para o sistema de 118 barras com demanda original e com incremento de demanda $\left(z^{M A X}=12\right.$ e $\left.w^{M I N}=0\right)$

Figura 6.9. Tarifas finais para as demandas 1 a 58 para o sistema de 118 barras com demanda original e com incremento de demanda $\left(z^{M A X}=12 \mathrm{e}\right.$ $\left.w^{M I N}=0\right)$

Figura 6.10. Tarifas finais para as demandas 60 a 118 para o sistema de 118 barras com demanda original e com incremento de demanda $\left(z^{M A X}=12 \mathrm{e}\right.$ $w^{M I N}=0$ )

Figura 8.1. Representação de um sistema multiárea

Figura 8.2. Sistema multiárea equivalente para alocação de tarifas pelo uso das LI

Figura 8.3. Sistema multiárea para alocação de custos da área interna 
Figura 8.4. Estrutura de alimentação de variáveis entre os problemas de tarifação e planejamento de geração e de transmissão

Figura B.1. Circuito П equivalente de uma linha de transmissão $\ell$ 


\section{Lista de tabelas}

Tabela 6.1. Fluxos de potência do sistema de 6 barras 63

Tabela 6.2. Valores de $\alpha_{G i j}$ e $\alpha_{G i j} P_{G i}$ para o sistema de 6 barras 63

Tabela 6.3. Valores de $\alpha_{D j i}$ e $\alpha_{D j i} P_{D j}$ para o sistema de 6 barras 63

Tabela 6.4. Componentes de fluxo provocadas pelo gerador 5 em MW 64

Tabela 6.5. Estatísticas das tarifas de demanda para o sistema de 118 barras com incremento de demanda

Tabela 6.6. Comparação de resultados do modelo ABTT para o sistema de 6 barras com $z^{M A X}=7$ e $w^{M I N}=0$

Tabela 6.7. Comparação de tempo de execução entre o modelo não-linear (solver CONOPT) e o modelo LIM via Expansão Binária (solver CPLEX) para o método ABTT

Tabela D.1. Dados de barra para o sistema de 6 barras 111

Tabela D.3. Dados de barra para o sistema de 118 barras 111

Tabela D.4. Dados de linha para o sistema de 118 barras 114 


\section{Abreviaturas e símbolos}

\section{Siglas}

ABTT Alocação binível de tarifas de transmissão

ATT Alocação de tarifas de transmissão

CMLP Custos marginais de longo prazo

DPC Despacho de geração de pior caso

EBE Equivalent bilateral exchange

FPO Fluxo de potência ótimo

NEF Fator de intercâmbio nodal / Nodal exchange factor

PDP Princípio da divisão proporcional

PTDF Fatores de distribuição da transferência de potência / Power transfer distribution factors

Tarifação de mínima amplitude

\section{Índices}

$b \quad$ Índice de barras

$i \quad$ Índice de geradores

j I Índice de demandas

$\ell \quad$ Índice de linhas de transmissão

$r \quad$ Índice da barra de referência do sistema

\section{Conjuntos}

$\Omega_{B} \quad$ Conjunto de barras

$\Omega_{G} \quad$ Conjunto de barras que contém geradores

$\Omega_{D} \quad$ Conjunto de barras que contém demandas

$\Omega_{L} \quad$ Conjunto de linhas de transmissão

\section{Constantes e variáveis}

$\alpha_{G i j} \quad$ Fator de intercambio nodal para o gerador $i$, referente ao par $(i, j)$

$\alpha_{D j i} \quad$ Fator de intercambio nodal para a demanda $j$, referente ao par $(i, j)$

$\boldsymbol{\beta} \quad$ Matriz de sensibilidade de fluxos do sistema 
$\beta_{\ell b} \quad$ Sensibilidade de fluxo da linha $\ell$ devido a uma injeção/extração de potência na barra $b$ dada uma barra de referência $r$

$\beta_{\ell i} \quad$ Sensibilidade de fluxo da linha $\ell$ devido a uma injeção de potência na barra $i$ e extração na barra de referência $r$

$\beta_{\ell j} \quad$ Sensibilidade de fluxo da linha $\ell$ devido a uma injeção de potência na barra de referência $r$ e extração na barra $j$

$\gamma_{i j \ell} \quad$ Fator de distribuição de potência da linha $\ell$ dada uma injeção de potência na barra $i$ e extração na barra $j$

$\triangle_{G}^{N O D A L} \quad$ Parcela selo fornecida pelo método Nodal para geradores, em \$/MW

$\triangle_{D}^{N O D A L} \quad$ Parcela selo fornecida pelo método Nodal para demandas, em \$/MW

$\Delta_{G}^{T M A} \quad$ Parcela selo fornecida pelo método TMA para geradores, em \$/MW

$\Delta_{D}^{T M A} \quad$ Parcela selo fornecida pelo método TMA para demandas, em $\$ / \mathrm{MW}$

$\varepsilon_{i}^{G}, \varepsilon_{j}^{D} \quad$ Variáveis duais das restrições de balanço de potência via NEFs de geradores $i$ e demandas $j$ do método TMA

$\theta_{i}^{U}, \theta_{i}^{L} \quad$ Variáveis duais das restrições de minimização da amplitude das tarifas dos geradores $i$ no método TMA

$\pi_{G i}^{N O D A L} \quad$ Tarifa locacional fornecida pelo método Nodal para o gerador $i$, em \$/MW

$\pi_{D j}^{N O D A L} \quad$ Tarifa locacional fornecida pelo método Nodal para a demanda $j$, em \$/MW

$\pi_{G i}^{T M A} \quad$ Tarifa locacional fornecida pelo método TMA para o gerador $i$, em \$/MW

$\pi_{D j}^{T M A} \quad$ Tarifa locacional fornecida pelo método TMA para a demanda $j$, em \$/MW

$\rho^{U}, \rho^{L} \quad$ Variáveis duais das restrições de limite máximo e mínimo das tarifas do método TMA, respectivamente

$\tau_{i j} \quad$ Variáveis duais das restrições de coerência dos NEFs do método TMA para cada par $(i, j)$

$\varphi_{j}^{U}, \varphi_{j}^{L} \quad$ Variáveis duais das restrições de minimização da amplitude das tarifas das demandas $j$ do método TMA

$c_{\ell} \quad$ Custo unitário da linha $\ell$ em $\$$ /MW

$C_{\ell}^{T} \quad$ Custo total da linha $\ell$ em $\$$ 
$C_{S I S T}^{T} \quad$ Custo total a ser remunerado na alocação de tarifas em $\$$

$\operatorname{Cap}_{\ell} \quad$ Capacidade de transmissão da linha $\ell$ em MW

$F_{\ell} \quad$ Fluxo de potência ativa DC através da linha $\ell$ em MW

$F_{\ell}^{i, j} \quad$ Componente de fluxo de potência através da linha $\ell$ em MW devido

à injeção de potência na barra $i$ e extração na barra $j$

Fpond $_{\ell} \quad$ Fator de ponderação da linha $\ell$

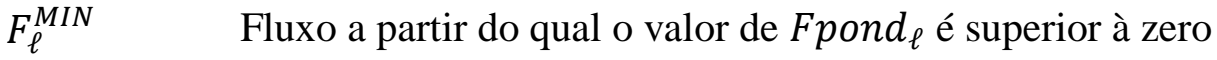

$M \quad$ Média das tarifas locacionais

$n_{G} \quad$ Número de geradores

$n_{D} \quad$ Número de demandas

$n_{L} \quad$ Número de linhas de transmissão

$n_{B} \quad$ Número de barras

$P_{b} \quad$ Potência líquida injetada na barra $b$ em MW

$P_{D b} \quad$ Demanda máxima na barra $b$ em MW

$P_{D j} \quad$ Demanda máxima na barra $j$ em MW

$P_{G b} \quad$ Despacho de potência do gerador na barra $b$ em MW

$P_{G i} \quad$ Despacho de potência do gerador na barra $i$ em MW

$P_{G i}^{M A X} \quad$ Máxima potência despachável do gerador na barra $i$, em MW

$P_{G i}^{M I N} \quad$ Mínima potência despachável do gerador na barra $i$, em MW

$t_{G i}^{N O D A L} \quad$ Tarifa final fornecida pelo método Nodal para o gerador $i$, em \$/MW

$t_{D j}^{N O D A L} \quad$ Tarifa final fornecida pelo método Nodal para a demanda $j$, em \$MW

$t_{G i}^{T M A} \quad$ Tarifa final fornecida pelo método TMA para o gerador $i$, em \$/MW

$t_{D j}^{T M A} \quad$ Tarifa final fornecida pelo método TMA para a demanda $j$, em \$/MW

$y_{D P C} \quad$ Valor da função objetivo do modelo DPC

$y_{\text {TMA }} \quad$ Valor da função objetivo do método TMA

$y_{T M A-D u a l}$ Valor da função objetivo do modelo dual do método TMA

$y_{A B T T} \quad$ Valor da função objetivo do modelo ABTT

$y_{V A R} \quad$ Valor da função objetivo do modelo de minimização da variância tarifária

$Z^{M A X}, W^{M I N} \quad$ Limites superior e inferior de tarifa, respectivamente, em \$/MW 
$z, w \quad$ Variáveis auxiliares para a minimização da amplitude de tarifas no método TMA

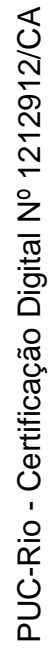




\section{1 \\ Introdução}

O sistema elétrico, ou rede, de transmissão é composto pelo conjunto de equipamentos (linhas de transmissão, transformadores, torres, etc.) que permitem o transporte de grandes blocos de energia elétrica dos geradores para as áreas de consumo. Investimentos neste sistema têm o intuito de garantir sua confiabilidade e robustez. A construção e manutenção de novas linhas de transmissão e de reforços na rede viabiliza o atendimento à demanda atual, ao crescimento de demanda previsto, bem como à conexão da expansão de geração ao sistema. $\mathrm{O}$ custo associado a estes investimentos (custo de uso do sistema) é repassado para os usuários da rede, geralmente concessionárias de geração e de distribuição, que aqui, por simplicidade, serão denominados geradores e demandas. Este repasse torna necessário estabelecer um método capaz de repartir o custo total a ser remunerado entre geradores e demandas. Na prática, tarifas de uso do sistema de transmissão são atribuídas a cada usuário da rede, ou a cada barra do sistema onde geradores e demandas se instalam, e aplicadas periodicamente de forma que o custo de uso do sistema seja recuperado. A este processo chamaremos de Alocação de Tarifas de Transmissão (ATT).

\section{1.}

\section{Multiplicidade de soluções na alocação de tarifas de transmissão}

O problema de ATT envolve diferentes aspectos, o que faz com que sua solução não seja única. Para cada país, ou sistema de transmissão, existem regras regulatórias e estruturas econômicas particulares. Além disso, a definição do uso do sistema de transmissão por cada gerador e demanda está aberta a diferentes interpretações. Assim, diversos métodos são propostos na literatura atual para resolver o problema de ATT, assumindo hipóteses e considerações distintas para caracterizar e atender às possíveis particularidades e restrições de cada sistema [1,2,3]. Apesar de possuir objetivos diferentes em relação à definição das tarifas de transmissão, todo método deve ser bem fundamentado e justificado por 
perspectivas econômicas e/ou por características físicas da rede de transmissão. Este contexto faz com que não exista um método ideal universal, mas sim métodos mais adequados a cada país ou sistema de transmissão.

Devido as estas características do problema de ATT, um possível critério de escolha para um método é adotar aquele que melhor representa os objetivos e expectativas do regulador, dos usuários e dos investidores do sistema de transmissão em relação às tarifas [1]. De maneira geral, as suas preferências podem variar entre dois extremos: (i) socializar os custos totais do sistema entre os usuários [4,5], com tarifas iguais para os geradores e demandas, assumindo que todos utilizam a rede de maneira igualitária e que a tarifa não desempenha um papel de prover sinais econômicos; (ii) diferenciar o uso das linhas de transmissão por cada usuário através da avaliação de componentes de fluxo de potência, e assim fornecer fortes sinais econômicos com tarifas que traduzem o quanto geradores e demandas efetivamente usam o sistema e afetam a necessidade de investimentos no mesmo [3]. Métodos que se encaixam em (i) são recomendados para sistemas consolidados e altamente interligados, com demanda e geração bem distribuídos geograficamente, e com previsão de crescimento pouco acentuado. Já métodos associados a (ii) se aplicam a sistemas de grande porte, com concentrações geográficas de demanda e geração, e em forte processo de expansão.

Neste contexto de adequação entre os métodos de ATT e as características dos sistemas de transmissão, a grande maioria dos sistemas está em expansão, com a existência de um mercado desregulado para a geração [5,6]. Como consequência, as tarifas de transmissão podem atuar como sinalizadores econômicos que apoiam as decisões de expansão da rede e encorajam novos usuários a se instalarem em pontos benéficos para o sistema. Esta sinalização, denominada sinal locacional, age como um auxílio para evitar investimentos adicionais em reforços e na criação de novas interligações na rede. A ideia geral é alocar tarifas maiores às barras nas quais a presença do usuário provoque maior uso do sistema e contribua para o esgotamento da capacidade de transmissão disponível, e consequentemente para seu congestionamento. De maneira análoga, tarifas menores são alocadas às barras nas quais a presença do usuário provoca menor uso das linhas, contribuindo para o alívio das linhas de transmissão. Para atender a este objetivo, métodos baseados na avaliação do uso da rede através de 
componentes de fluxos de potência são amplamente utilizados, e serão o foco deste trabalho.

Nesta classe de métodos, é avaliada a responsabilidade ou impacto de cada usuário na composição dos fluxos de potência ativa pelas linhas. Assim, a partir de um resultado de fluxo de potência do sistema (caso base), o fluxo em cada uma das linhas é decomposto, suas componentes atribuídas aos geradores e demandas, e desta atribuição o valor da tarifa é definido em função de custos associados às linhas. Na prática atual, os problemas que definem o caso base de fluxo de potência e a decomposição dos fluxos são resolvidos em separado e sequencialmente [6]. Conforme mencionado anteriormente, este processo de cálculo está aberto a diferentes hipóteses e interpretações, e por isso possui múltiplas soluções viáveis. Mais especificamente, tal diversidade pode ser associada a dois pontos: (i) as hipóteses assumidas para calcular o caso base de fluxo de potência e (ii) os métodos possíveis para a decomposição dos fluxos nas linhas e atribuição das componentes resultantes aos usuários.

\section{2. \\ Fluxo de potência e decomposição de fluxos via modelos de otimização}

A solução do caso base de fluxo de potência pode representar um ponto de operação real do sistema, atender a um nível de carregamento de uma área ou elemento específico da rede, ou qualquer outra escolha justificável. Conforme mencionado anteriormente, esta decisão depende do(s) objetivo(s) definido(s) para o resultado final de ATT. Nos casos em que tal objetivo não corresponde a um resultado fixo previamente definido (como um ponto de operação real da rede, por exemplo), a melhor solução possível pode encontrada através de um modelo de otimização que segue o conceito de fluxo de potência ótimo (FPO). O FPO determina o ponto de operação ou estado do sistema que otimiza um objetivo predefinido, respeitando os limites físicos e operativos da rede. É frequentemente utilizado em problemas de operação e planejamento de sistemas [7,8,9], em aplicações no mercado de energia elétrica [10,11], entre outros [12,13,14]. No contexto deste trabalho, o estado do sistema desejado para o cálculo das tarifas pode ser representado em uma função objetivo a ser otimizada (maximizada ou minimizada). Tal otimização fica sujeita ao conjunto viável de soluções de fluxo 
de potência, delimitado por restrições que definem as grandezas e limites físicos do sistema considerados. Assim, neste trabalho é proposto que o caso base de fluxo de potência atenda através de um modelo de otimização a um objetivo predefinido.

A partir do resultado de fluxo de potência desejado, a decomposição dos fluxos em cada linha pode ser feita por diferentes métodos, utilizando hipóteses distintas, e assim criando um conjunto de múltiplas soluções possíveis. Neste conjunto, todos os resultados recuperam o caso base do fluxo de potência, e por isso são viáveis e corretos. Esta ideia é ilustrada na Figura 1.1, na qual o fluxo de potência por uma linha $k-m$ pode ser recuperado por $n$ soluções de decomposição de fluxo. Entre outros fatores, desta multiplicidade de soluções surgem diferentes métodos de ATT, cada um com seus critérios para acessar uma das soluções viáveis. Como exemplo, entre os muitos métodos tradicionais existentes na literatura, os métodos baseados no conceito de Custos Marginais de Longo Prazo (CMLP) [15] têm como objetivo fornecer tarifas que representem o custo adicional de investimento na rede para suprir um incremento unitário (1 MW) de geração/demanda de um usuário em particular. É considerada a hipótese de uma rede ideal de custo mínimo que não possui folgas de transmissão. Para tanto, parâmetros de sensibilidade de fluxo da rede, e simplificações do fluxo de potência DC são utilizados na decomposição de fluxos e na formulação da tarifa.

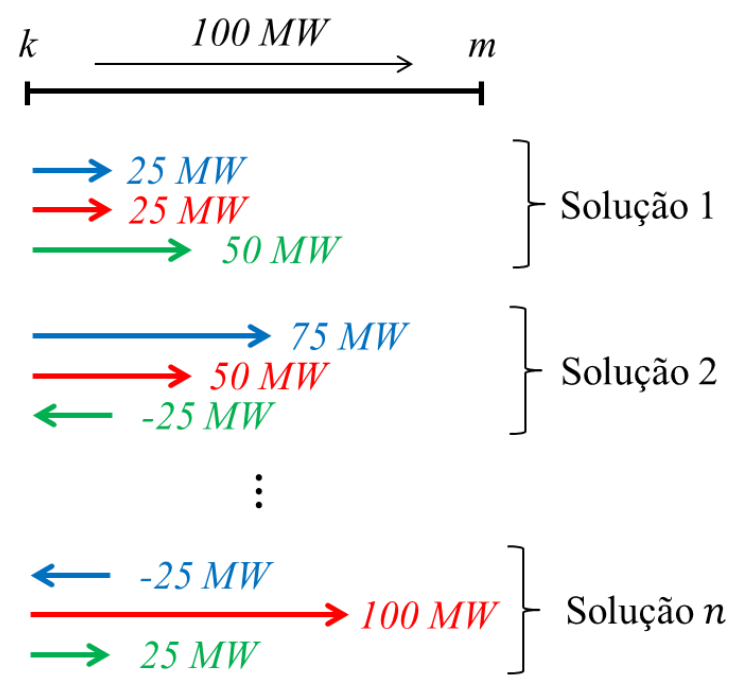

Figura 1.1. Ilustração da multiplicidade de soluções da decomposição de fluxo

Quando os métodos tradicionais não atingem de maneira eficiente o resultado de decomposição que resulta nas características desejadas para as tarifas, uma abordagem alternativa é representá-las em um problema de otimização. Neste 
caso, entre todas as soluções possíveis para a decomposição, a escolhida será aquela que resulte no valor ótimo da função objetivo, que por sua vez é a representação do critério desejado para as tarifas. Naturalmente, neste tipo de abordagem, é definida uma ou mais variáveis de decisão que criam um grau de liberdade na definição da decomposição de fluxo. Um exemplo desta classe de métodos tem como objetivo minimizar a diferença entre as tarifas de um método baseado em fluxos e as de um método de socialização de custos, visando aumentar a equidade das tarifas mantendo uma sinalização locacional [16]. Neste caso as soluções de decomposição de fluxo são acessadas através do traçado de potência pela rede (variável de decisão). Aqui, o traçado de potência associado a um usuário pode ser definido como o caminho formado pelas componentes de fluxo associadas a ele ao longo das linhas de transmissão.

Assim, conforme proposto para o resultado de caso base de fluxo de potência, neste trabalho o resultado de decomposição de fluxos, e consequentemente de tarifas de transmissão, será obtido através de um modelo de otimização que atende a um critério predefinido. A solução de ambos os problemas por modelos de otimização cria uma grande adaptabilidade de todo o processo de ATT ao sistema de transmissão no qual está sendo aplicado.

\section{3. \\ Alocação de tarifas de transmissão via otimização binível}

Seguindo a ideia de definir o caso base de fluxo de potência e as tarifas (ou a decomposição de fluxos) através de problemas de otimização, vemos que há uma interdependência entre os respectivos conjuntos viáveis. $\mathrm{Na}$ prática, dependendo dos objetivos estabelecidos, o problema de cálculo de tarifas pode influenciar o conjunto viável do problema de fluxo de potência, e vice-versa. Esta relação é evidenciada em [17], e será abordada nos Capítulos 5 e 6 deste documento. Desta forma, resolver os dois problemas separadamente e em sequência pode resultar em tarifas subótimas ou inviáveis para os objetivos escolhidos. Assim, os cálculos do caso base de fluxo de potência e das tarifas de transmissão podem ser tratados em um único problema baseado em otimização binível. Neste problema, a otimização da tarifa é restrição na definição do conjunto viável do problema de fluxo de potência, conforme representado na 
Figura 1.2. Esta estrutura geral fica aberta às escolhas das funções objetivo que representam a diretriz para o fluxo de potência (nível superior) e o critério adotado para as tarifas (nível inferior) que melhor atende a determinado sistema. Consequentemente, a abordagem proposta pode ser aplicada em diferentes sistemas para objetivos distintos.

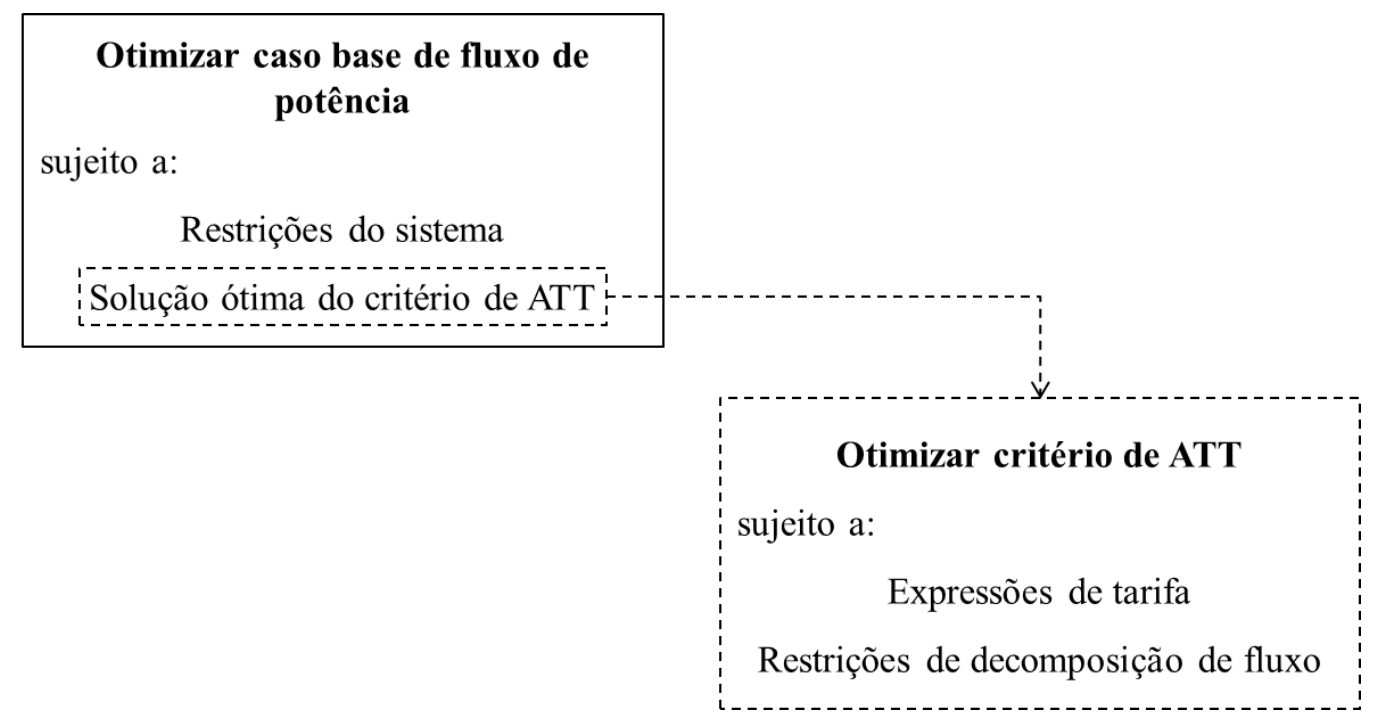

Figura 1.2. Estrutura geral da alocação de tarifas de transmissão via otimização binível

A partir da abordagem apresentada na Figura 1.2, este trabalho propõe um novo método de ATT que consiste na particularização da estrutura geral de otimização binível para um cenário prático.

No nível superior, um exemplo prático consiste em utilizar a solução do fluxo de potência que provoca a maior necessidade de investimentos na transmissão [15,17]. Esta diretriz, além de ser aplicada em sistemas de transmissão reais como o brasileiro, está contida nas hipóteses e indicações de métodos baseados em CMLP, que serão a base para a definição das tarifas no nível inferior.

Neste caso, assume-se que as configurações de geração e demanda são tais que os fluxos de potência pelas linhas são os máximos possíveis. Do ponto de vista da alocação de custos de transmissão, as tarifas são calculadas sob um cenário de pior caso ou de máximo estresse do sistema. Para atingir a situação de máximo estresse, uma prática comum consiste em despachar os geradores proporcionalmente à sua capacidade de geração até que a demanda máxima da rede, ou de subsistemas predefinidos, seja atendida $[15,17,18]$. No entanto, ao não avaliar diretamente como a disposição de geração pelo sistema impacta nos fluxos de potência, a solução ótima de máximo estresse da rede não pode ser garantida 
[17]. Assim, neste trabalho é proposto que o caso base de fluxo de potência atenda ao objetivo de maximizar os fluxos pelas linhas considerando em suas restrições a estrutura da rede e o impacto da disposição de geração nos fluxos pelas linhas. A função objetivo a ser maximizada é o somatório dos fluxos de potência de todas as linhas, tendo como variável de decisão o despacho de geração. Neste caso, as restrições que delimitam o conjunto de soluções viáveis devem considerar também os limites físicos gerais do sistema, e a demanda máxima do sistema. Ao longo deste documento, este problema será referido como Despacho de Geração de Pior Caso (DPC).

No nível inferior, o critério de ATT proposto envolve o contexto de usuários instalados em pontos isolados na rede e as tarifas de transmissão que eles recebem. Em sistemas de grande porte, que são altamente congestionados e/ou estão em expansão, usuários localizados em regiões mais isoladas tendem a receber sinais locacionais rigorosos em suas tarifas quando métodos baseados em fluxo são utilizados. Um exemplo realista de tal quadro ocorre com os geradores renováveis, principalmente grandes usinas hidrelétricas, no sistema de transmissão brasileiro. Neste sistema, as tarifas são alocadas utilizando o método Nodal [18], que é baseado em CMLP.

A matriz de energia elétrica brasileira é majoritariamente composta por fontes renováveis, com destaque para a geração hidrelétrica que atualmente ocupa $65,2 \%$ da oferta total de energia [19]. Com o acentuado crescimento de consumo de energia elétrica no país, a maior parte dos aproveitamentos hidrelétricos existentes próximos às maiores concentrações de demandas, que ocorrem na região sudeste, já foram explorados. Assim, o planejamento ótimo de expansão de geração do sistema inclui cada vez mais o aproveitamento de rios e bacias hidrográficas disponíveis em pontos mais distantes. É o caso da região hidrográfica amazônica no norte do país, que concentra 93\% da expansão em potência instalada prevista até 2024 [20]. Além disso, novos empreendimentos de energia solar e eólica apresentam notável crescimento na região nordeste [20]. A disposição das concentrações de consumo e expansão de geração no território do país é ilustrada na Figura 1.3. 


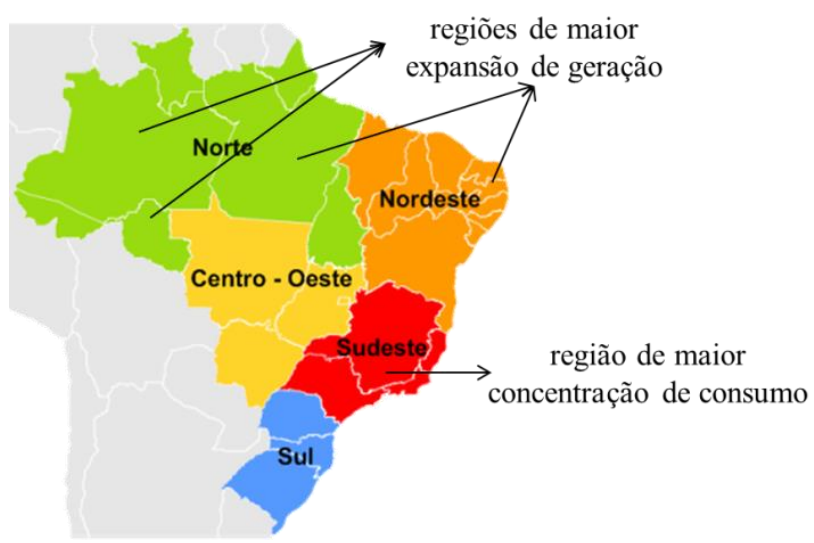

Figura 1.3. Localização das regiões de maior consumo e maios expansão de geração no Brasil

Com a utilização do método Nodal, e as dimensões continentais do país, a localização dos geradores mencionados faz com que recebam sinais locacionais rigorosos e consequentemente tarifas elevadas. Como exemplo, no ciclo tarifário 2015-2016, usinas renováveis nos estados do Acre e Rondônia (região norte), e no do estado do Rio Grande do Norte (região nordeste) apresentam tarifas de 2 a 4 vezes mais elevadas que a média tarifária do restante do sistema [21]. Adicionalmente, tais geradores têm sua localização condicionada à presença geográfica do recurso renovável, não possuindo a opção de instalar-se em uma região do sistema com tarifas menores. Assim, forma-se um quadro no qual os sinais locacionais das tarifas não incentivam o aproveitamento da disponibilidade de recursos energéticos renováveis e, simultaneamente, algum tipo de sinal locacional é necessário para atender às características do sistema e de seu mercado.

Um indicativo da relevância das tarifas na viabilidade dos empreendimentos de geração, são as intervenções realizadas pela Agência Nacional de Energia Elétrica (ANEEL). Tais intervenções atuam diretamente no valor das tarifas, e são externas à formulação do método Nodal. Com o intuito de incentivar principalmente o ingresso de fontes renováveis no sistema, é dado um desconto na tarifa que pode variar de $50 \%$ a $100 \%$ do valor original fornecido pelo método Nodal para um grupo específico de usinas de geração. Neste grupo estão usinas de até 30 MW de potência com geração eólica, solar, a base de biomassa e de cogeração qualificada, ou pequenas centrais hidrelétricas $(\mathrm{PCH})$ de até $1 \mathrm{MW}$ de potência [22]. Além disso, para controlar a variabilidade temporal das tarifas fornecidas pelo método Nodal frente às diversas mudanças previstas na rede, os geradores possuem tarifa fixa por 10 ciclos tarifários anuais. Esta tarifa fixa é 
igual à média aritmética das tarifas originais calculadas para cada ciclo tarifário com base no estudo oficial de planejamento para expansão do sistema [23]. Especialmente para usinas vencedoras de leilões de energia nova (LEN), tal tarifa fixa é estabelecida no ato do leilão, além de ter validade estendida para toda a vigência de sua outorga. Nestas intervenções, destaca-se principalmente que são feitas externamente ao método de cálculo das tarifas, distorcendo a influência do uso do sistema em seu valor.

Neste caso, tendo como inspiração [17,24], um critério prático seria estabelecer limites tarifários, e minimizar a amplitude de variação das tarifas com o objetivo de suavizar o impacto dos sinais locacionais para os geradores isolados. Simultaneamente, o critério também deve incluir a manutenção de sinais locacionais coerentes para todos os usuários do sistema. Os limites tarifários (máximo e mínimo) tem o papel de permitir ao regulador inserir um valor ideal para a faixa máxima de variação das tarifas. A partir desta faixa, a minimização da amplitude tarifária garante o melhor incentivo viável para os geradores em foco através da redução dos valores mais elevados ou picos de tarifa. Neste processo, os parâmetros do sistema são considerados nas expressões de tarifa e na decomposição de fluxo. Consequentemente, a coerência dos sinais locacionais é mantida. A Figura 1.4 ilustra o efeito esperado ao adotar o critério descrito.

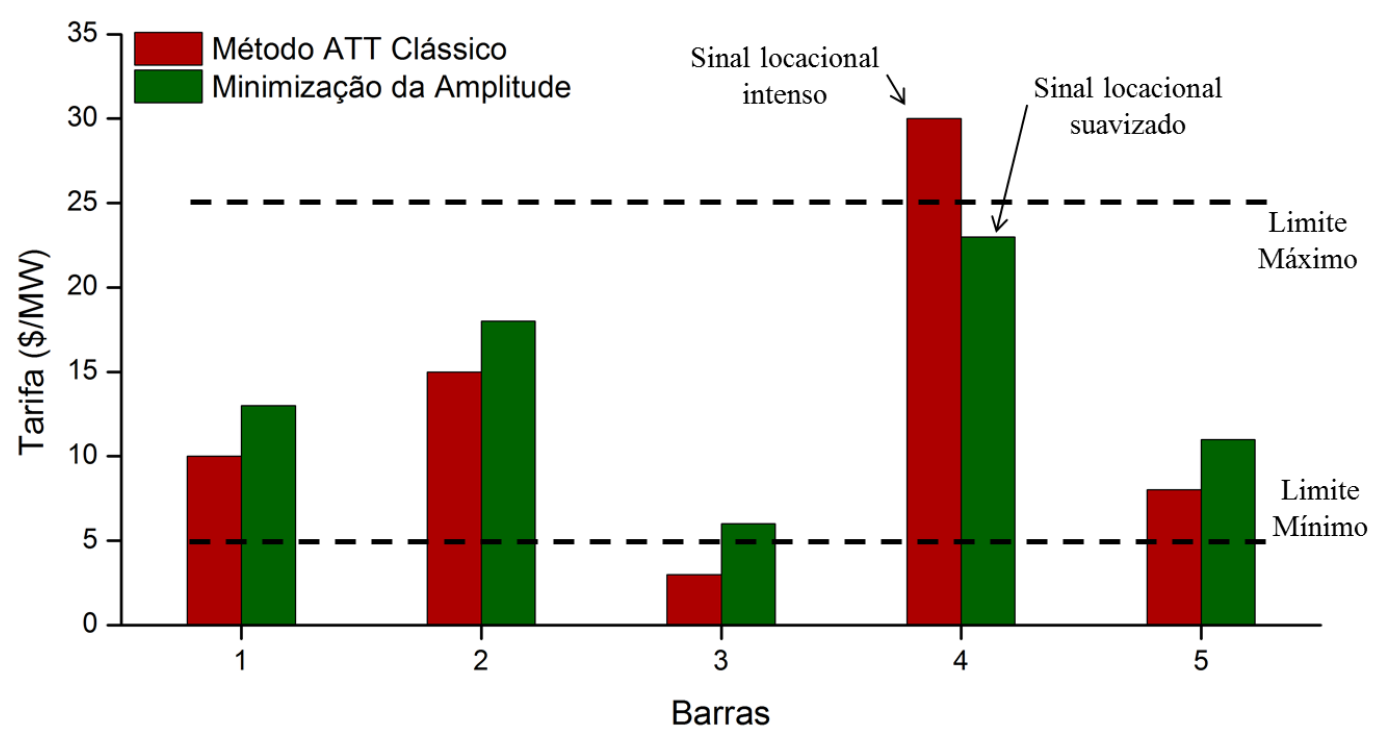

Figura 1.4. Ilustração do objetivo de tarifas de mínima amplitude

Ainda no nível inferior do modelo binível, é proposta uma expressão de tarifa que tem como inspiração o método Nodal, a partir do qual é feita uma generalização para incorporar a existência de um conjunto viável de 
decomposição de fluxos. Esta generalização se dá através dos fatores de intercâmbio nodal (NEFs, do inglês nodal exchange factors) que representam trocas bilaterais fictícias entre geradores e demandas. Os NEFs, que atuarão como variáveis de decisão, adicionam os graus de liberdade para a otimização. Ao problema do nível inferior daremos o nome de Tarifação de Mínima Amplitude (TMA).

Assim, o método de Alocação Binível de Tarifas de Transmissão (ABTT) maximiza os fluxos das linhas de transmissão no nível superior levando em conta as tarifas de mínima amplitude obtidas no nível inferior, a partir de limites tarifários máximo e mínimo. A representação da particularização proposta é apresentada na Figura 1.5.

Despacho de geração de pior caso (DPC)

Maximizar (estresse da rede) sujeito a:

Restrições do sistema

Solução ótima do critério de ATT

i Solução otima do criterio de ATT

Tarifas de mínima amplitude (TMA)

Minimizar (amplitude das tarifas) sujeito a:

Expressões de tarifa

Limites tarifários

Restrições de decomposição de fluxo

Figura 1.5. Método de alocação binível de tarifas de transmissão

Conforme será visto em detalhes posteriormente, a escolha dos limites tarifários no nível inferior terá influência direta na viabilidade e no acoplamento dos dois níveis na solução ótima do método. Em resumo, no caso de inviabilidade, não há solução de fluxo de potência capaz de resultar em tarifas que atendam o limite estabelecido. Se limites estreitos, porém viáveis, são escolhidos no nível inferior, os dois níveis estarão acoplados e o estresse do sistema estará abaixo de seu máximo possível (correspondente à solução isolada do nível superior). Por outro lado, para limites de tarifas menos restritivos, os níveis se desacoplam e a solução ótima é igual à solução sequencial dos dois níveis na qual o problema TMA pode ser resolvido independentemente, uma vez que o problema DPC esteja resolvido. Este é um ponto relevante e inovador da proposta deste trabalho, pois 
nos permite analisar diretamente a interdependência entre os dois problemas. Além disso, evidencia que a prática atual de solução sequencial dos problemas de fluxo de potência e de cálculo das tarifas é um caso particular da metodologia proposta.

Em resumo, as principais contribuições e inovações deste trabalho são:

- Propor uma abordagem geral inovadora de ATT na qual é caracterizada uma interdependência entre os problemas de caso base de fluxo de potência e cálculo das tarifas;

- Explorar a flexibilidade da decomposição dos fluxos de potência para atingir diferentes critérios regulatórios para as tarifas;

- Fornecer soluções ótimas para as tarifas de transmissão, uma vez que o critério de ATT é definido;

- Propor um critério para as tarifas particularmente adequado para mitigar o impacto de sinais locacionais rigorosos para geradores renováveis isolados dos centros de demanda enquanto a coerência geral dos sinais locacionais é mantida.

\section{4 . \\ Organização do documento}

O documento desta tese está organizado conforme a seguir:

O Capítulo 2 apresenta uma revisão bibliográfica acerca dos principais trabalhos presentes na literatura relacionados com a alocação de tarifas de transmissão.

Os Capítulos 3 e 4 apresentam os problemas de otimização que compõe o método proposto. No Capítulo 3 é apresentado o nível superior que define o caso base de fluxo de potência para o cálculo das tarifas. Nele o modelo DPC é definido. No Capítulo 4, apresenta-se o nível inferior que define as tarifas de acordo com o critério de ATT proposto. É proposta a formulação das tarifas com base no método Nodal, e é apresentado o modelo do problema TMA.

No Capítulo 5 os modelos DPC e TMA são unidos em um problema de otimização binível, gerando o modelo ABTT. São discutidas análises acerca da interdependência entre os dois níveis do modelo, e é proposto ainda um passo 
extra no processo de alocação para garantir a unicidade da solução final das tarifas.

No Capítulo 6, o método proposto é aplicado a um sistema didático de 6 barras para explorar em detalhes a dinâmica da proposta, e ao sistema IEEE 118 barras para que os resultados de tarifa e suas características possam ser avaliadas em um sistema de maior porte. São observados e comentados os sinais locacionais de usuários isolados, bem como a coerência geral das tarifas de acordo com as características do sistema. Ainda para este sistema, comparações com diferentes métodos de tarifação são apresentadas, além de uma análise detalhada acerca do método de solução escolhido para o modelo de otimização proposto.

No Capítulo 7, conclusões gerais do trabalho são enumeradas e discutidas, enquanto no Capítulo 8 perspectivas de trabalhos futuros são apresentadas.

No Apêndice A e Apêndice B, são apresentadas respectivamente a matriz de sensibilidade de fluxos de um sistema de transmissão e métodos de alocação de custos utilizados para comparações de resultados no Capítulo 6. No Apêndice C, é apresentada uma linearização do modelo do método proposto, utilizada para avaliação do método de solução escolhido no Capítulo 6. E finalizando o documento, no Apêndice D os dados completos dos sistemas utilizados em simulações são disponibilizados. 


\section{2 Revisão bibliográfica}

Este capítulo se destina a revisitar trabalhos presentes na literatura relacionados com o tema de alocação de tarifas de transmissão. Diferentes métodos são citados tendo como foco ressaltar seus objetivos, suas hipóteses e principais características dos resultados que fornecem. Ao longo do capítulo, é dado maior destaque àqueles que serviram como inspiração para a composição do método proposto neste trabalho.

Conforme discutido no Capítulo 1, os métodos de alocação de tarifas de transmissão podem variar nas premissas e objetivos assumidos em relação ao papel que as tarifas devem desempenhar no sistema de transmissão. Esta variação possui reflexos na complexidade dos métodos, bem como na sua capacidade de fornecer sinais econômicos bem ajustados. Neste ponto ressalta-se que cada método possui suas vantagens e desvantagens, adequando-se melhor a determinado tipo de sistema.

Os métodos precursores da alocação de custos e de tarifas pelo uso do sistema de transmissão são métodos do tipo Selo Postal, como o Pro-rata [2,4,5]. Nestes métodos, a alocação de tarifas não diferencia os geradores e demandas pela extensão do uso do sistema, localização na rede ou pelas componentes de fluxos provocadas nas linhas de transmissão. São considerados apenas o custo unitário do sistema, e a potência envolvida em uma transação bilateral ou injetada por um usuário. Tais características fazem com que seja um método simples e de fácil aplicação. Em contra partida, as tarifas não oferecem qualquer tipo de sinalização econômica ao não considerar os fluxos de potência pelas linhas e a localização dos usuários para diferenciar as tarifas.

O método de Caminho Contratado [25] consiste em uma variação de métodos do tipo Selo Postal. O método é aplicável no caso de transações de potência entre geradores e demandas em áreas ou regiões de um sistema pertencentes a diferentes concessionárias de transmissão. Neste caso é predefinido o caminho de menor custo, e com capacidade disponível, entre os usuários 
envolvidos. A tarifa é então composta pelo selo postal de cada região pertencente ao traçado. A principal crítica ao método é a diferença existente entre o caminho predefinido e o traçado real dos fluxos de potência envolvidos em cada transação.

O método MW-milha proposto em [26] foi uma das primeiras metodologias de alocação de tarifas de transmissão a de fato considerar o uso do sistema de transmissão pelos fluxos de potência. O método tem como base contratos bilaterais físicos dos quais os usuários do sistema participam. A ideia é que a alocação de custo seja condizente com reserva de capacidade das linhas necessária para garantir a ocorrência de cada transação. Neste sentido, os valores de geração e demanda de cada transação devem ser tais que maximizam o fluxo provocado nas linhas de transmissão. Para cada contrato bilateral, a parcela de custo alocada é uma função do montante de potência envolvido, do traçado e valor do fluxo provocado em cada linha de transmissão, e do comprimento das linhas efetivamente utilizadas. O uso do comprimento das linhas cria incentivos para transações entre agentes fisicamente próximos no sistema, uma vez que tendem a receber uma parcela menor dos custos. Comparado a outros métodos baseados em fluxo, o MW-milha alia um cálculo simples, intuitivo e de fácil aplicação com uma representação simplificada de sinalização econômica locacional através da distância física entre os agentes. No entanto, esta simplificação não reflete a distância elétrica entre geradores e demandas, mais bem representada em métodos mais complexos. Como métodos que se baseiam nas premissas do MW-milha, pode-se citar o método MVA-milha e suas variações [27], bem como os métodos Módulo, Zero Contrafluxo e Fluxo Dominante [28].

Inspirado no MW-milha, em [29] é proposto o método baseado no princípio da divisão proporcional (PDP). Este princípio parte da ideia de que cada barra do sistema é um misturador dos fluxos injetados de forma que não é possível definir para qual linha de saída de um nó se destina cada elétron injetado. Assim, respeitando a primeira Lei de Kirchhoff para circuitos elétricos, o PDP assume que cada injeção nodal é dividida proporcionalmente entre as extrações. Tal hipótese permite definir o destino, e correspondente traçado pela rede, da injeção de potência de cada gerador do sistema. O mesmo vale para a origem e traçado das extrações de potência de cada demanda. A partir deste conceito, os fluxos das linhas de transmissão são partilhados entre os usuários, e a tarifa é definida. Por utilizar a partilha de fluxo entre os usuários, e não o impacto que os mesmos 
provocam nas linhas, não há componentes de contrafluxo e a tarifa é sempre positiva.

O método Nodal [18], utilizado no sistema brasileiro, busca refletir a variação dos custos de expansão do sistema de transmissão devido à presença de cada usuário na rede, sendo um método baseado em CMLP. Como será visto em maiores detalhes ao longo deste documento, a partir de uma representação da rede que não possui folgas de capacidade, cada tarifa corresponde à variação de investimentos necessária para elevar marginalmente a capacidade das linhas, dado a variação unitária (1 MW) de potência de um usuário do sistema. Tais hipóteses produzem tarifas com forte influência da localização dos usuários na rede. $\mathrm{O}$ método Nodal é utilizado como base para a expressão de tarifa do método proposto e é apresentado em maiores detalhes no Capítulo 4 (Seção 4.1).

A partir da formulação base do método Nodal, em [30] é proposta uma metodologia que particulariza o método para melhor adequação às redes nas quais uma estrutura de subsistemas (econômicos, geográficos, e etc.) interligados é identificada. A tarifa de cada usuário é decomposta de forma que se contabiliza a variação de custos de cada subsistema em particular, dada uma variação na injeção de potência. Além disso, são propostas soluções para tratar a alocação de tarifas negativas (característica de métodos de CMLP), e a consideração de perdas no modelo de fluxo de potência linear utilizado no método Nodal no caso de sistemas de grande porte. Também são apresentadas generalizações para a consideração de um único cenário de caso base de fluxo de potência no cálculo das tarifas, e para a divisão igualitária do custo total do sistema entre geradores e demandas.

Outra proposta de aperfeiçoamento do método Nodal é apresentada em [31], onde é feita uma análise geral acerca de melhoria que podem ser empregadas ao método e ao processo tarifário do sistema brasileiro. As propostas apresentadas possuem como objetivo melhorar a qualidade do sinal locacional oferecido, de acordo com as características do sistema de transmissão e de sua operação. Dentre elas estão tarifas zonais ou regionais para o método definidas com base nas restrições de rede do sistema, e substituição do despacho proporcional por submercados por despacho mais próximo da realidade operativa do sistema.

O método Equivalent Bilateral Exchanges (EBE) [32] propõe a existência de trocas bilaterais fictícias entre geradores e demandas, para as quais o montante 
de potência envolvido é arbitrariamente definido. Seguindo a ideia de o sistema funcionar como um misturador de fluxos (da mesma forma que em [29]) o método assume que a cada gerador é designada uma fração de cada demanda uniformemente dividida entre todos os geradores. De maneira análoga, cada demanda recebe uma fração de cada gerador que é uniformemente dividido entre todas as demandas. A partir desta divisão, o fluxo provocado nas linhas por cada par de gerador e demanda é contabilizado, e as tarifas calculadas. Nesta contabilização, contrafluxos são considerados como uso e não como alivio das linhas, o que gera tarifas sempre positivas e com tendência a baixa variabilidade ao longo do tempo. A generalização das hipóteses de trocas bilaterais fictícias propostas pelo método EBE deram origem aos fatores de intercambio nodal (NEFs) utilizados neste trabalho, e em outros métodos baseados em otimização. Em [33] é proposta ainda uma metodologia de aplicação dos conceitos do método EBE para a alocação de tarifas de transmissão em sistemas multiárea.

Em [34], o método Zbus propõe a definição do uso da rede e respectivas tarifas através da teoria de circuitos, com o uso da matriz de admitâncias $Z_{B U S}$. Os fluxos de potência são atribuídos a injeções de corrente nas barras, que por sua vez representam os usuários do sistema. Neste desenvolvimento é destacado um parâmetro que quantifica um efeito de proximidade elétrica entre usuários e linhas de transmissão, e que depende apenas de parâmetros da rede. Por este efeito, há uma tendência de que as barras conectadas diretamente a uma linha recebam a maior parte dos custos desta linha. Outros métodos baseados na teoria de circuitos e que fazem uso de uma matrix $Z_{B U S}$ modificada são propostos em [35,36].

Em [3] uma análise comparativa de métodos de alocação de tarifas é apresentada. Os métodos Pro-rata, EBE, Zbus, Nodal e método baseado no PDP, são avaliados em relação a sinais locacionais, e a alterações e volatilidade das tarifas frente a mudanças no sistema. A partir de simulações com sistemas de teste, é ressaltado que a escolha do melhor método é relativa, e deve levar em conta as expectativas existentes para as tarifas. São destacados a simplicidade do método Pro-rata, a volatilidade elevada para o método baseado em PDP e reduzida para os métodos Nodal e EBE. Também se destaca o bom desempenho do método Zbus em relação à sinalização locacional. Adicionalmente, em [28] são feitas comparações entre o método MW-milha e suas variações. Já em [2], entre outras análises, são comparadas diferentes formas de contabilizar o uso das linhas de 
transmissão por parte dos agentes do sistema, como a utilização de resultados de fluxo de potência, fatores de distribuição, fatores de sensibilidade e traçados de fluxo.

A partir de alguns dos métodos tradicionais citados, novas alternativas foram apresentadas na literatura recente. Muitas delas se baseiam em teoria dos jogos e otimização, que é o foco deste trabalho. A ideia geral destes métodos é atender a objetivos ou características relacionados às tarifas que os métodos tradicionais não são capazes de fornecer, porém sem descartar seus pontos fortes. Para esta classe de métodos, será dado maior enfoque e detalhamento para os principais trabalhos que serviram de inspiração para esta tese.

A motivação para o uso de teoria de jogos na alocação de custos se justifica por seu comportamento satisfatório e benéfico em termos de "justiça", eficiência e estabilidade, que são características desejáveis para a alocação de custos de transmissão [37]. Em [38] os custos da transmissão são alocados através de despachos econômicos avaliados para diferentes coalizões de demanda, tendo em conta o máximo fluxo por cada linha de transmissão.

Já em [39], é apresentado um método baseado em otimização e teoria de jogos utilizando a metodologia Aumann-Shapley. O objetivo do método proposto é agregar as características dos CMLP e de uma metodologia de tarifação baseada em fatores de participação média, que considerando o PDP define o traçado de fluxo de uma injeção de potência na rede [40]. Como resultado, esperam-se tarifas com sinais locacionais competitivos no contexto do sistema brasileiro no qual geradores renováveis isolados (com altos custos pelo uso da transmissão) competem com geradores térmicos próximos aos centros de demanda (com custos pelo uso da transmissão relativamente baixos). Um contexto de motivação análogo é abordado nesta tese. O método é desenvolvido de forma que cada gerador seleciona um conjunto de cargas para suprir. Este conjunto é determinado por um problema de otimização que tem por objetivo minimizar a tarifa de cada gerador que está escolhendo suas demandas. Tal dinâmica de alocação serviu de inspiração para a proposta dos NEFs (mencionados na Seção 1.3 do Capítulo 1, e apresentados em detalhes no Capítulo 4) presente nesta tese e em demais publicações oriundas dela $[17,24,41]$.

Já na área de otimização, alguns trabalhos definem a solução de fluxo de potência (a partir da qual as tarifas são calculadas) através de problemas de FPO e 
suas variações. Em [14] são avaliadas ocorrências de contingência na rede, e definido um resultado de fluxo de potência que minimiza a necessidade de variações nas transações de mercado entre geradores e demandas definidas na situação precontingência. A partir destes resultados os custos fixos do sistema são definidos através do método Módulo [28]. Os custos associados a congestionamento, operação e perdas também são definidos. Já em [42] um FPO de mínimo custo é apresentado incluindo os custos do sistema de transmissão, de geração, entre outros, no custo total a ser minimizado. Neste caso, a alocação de custos/tarifas de transmissão é uma das soluções do problema FPO.

Em outras propostas, a otimização está diretamente aplicada no cálculo das tarifas, e define-se um grau de liberdade envolvendo o traçado de potência e/ou transações bilaterais entre geradores e demandas, que são resultados que admitem um conjunto viável de soluções. Em [16] é apresentado um método minimiza a diferença entre uma formulação baseada em fluxos de potência e o método Prorata. A formulação proposta possui o conjunto viável de traçado de potência pela rede como grau de liberdade sobre o qual é aplicada a otimização (generalização do PDP). O objetivo da abordagem proposta é obter uma metodologia de tarifação o mais equitativa possível ao passo que considera a avaliação de uso da rede através de fluxos de potência. Este critério foi proposto para atender a sistemas em desenvolvimento, nos quais a nova fase do mercado requer sinalização locacional das tarifas. Com a concentração de geração em uma área, o uso de uma metodologia do tipo Pro-rata claramente favorece demandas afastadas do centro de geração. Por outro lado, um método tradicional baseado em fluxo favorece as demandas próximas. Assim, deseja-se agregar os pontos positivos de cada método, utilizando o resultado de traçado de fluxos que gera tarifas mais próximas ao método Pro-rata. O modelo de otimização proposto é do tipo linear e contempla os limites e a topologia da rede em suas restrições.

Propostas posteriores em [43] e [44] aperfeiçoaram matematicamente o modelo apresentado em [16] abordando o mesmo contexto e objetivos para as tarifas. Em [43] a máxima equidade das tarifas é obtida através da técnica de otimização min-max aplicada para tarifação. A técnica garante uma situação de equilíbrio, na qual não é possível reduzir uma tarifa sem necessariamente incrementar outra que seja maior ou igual a ela. $\mathrm{Na}$ prática, é proposto um processo iterativo que minimiza uma tarifa por iteração seguindo a ordem 
decrescente definida por uma solução inicial (solução do método baseado no PDP). A cada iteração, os valores de tarifa já obtidos são restrições para os problemas subsequentes. Em [44] a aplicação da técnica min-max é aperfeiçoada de forma que se garante uma solução ótima robusta. São discutidas e solucionadas questões como ciclagem e falhas relacionadas à precisão numérica. Além disso, uma análise acerca das variáveis duais das restrições ao longo do processo iterativo elimina a necessidade de solução inicial para definir a ordem decrescente das tarifas.

Com base no desenvolvimento da otimização do traçado de fluxo de potência nos trabalhos mencionados, novas alternativas foram propostas. Em [45] é apresentado um método que tem como motivação reunir as principais características desejáveis para resultados de alocação de tarifas. São considerados: avaliar o uso do sistema por meio de componentes de fluxos; a capacidade de recuperar os custos fixos totais do sistema; e a provisão de sinais econômicos aderentes aos preços marginais do despacho ótimo de mínimo custo. $\mathrm{O}$ caso base de fluxo de potência utilizado avalia, em um despacho ótimo de menor custo, possíveis pontos de operação do sistema de forma a criar um resultado médio representativo. São consideradas ainda situações com e sem contingências de rede. A partir deste resultado, em um segundo problema de otimização, os traçados de fluxo são otimizados de forma minimizar a diferença entre as tarifas de transmissão e os preços marginais citados.

Utilizando a técnica min-max de tarifação conforme apresentada em [44], são propostas ainda mais duas abordagens [46, 24]. Em [46] a técnica min-max é aplicada no método clássico de participação marginal [47] levando em conta os graus de liberdade existentes na escolha da barra de referência para cada usuário, e na quantidade de potência utilizada para contabilizar a participação dos usuários no fluxo das linhas.

Em [24] o método Nodal Min-max é proposto. Nele, um contexto análogo ao abordado em [39] é utilizado como motivação para adaptar a técnica min-max a um método baseado e CMLP (método Nodal). A hipótese de avaliar a variação marginal de custos do sistema compensando injeções/extrações na barra de referência da rede é generalizada para a existência de trocas bilaterais entre geradores e demandas, assim como no método EBE. No entanto, os montantes de potência não são arbitrados, mas sim definidos pela variável NEF (citada no 
Capítulo 1), que é decisão do processo de otimização característico da técnica min-max.

Em [17] é proposta uma metodologia que consiste na parte inicial de desenvolvimento deste trabalho. Com base nos métodos que utilizam a técnica min-max para tarifação, e tendo como motivação as elevadas tarifas alocadas a geradores isolados no sistema brasileiro, propõe-se uma simplificação que aproxima o resultado do processo iterativo de otimizações pela minimização da amplitude das tarifas, resolvida em um único problema. As tarifas são obtidas com base na generalização das hipóteses do método EBE, com o uso dos NEFs propostos em [24] como variáveis de decisão. Neste caso, a ordem decrescente das tarifas, definida pela solução do método EBE original, é fixada em restrições do problema. Adicionalmente, a questão do despacho de geração adequado para representar a situação de máximo estresse do sistema é abordada. É proposta a maximização dos fluxos, tendo como decisão a variações a partir de uma solução de despacho proporcional à capacidade máxima dos geradores. Resultados apresentados sinalizam uma distorção severa nos sinais locacionais quando o máximo estresse do sistema é definido em um problema externo ao da definição das tarifas. Desta conclusão surgiu a motivação para avaliar e propor a abordagem inovadora de interdependência entre os dois modelos de otimização (caso base de fluxo de potência e definição das tarifas). 


\section{3 Modelo de despacho de geração de pior caso}

Neste capítulo é apresentado o nível superior do método de alocação binível de tarifas de transmissão, nomeado como Despacho de Geração de Pior Caso (DPC). O modelo DPC é responsável por fornecer um resultado de fluxo de potência que maximiza o estresse do sistema. Conforme mencionado no Capítulo 1, diferentes diretrizes podem ser seguidas para definir a solução de fluxo de potência sobre a qual o uso do sistema será definido. Neste trabalho, propõe-se que dentre todos os resultados possíveis de fluxo de potência, seja escolhido àquele que provoca a maior necessidade de investimentos na rede, de forma que as tarifas sejam obtidas em um cenário de pior caso. Este resultado corresponde ao estado de máximo estresse da rede. Uma prática comum para atender esta condição é despachar os geradores proporcionalmente à sua capacidade máxima até que a demanda máxima seja atendida $[15,17,18]$. No entanto, esta prática não garante de maneira ótima a situação de máximo estresse uma vez que a escolha dos valores despachados não considera de forma direta a estrutura e os parâmetros da rede.

Para garantir a solução ótima da diretriz adotada, é proposto um problema de otimização baseado em FPO, que possui como objetivo maximizar os fluxos nas linhas de transmissão. Nele a variável de decisão é o despacho de geração para atender a configuração de máxima demanda, respeitando os limites da rede. Conforme será pontuado no Capítulo 4, o resultado do DPC atende ainda às indicações do cálculo dos custos marginais de longo prazo (CMLP) que serão base para o cálculo das tarifas no modelo proposto. Ao longo do capítulo, são apresentadas as premissas utilizadas e modelo matemático desenvolvido.

\section{1.}

\section{Modelo de otimização DPC}

No modelo proposto, o estresse da rede a ser maximizado será quantificado pelo somatório dos fluxos em todas as linhas de transmissão. A intenção com tal 
função objetivo é definir o despacho de geração do sistema que maximiza os fluxos na rede como um todo. Ainda assim, a função objetivo poderia incluir também particularidades da rede em estudo que estejam relacionadas aos fluxos e a situação de máximo estresse. Como restrições do sistema, o despacho deve atender à demanda máxima da rede, que consiste no pior caso de configuração de demanda, contribuindo para o máximo estresse. Além disso, são considerados os limites de transmissão das linhas e de despacho máximo e mínimo dos geradores.

As expressões de fluxo de potência ativa utilizadas neste trabalho assumem as simplificações do estudo de fluxo de potência DC [48], que excluem a consideração de perdas elétricas nos cálculos de fluxo de potência. A partir de tais simplificações é utilizada a matriz $\boldsymbol{\beta}$ de sensibilidade de fluxos das linhas. $\mathrm{O}$ cálculo de $\boldsymbol{\beta}$ depende apenas dos parâmetros do sistema e é apresentado em detalhes no Apêndice A. Cada elemento $\beta_{\ell b}$ de $\boldsymbol{\beta}$ representa a variação de fluxo em uma linha $\ell$ provocada por uma variação unitária de potência em uma barra $b$ do sistema e compensação correspondente na barra de referência, conforme (3.1). Assim, a matriz possui dimensão $n_{L} \times n_{B}$, sendo $n_{L}$ o número de linhas e $n_{B}$ o número de barras.

$$
\beta_{\ell b}=\frac{\Delta F_{\ell}}{\Delta P_{b}}, \quad \forall \ell \in \Omega_{L}, \forall b \in \Omega_{B}
$$

Sendo $\Omega_{B}$ o conjunto de barras $b$ do sistema, $\Omega_{L}$ o conjunto de linhas de transmissão $\ell, F_{\ell}$ o fluxo em MW através da linha $\ell$, e $P_{b}$ a potência em MW injetada na barra $b$.

Para cada linha $\ell$ o fluxo será o somatório das variações ou componentes provocadas por cada injeção/extração de potência nas barras do sistema conforme em (3.2).

$$
F_{\ell}=\sum_{b \in \Omega_{B}} \beta_{\ell b}\left(P_{G b}-P_{D b}\right), \quad \forall \ell \in \Omega_{L}
$$

Sendo $P_{G b}$ e $P_{D b}$ a geração e a demanda, ambas em MW, verificadas na barra $b$. Considerando a separação de geradores nas barras $i$ do conjunto $\Omega_{G}$ e de demandas nas barras $j$ do conjunto $\Omega_{D}$, (3.2) pode ser reescrita como (3.3).

$$
F_{\ell}=\sum_{i \in \Omega_{G}} \beta_{\ell i} P_{G i}-\sum_{j \in \Omega_{D}} \beta_{\ell j} P_{D j}, \quad \forall \ell \in \Omega_{L}
$$


De acordo com (3.3), o modelo proposto para o DPC é apresentado em (3.4)-(3.10). Destaca-se que o problema possui restrições e função objetivo lineares, sendo um programa linear.

\section{Modelo de Despacho de Pior Caso (DPC)}

$\operatorname{maximizar}_{\substack{P_{G i}, \forall i \in \Omega_{G} \\ F_{\ell}, \forall \ell \in \Omega_{L}}} y_{D P C}=\sum_{\ell \in \Omega_{L}} F_{\ell}$

s.a.:

$$
\begin{gathered}
F_{\ell}=\sum_{i \in \Omega_{G}} \beta_{\ell i} P_{G i}-\sum_{j \in \Omega_{D}} \beta_{\ell j} P_{D j}, \quad \forall \ell \in \Omega_{L} \\
\sum_{i \in \Omega_{G}} P_{G i}=\sum_{j \in \Omega_{D}} P_{D j} \\
0 \leq F_{\ell} \leq \operatorname{Cap}_{\ell}, \quad \forall \ell \in \Omega_{L} \\
P_{G i}^{M I N} \leq P_{G i} \leq P_{G i}^{M A X}, \quad \forall i \in \Omega_{G} \\
F_{\ell} \in \mathbb{R}, \quad \forall \ell \in \Omega_{L} \\
P_{G i} \in \mathbb{R}, \quad \forall i \in \Omega_{G}
\end{gathered}
$$

Em (3.4), a função objetivo $y_{D P C}$ contabiliza o somatório dos fluxos de todas as linhas de transmissão, que por sua vez quantifica o estresse da rede a ser maximizado. As restrições (3.5)-(3.10) definem o conjunto viável do caso base de fluxo de potência. Em (3.5) a formulação do fluxo previamente definida é inserida no modelo. Em (3.6) é garantido o balanço de potência do sistema para a máxima demanda $P_{D j}$, desprezando as perdas elétricas da rede, conforme mencionado anteriormente neste capítulo.

As restrições (3.7)-(3.8) representam os limites das linhas e limites de geração, respectivamente. Em (3.7), o limite de capacidade de transmissão das linhas $\operatorname{Cap}_{\ell}$, em MW, corresponde ao limite térmico das mesmas. Os fluxos são restritos a valores positivos considerando que em sistemas de transmissão o sentido de fluxo da maioria das linhas é conhecido e bem definido, e assumido como positivo. 
Em (3.8), o limite máximo $P_{G i}^{M A X}$ corresponde ao máximo despachável por cada gerador. Para o limite mínimo, é utilizado o parâmetro $P_{G i}^{M I N}$ que pode ser maior que zero ou nulo. Por se tratar de um problema de alocação de tarifas, pode ser estabelecido que os geradores sejam despachados, de forma que todos os agentes do sistema participem da composição do caso base de fluxo de potência [18]. Neste caso, $P_{G i}^{M I N}$ é maior que zero, e caso contrário, será nulo. É interessante observar que os limites de geração podem levar em conta inclusive dados históricos, e valores máximo e mínimo fornecido por perfis de geração de cada usuário principalmente no caso de geradores renováveis. 


\section{4 Modelo de tarifação de mínima amplitude}

Neste capítulo é apresentado o nível inferior do método binível de alocação de tarifas de transmissão, nomeado como Tarifação de Mínima Amplitude (TMA). O modelo TMA é responsável por fornecer tarifas de mínima amplitude considerando limites tarifários predefinidos. Conforme abordado no Capítulo 1, há um conjunto de possíveis soluções de decomposição de fluxo a serem utilizadas na alocação de tarifas. Assim, uma forma de escolher uma solução dentro deste conjunto viável é atender de maneira ótima a um ou mais critérios desejáveis para as tarifas. Neste trabalho o critério a ser atendido consiste minimizar o impacto dos sinais locacionais nas tarifas de usuários em pontos isolados da rede. Além disso, simultaneamente, deve ser mantida a avaliação coerente do uso do sistema com base nos fluxos de potência. Para tanto, a amplitude de variabilidade das tarifas é minimizada, tendo como base o método Nodal para definir a expressão de cálculo das tarifas.

As seções seguintes apresentam o método Nodal, com suas hipóteses e formulações, e o modelo proposto para a obtenção de tarifas de mínima amplitude. É abordada a formação do conjunto viável de decomposição de fluxos, a formulação da tarifa para que possa ser aplicado um problema de otimização e o modelo TMA propriamente dito. Neste capítulo, a geração $P_{G i}$, demanda $P_{D j}$ e fluxo $F_{\ell}$ são referentes ao resultado de caso base de fluxo de potência a ser utilizado na alocação de tarifas.

\section{1.}

\section{Método Nodal}

O método Nodal é baseado no conceito dos CMLP, sendo refletido na tarifa o custo adicional provocado pelo incremento marginal na injeção/extração de potência em uma barra do sistema, considerando uma rede ideal de custo mínimo. Esta rede é a estritamente necessária (sem capacidade excedente) para atender à demanda máxima total, de forma que ocorra o máximo estresse do sistema [15]. 
Particularmente para este trabalho, o usual despacho proporcional (mencionado em [15]) é substituído pelo modelo DPC proposto no Capítulo 3 que fornece a solução ótima de máximo estresse do sistema.

A partir das considerações da rede ideal, a variação de custos mencionada possui relação direta com a alteração nos fluxos em decorrência dos incrementos de injeção/extração. Esta alteração de fluxos por sua vez pode ser aproximada pelos fatores de sensibilidade dos fluxos nas linhas de transmissão. Estes fatores são os elementos $\beta_{\ell b}$ da matriz $\boldsymbol{\beta}$ de sensibilidade, apresentada no Capítulo 3 e no Apêndice A. Assim, para cada usuário localizado em uma barra $b$ do sistema, a tarifa contabiliza, através dos elementos $\beta_{\ell b}$, o impacto de fluxo provocado em uma linha $\ell$ devido à presença do usuário na rede e respectiva compensação na barra de referência $r$ do sistema.

Para calcular as tarifas, são utilizados ainda dois termos: o custo unitário e o fator de ponderação das linhas de transmissão. $O$ custo unitário $c_{\ell}$ de uma linha $\ell$, dado em \$/MW, corresponde ao custo de ocupar $1 \mathrm{MW}$ da capacidade de transmissão $\operatorname{Cap}_{\ell}$, conforme (4.1). O termo $C_{\ell}^{T}$ corresponde ao custo total da linha $\ell$ em $\$$.

$$
c_{\ell}=\frac{C_{\ell}^{T}}{\operatorname{Cap}_{\ell}}, \quad \forall \ell \in \Omega_{L}
$$

O fator de ponderação Fpond $_{\ell}$ corresponde ao percentual de utilização da linha $\ell$ pelo fluxo $F_{\ell}$ (definido em (3.3)) em relação à $C a p_{\ell}$, e ao fluxo mínimo $F_{\ell}^{M I N}$ que traduz o limite abaixo do qual o incremento de fluxo não representa a

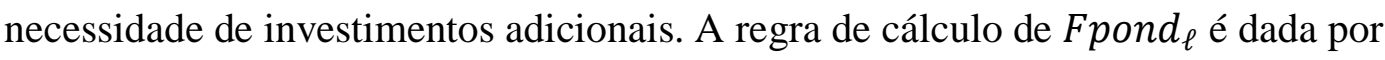
(4.2).

$$
\text { Fpond }_{\ell}=\left\{\begin{array}{c}
0 \text { se } F_{\ell}<F_{\ell}^{M I N} \\
\frac{F_{\ell}}{\operatorname{Cap}_{\ell}} \quad \text { se } F_{\ell}^{M I N} \leq F_{\ell} \leq \operatorname{Cap}_{\ell}
\end{array} \quad \forall \ell \in \Omega_{L}\right.
$$

Combinando os parâmetros Fpond $_{\ell}, c_{\ell}$ e os elementos da matriz de sensibilidade $\boldsymbol{\beta}$, compõem-se as tarifas locacionais $\pi_{G i}^{N O D A L}$ para um gerador localizado na barra $i$, e $\pi_{D j}^{N O D A L}$ para uma demanda localizada na barra $j$, em \$/MW conforme em (4.3) e (4.4), respectivamente. As tarifas são nomeadas como locacionais, pois seus elementos fornecem o sinal locacional para cada barra (ou usuário) do sistema. 


$$
\begin{gathered}
\pi_{G i}^{N O D A L}=\sum_{\ell \in \Omega_{L}} c_{\ell} \text { Fpond }_{\ell} \beta_{\ell i}, \quad \forall i \in \Omega_{G} \\
\pi_{D j}^{N O D A L}=-\sum_{\ell \in \Omega_{L}} c_{\ell} \text { Fpond }_{\ell} \beta_{\ell j}, \quad \forall j \in \Omega_{D}
\end{gathered}
$$

Destaca-se que os elementos da matriz $\boldsymbol{\beta}$ em (4.3) e (4.4) consideram a compensação de geradores e demandas na barra de referência $r$. No entanto, como o termo $\beta_{\ell r}$ é nulo (conforme apresentado no Apêndice A), não é representado explicitamente. Assim, em $\pi_{G i}^{N O D A L}$, o impacto na linha $\ell$ da injeção na barra $i$ e extração na barra de referência $r$ é representado por $\beta_{\ell i}-\beta_{\ell r}=\beta_{\ell i}$. Em $\pi_{D j}^{N O D A L}$, o impacto na linha $\ell$ da injeção na barra de referência $r$ e extração na barra $j$ é representado por $\beta_{\ell r}-\beta_{\ell j}=-\beta_{\ell j}$, o que faz com que o somatório seja precedido por um sinal negativo.

Devido às características da rede ideal dos CMLP, que assumem a ausência de capacidade ociosa nas linhas, as tarifas locacionais (4.3) e (4.4) não recuperam o custo total do sistema. Por isso, uma parcela adicional de ajuste dos custos é necessária para remunerar a capacidade ociosa da rede e eventuais custos adicionais. Esta parcela, denominada "parcela selo", faz uma divisão pro-rata da parte dos custos que não foi remunerada pela tarifa locacional conforme apresentado em (4.5) e (4.6). São definidos dois valores de parcela selo, em $\$ / \mathrm{MW}$, um válido para todos os geradores $\triangle_{G}^{N O D A L}$ e outro para todas as demandas $\triangle_{D}^{N O D A L}$. O termo $C_{S I S T}^{T}$ correspondente ao custo total a ser remunerado na alocação, em \$, que é dividido por 2 para que os custos sejam divididos igualmente entre geradores e demandas. Entretanto, qualquer proporção de divisão de custos poderia ser adotada.

$$
\begin{gathered}
\Delta_{G}^{N O D A L}=\frac{\frac{C_{S I S T}^{T}}{2}-\sum_{i \in \Omega_{\mathrm{G}}} \pi_{G i}^{N O D A L} P_{G i}}{\sum_{i \in \Omega_{\mathrm{G}}} P_{G i}} \\
\Delta_{D}^{N O D A L}=\frac{\frac{C_{S I S T}^{T}}{2}-\sum_{j \in \Omega_{D}} \pi_{D j}^{N O D A L} P_{D j}}{\sum_{j \in \Omega_{D}} P_{D j}}
\end{gathered}
$$

A tarifa final dada pelo método Nodal é definida por (4.7) e (4.8).

$$
t_{G i}^{N O D A L}=\pi_{G i}^{N O D A L}+\Delta_{G}^{N O D A L}, \quad \forall i \in \Omega_{G}
$$




$$
t_{D j}^{N O D A L}=\pi_{D j}^{N O D A L}+\Delta_{D}^{N O D A L}, \quad \forall j \in \Omega_{D}
$$

Definida a formulação das tarifas, as seguintes observações adicionais são feitas para o método Nodal:

- A tarifa locacional alocada para a barra de referência é nula. Isto porque, conforme o desenvolvimento apresentado no Apêndice A, a coluna da matriz $\boldsymbol{\beta}$ relativa a tal barra possui todos os elementos iguais à zero;

- Independente da escolha da barra de referência, a diferença entre duas tarifas locacionais quaisquer se mantém constante. Isto ocorre, pois na matriz $\boldsymbol{\beta}$, para qualquer barra de referência, a diferença entre as suas colunas (como exemplo, $\left.\beta_{\ell m}-\beta_{\ell n}\right)$ é constante [18]. Desta forma, a sinalização locacional relativa é sempre a mesma;

- Com a aplicação da parcela selo, a tarifa final de cada agente é independente da escolha da barra de referência. As alterações em cada tarifa locacional devido a escolha da barra de referência são naturalmente compensadas na parcela selo de maneira que a tarifa final é única.

\section{2. \\ Método de Tarifação de Mínima Amplitude}

Tendo como base o método Nodal apresentado na Seção 4.1, nesta seção é proposto o modelo TMA. A partir das formulações de tarifa (4.3)-(4.8), uma generalização é proposta de forma que se caracteriza um conjunto viável de decomposição de fluxos, e a otimização desejada pode ser aplicada às tarifas. Nas subseções seguintes são formulados o conjunto viável de decomposição de fluxos, a expressão da tarifa, e o modelo TMA.

\subsection{1.} Decomposição de fluxos via fatores de intercâmbio nodal

Uma forma de acessar uma solução de decomposição de fluxos é utilizar trocas bilaterais fictícias de potência entre geradores e demandas. A partir destas trocas, é definido o impacto na variação de fluxo em cada uma das linhas. Esta ideia é utilizada no método EBE [32], revisitado no Capítulo 2, que define de maneira arbitrária a quantidade de potência envolvida em cada troca. O método assume que cada gerador alimenta obrigatoriamente todas as demandas do 
sistema, no percentual que cada uma ocupa na demanda total. De maneira semelhante, cada demanda do sistema é alimentada por todos os geradores no percentual que cada um ocupa na geração total. Esta regra não é única que pode ser adotada para definir as trocas bilaterais, e também não se pode provar que ela é verdadeira ou falsa, sendo apenas uma hipótese válida para o método EBE. Dada esta flexibilidade na definição das trocas bilaterais, a hipótese é generalizada para que qualquer solução do conjunto viável de decomposições possa ser acessada, e seja escolhida aquela que melhor atende a um critério para as tarifas. Para tal, é definida uma variável nomeada fator de intercâmbio nodal, ou NEF (do inglês, nodal exchange factor).

Cada NEF está associado a um par $(i, j)$ de gerador $i$ e demanda $j$, e define o montante de potência trocada entre eles. Do ponto de vista dos geradores, o NEF $\alpha_{G i j}$ corresponde ao percentual da potência do gerador instalado na barra $i$ que alimenta a demanda instalada na barra $j$. De maneira análoga, do ponto de vista das demandas, o NEF $\alpha_{D j i}$ representa o percentual da demanda instalada na barra $j$ que é alimentada pelo gerador na barra $i$. Para que a troca bilateral seja coerente, ambos NEFs devem resultar no mesmo montante como formulado em (4.9). Aqui ressalta-se que por definição $\alpha_{G i j}$ e $\alpha_{D j i}$ não são necessariamente iguais, uma vez que $P_{G i}$ e $P_{D j}$ podem ser distintos entre si.

$$
\alpha_{G i j} P_{G i}=\alpha_{D j i} P_{D j}, \quad \forall i \in \Omega_{G}, \forall j \in \Omega_{D}
$$

Adicionalmente, para que os NEFs respeitem o resultado de caso base de fluxo de potência, $100 \%$ da potência de cada gerador e demanda deve participar das trocas bilaterais. Estas condições são modeladas em (4.10) e (4.11), respectivamente.

$$
\begin{aligned}
& \sum_{j \in \Omega_{D}} \alpha_{G i j}=1, \quad \forall i \in \Omega_{G} \\
& \sum_{i \in \Omega_{G}} \alpha_{D j i}=1, \quad \forall j \in \Omega_{D}
\end{aligned}
$$

A partir de valores de NEFs que respeitem as relações (4.9)-(4.11), é possível formular a decomposição dos fluxos de potência pelo sistema. Para tanto, utilizam-se os fatores de distribuição da transferência de potência, ou PTDFs (do 
inglês, power transfer distribution factors). O PTDF $\gamma_{i j \ell}$ corresponde à variação de fluxo em uma linha de transmissão $\ell$ dada a injeção de $1 \mathrm{MW}$ de potência em uma barra $i$ e correspondente extração em uma barra $j$. Utilizando a já conhecida matriz $\boldsymbol{\beta}$ de sensibilidade de fluxos, $\gamma_{i j \ell}$ é obtido conforme (4.12).

$$
\gamma_{i j \ell}=\beta_{\ell i}-\beta_{\ell j}, \quad \forall i \in \Omega_{G}, \forall j \in \Omega_{D}, \forall \ell \in \Omega_{L}
$$

A partir deste parâmetro, a componente de fluxo $F_{\ell}^{i, j}$, em MW, de uma linha $\ell$ devido a uma troca entre o par $(i, j)$ é formulada em (4.13) utilizando o montante de potência envolvido na troca definido em (4.9).

$$
F_{\ell}^{i, j}=\gamma_{i j \ell} \alpha_{G i j} P_{G i}=\gamma_{i j \ell} \alpha_{D j i} P_{D j}, \quad \forall \ell \in \Omega_{L}, \forall i \in \Omega_{G}, \forall j \in \Omega_{D}
$$

Como (4.13) está aberta ao valor dos NEFs, quando os mesmos são variáveis de decisão em um problema de otimização, todas as soluções de decomposição de fluxos podem ser acessadas. O conjunto viável de soluções de tal decomposição é delimitado por (4.9)-(4.11) e (4.13).

Através de (4.13) é possível obter o traçado de fluxo pela rede provocado por uma troca bilateral, ou por um gerador/demanda isoladamente. Este resultado é particularmente interessante para analisar e justificar o valor de uma tarifa. Esta possibilidade será explorada na apresentação de resultados do Capítulo 6. Destaca-se ainda que ao utilizar o valor real (e não o módulo) de $\gamma_{i j \ell}$ são identificadas as componentes de fluxo (possuem o mesmo sentido do fluxo total da linha) e contrafluxo (possuem sentido contrário ao fluxo total da linha).

\subsection{2.}

\section{Formulação da tarifa de transmissão}

A formulação da tarifa proposta neste trabalho pode ser definida como uma generalização que mescla o método Nodal com os NEFs em uma formulação única. Nas expressões de tarifa em (4.3) e (4.4) é inserida a decomposição de fluxos via NEFs proposta em (4.13). Neste caso, é generalizada a ideia do método Nodal de contabilizar a variação de fluxo devido à injeção/extração em uma barra e correspondente compensação na barra de referência do sistema. De acordo com o conjunto de valores de NEFs, cada injeção de potência é compensada em uma ou mais barras do sistema, criando um efeito de barra de referência distribuída. 
Com a presença dos NEFs na formulação da tarifa, o conjunto viável de decomposição de fluxo se traduz em um conjunto viável de tarifa.

Tendo como base as tarifas locacionais em (4.3) e (4.4), a formulação proposta para a tarifa é apresentada em (4.14) e (4.15) para geradores e demandas, respectivamente.

$$
\begin{array}{ll}
\pi_{G i}^{T M A}=\sum_{\ell \in \Omega_{L}} \sum_{j \in \Omega_{D}} \frac{c_{\ell}}{2} \text { Fpond }_{\ell} \gamma_{\ell i j} \alpha_{G i j}, & \forall i \in \Omega_{G} \\
\pi_{D j}^{T M A}=\sum_{\ell \in \Omega_{L}} \sum_{i \in \Omega_{G}} \frac{c_{\ell}}{2} \text { Fpond }_{\ell} \gamma_{\ell i j} \alpha_{D j i}, \quad \forall j \in \Omega_{D}
\end{array}
$$

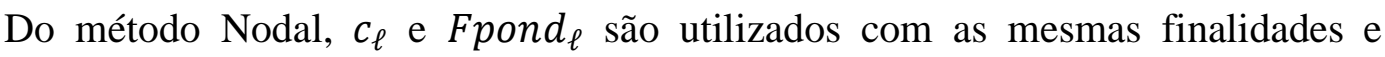
características apresentadas na Seção 4.1. O termo $c_{\ell}$ é dividido por 2 para que o custo unitário associado a cada troca seja igualmente dividido entre geradores e demandas. Os parâmetros $\beta_{\ell i}$ e $\beta_{\ell j}$ são substituídos por (4.13), considerando injeção e extração unitárias de potência.

Assim como no método Nodal, as tarifas (4.14) e (4.15) são tarifas locacionais e uma parcela selo adicional é necessária para complementar à remuneração dos custos.

$$
\begin{aligned}
& \Delta_{G}^{T M A}=\frac{\frac{C_{S I S T}^{T}}{2}-\sum_{i \in \Omega_{G}} \pi_{G i}^{T M A} P_{G i}}{\sum_{i \in \Omega_{G}} P_{G i}} \\
& \Delta_{D}^{T M A}=\frac{\frac{C_{S I S T}^{T}}{2}-\sum_{j \in \Omega_{D}} \pi_{D j}^{T M A} P_{D j}}{\sum_{j \in \Omega_{D}} P_{D j}}
\end{aligned}
$$

A formulação final da tarifa é dada por:

$$
\begin{array}{ll}
t_{G i}^{T M A}=\pi_{G i}^{T M A}+\Delta_{G}^{T M A}, & \forall i \in \Omega_{G} \\
t_{D j}^{T M A}=\pi_{D j}^{T M A}+\Delta_{D}^{T M A}, & \forall j \in \Omega_{D}
\end{array}
$$

\subsection{3.}

\section{Modelo de otimização TMA}

A formulação da tarifa proposta em (4.14) e (4.15) é aberta aos valores dos NEFs, o que possibilita utilizá-la em um problema de otimização que busca 
atender aos objetivos definidos para as tarifas. Dentro deste contexto, as restrições (4.9)-(4.11), (4.14) e (4.15) delimitam o conjunto viável de soluções para as tarifas, sendo os NEFs as variáveis de decisão. Como apresentado no Capítulo 1, o objetivo definido neste trabalho é minimizar os severos sinais locacionais alocados a usuários isolados, quando um método baseado em fluxo é utilizado. Para isso, a amplitude de variação das tarifas é minimizada. Ao minimizar a amplitude levando em conta as tarifas locacionais (4.14) e (4.15), os picos de tarifa são reduzidos, e os sinais locacionais coerentes mantidos já que os PTDFs $\gamma_{\ell i j}$ são considerados.

A metodologia para alcançar a mínima amplitude considera duas variáveis auxiliares $z$ e $w$. A variável $z$ é minimizada e tem todas as tarifas como limite inferior. Já $w$ é maximizada e tem todas as tarifas como limite superior. A ideia é ilustrada na Figura 4.1.
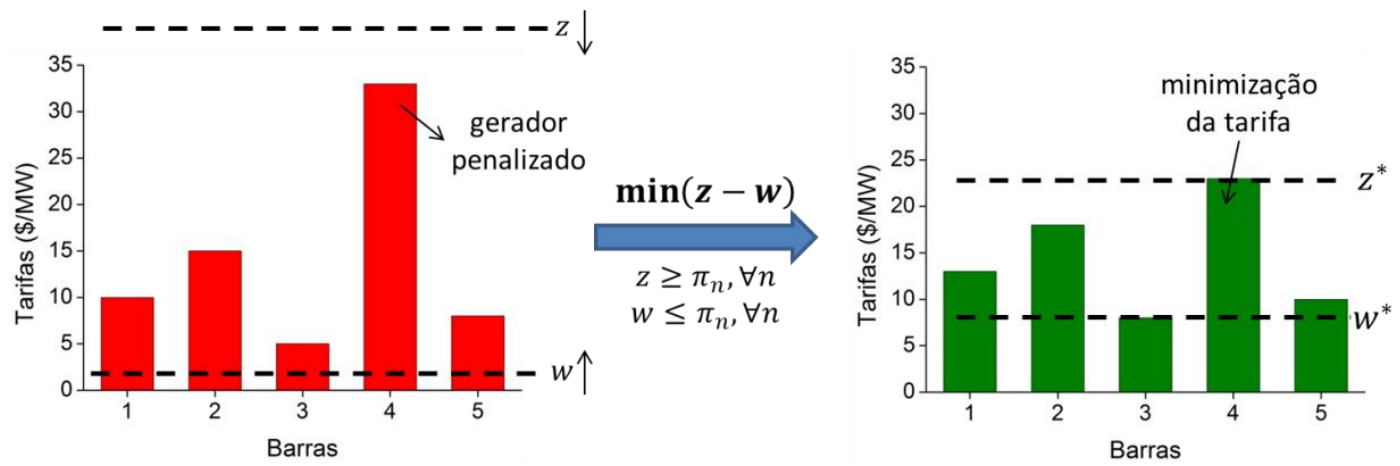

Figura 4.1. Metodologia de minimização da amplitude tarifária

Adicionalmente, são introduzidos no modelo limites predefinidos máximo $z^{M A X}$ e mínimo $w^{M I N}$ de tarifa. Estes limites devem ser estabelecidos pelo regulador do sistema de forma a proporcionar uma minimização de tarifa satisfatória, ou seja, informa ao modelo a faixa de valores de tarifa na qual a intensidade dos sinais locacionais pode existir sem comprometer a viabilidade ou incentivo a usuários isolados. É possível ainda incorporar regras para a alocação, como, por exemplo, permitir apenas tarifas positivas através de $w^{M I N} \geq 0$. A partir desta faixa, a minimização da amplitude garante o melhor incentivo viável.

Como as parcelas selo (4.16) e (4.17) são uma função das tarifas locacionais (4.14) e (4.15), a minimização da amplitude e os limites tarifários serão aplicados somente para as tarifas locacionais. As parcelas selo e as tarifas finais (4.18)(4.19) são calculadas após a otimização. O modelo do método de Tarifação de Mínima Amplitude apresentado em (4.20)-(4.31). 


\section{Método de Tarifação de Mínima Amplitude (TMA)}

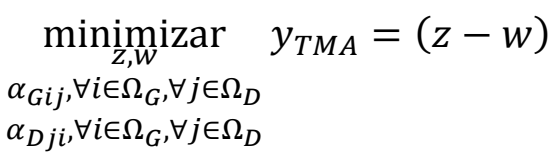

s.a.:

$$
\begin{aligned}
& \sum_{\ell \in \Omega_{L}} \sum_{j \in \Omega_{D}} \frac{c_{\ell}}{2} \text { Fpond }_{\ell} \gamma_{\ell i j} \alpha_{G i j} \leq z, \quad \forall i \in \Omega_{G} \\
& \sum_{\ell \in \Omega_{L}} \sum_{i \in \Omega_{G}} \frac{c_{\ell}}{2} \text { Fpond }_{\ell} \gamma_{\ell i j} \alpha_{D j i} \leq z, \quad \forall j \in \Omega_{D} \\
& \sum_{\ell \in \Omega_{L}} \sum_{j \in \Omega_{D}} \frac{c_{\ell}}{2} \text { Fpond }_{\ell} \gamma_{\ell i j} \alpha_{G i j} \geq w, \quad \forall i \in \Omega_{G} \\
& \sum_{\ell \in \Omega_{L}} \sum_{i \in \Omega_{G}} \frac{c_{\ell}}{2} \text { Fpond }_{\ell} \gamma_{\ell i j} \alpha_{D j i} \geq w, \quad \forall j \in \Omega_{D} \\
& Z \leq Z^{M A X} \\
& w \geq w^{M I N} \\
& \sum_{j \in \Omega_{D}} \alpha_{G i j}=1, \quad \forall i \in \Omega_{G} \\
& \sum_{i \in \Omega_{G}} \alpha_{D j i}=1, \quad \forall j \in \Omega_{D} \\
& \alpha_{G i j} P_{G i}=\alpha_{D j i} P_{D j}, \quad \forall i \in \Omega_{G}, \forall j \in \Omega_{D} \\
& \alpha_{G i j}, \alpha_{D j i} \in \mathbb{R}_{+}, \quad \forall i \in \Omega_{G}, \forall j \in \Omega_{D} \\
& z, w \in \mathbb{R}
\end{aligned}
$$

A função objetivo $y_{T M A}$ (4.20) minimiza a diferença entre duas as variáveis auxiliares $z$ e $w$. Em (4.21) e (4.22) todas as tarifas são limite inferior para $z$, e a maior tarifa é minimizada. Em (4.23) e (4.24) todas as tarifas são limite superior para $w$, e a menor tarifa é maximizada. Desta maneira, a amplitude das tarifas é minimizada, conforme ilustrado na Figura 4.1. As restrições (4.25) e (4.26) 
asseguram os limites máximo $z^{M A X}$ e mínimo $w^{M I N}$ para as tarifas. Como a formulação das tarifas é considerada em (4.21)-(4.24), não é necessário saber $a$ priori qual barra do sistema receberá a maior ou menor tarifa. Isso faz com que o problema seja independente de uma solução inicial. Todas as demais restrições (4.27)-(4.29) asseguram valores coerentes para os NEFs conforme apresentado na Seção 4.2.1.

Conhecidos os valores ótimos dos NEFs, as tarifas locacionais (4.14)-(4.15), as parcelas selo (4.16)-(4.17) e as tarifas finais (4.18)-(4.19) podem ser calculadas, finalizando a alocação.

Definido o modelo de cálculo das tarifas (4.20)-(4.31), as seguintes observações adicionais são feita para o método TMA:

- O método é independente da escolha da barra de referência do sistema. O parâmetro $\gamma_{\ell i j}$, utilizado para captar a sensibilidade dos fluxos, possui valor constante para qualquer barra de referência por ser a subtração de dois elementos de colunas diferentes de $\boldsymbol{\beta}$;

- Pelo mesmo motivo exposto no ponto anterior, todas as barras do sistema, incluindo a de referência, recebem tarifa locacional;

- A flexibilidade fornecida pelos limites tarifários $z^{M A X}$ e $w^{M I N}$ permite outras vantagens nas tarifas, como manter um intervalo de variação tarifária ao longo do tempo;

- O modelo (4.20)-(4.29) proposto para o método possui função objetivo e restrições lineares, sendo um programa linear. 


\section{5}

\section{Alocação binível de tarifas de transmissão}

De acordo com o exposto no Capítulo 1, uma vez definido um critério para as tarifas de transmissão, a solução separada e sequencial dos problemas de definição do caso base de fluxo de potência, e de cálculo de tarifa de transmissão pode levar à um resultado final subótimo. Isto porque, o problema de alocação de tarifas pode influenciar o conjunto viável do fluxo de potência, e vice-versa. Assim, este trabalho propõe a união dos dois modelos citados em um único problema de otimização denominado Alocação Binível de Tarifas de Transmissão (ABTT). Nele, o modelo DPC apresentado no Capítulo 3, tem como restrição adicional o método TMA apresentado no Capítulo 4. Conforme será visto ao longo deste capítulo, os objetivos do nível inferior terão influência no acoplamento dos dois níveis na solução ótima.

Neste capítulo, são apresentados o modelo matemático de ABTT, uma análise do acoplamento dos níveis na solução ótima e seu significado nos resultados, além de uma avaliação da unicidade da solução final fornecida pelo modelo.

\section{1. Modelo de otimização ABTT}

Para unir os modelos propostos nos Capítulos 3 e 4 em um problema binível, duas restrições são modificadas no modelo DPC para incluir as variáveis NEFs de geração $\alpha_{G i j}$, e caracterizar de maneira adequada a interdependência entre os conjuntos viáveis dos dois níveis. Desta forma, os dois modelos podem se acoplar, com as restrições do nível superior sendo função de variáveis de decisão do nível inferior. A definição dos fluxos de potência em (3.5), e restrição de balanço de potência em (3.6) são substituídas por (5.1) e (5.2), respectivamente.

$$
F_{\ell}=\sum_{i \in \Omega_{G}} \sum_{j \in \Omega_{D}} F_{\ell}^{i, j}=\sum_{i \in \Omega_{G}} \sum_{j \in \Omega_{D}} \gamma_{\ell i j} P_{G i} \alpha_{G i j}, \quad \forall \ell \in \Omega_{L}
$$




$$
\sum_{i \in \Omega_{G}} P_{G i} \alpha_{G i j}=P_{D j}, \quad \forall j \in \Omega_{D}
$$

Para uma linha $\ell$, a expressão do fluxo é dada pelo somatório das componentes $F_{\ell}^{i, j}$ (definidas em (4.13)) provocadas por cada troca bilateral entre pares $(i, j)$. No balanço de potência, cada demanda $P_{D j}$ deve ser inteiramente suprida pelo somatório das contribuições $P_{G i} \alpha_{G i j}$ de todos os geradores do sistema. Os NEFs $\alpha_{G i j}$ presentes em (5.1) e (5.2), serão oriundos nível inferior do problema binível.

Feitas as modificações apresentadas acima, o modelo de Alocação Binível de Tarifas de Transmissão é dado por (5.3)-(5.21).

\section{Modelo de Alocação Binível de Tarifas de Transmissão (ABTT)}

$$
\operatorname{maximizar}_{\substack{P_{G i}, \forall i \in \Omega_{G} \\ F_{\ell}, \forall \ell \in \Omega_{L}}} y_{D P C}=\sum_{\ell \in \Omega_{L}} F_{\ell}
$$

s.a.:

$$
\begin{gathered}
F_{\ell}=\sum_{i \in \Omega_{G}} \sum_{j \in \Omega_{D}} \gamma_{\ell i j} P_{G i} \alpha_{G i j}, \quad \forall \ell \in \Omega_{L} \\
\sum_{i \in \Omega_{G}} P_{G i} \alpha_{G i j}=P_{D j}, \quad \forall j \in \Omega_{D} \\
0 \leq F_{\ell} \leq \operatorname{Cap}_{\ell}, \quad \forall \ell \in \Omega_{L} \\
P_{G i}^{M I N} \leq P_{G i} \leq P_{G i}^{M A X}, \quad \forall i \in \Omega_{G} \\
F_{\ell} \in \mathbb{R}, \quad \forall \ell \in \Omega_{L} \\
P_{G i} \in \mathbb{R}, \quad \forall i \in \Omega_{G}
\end{gathered}
$$

Onde $\alpha_{G i j}$ é obtido de:

$$
\begin{aligned}
& \quad \underset{Z, W}{\operatorname{minimizar}} y_{T M A}=(z-w) \\
& \alpha_{G i j} ; \forall i \in \Omega_{G}, \forall j \in \Omega_{D} \\
& \alpha_{D j i} ; \forall i \in \Omega_{G}, \forall j \in \Omega_{D} \\
& \text { s.a.: }
\end{aligned}
$$




$$
\begin{aligned}
& \sum_{\ell \in \Omega_{L}} \sum_{j \in \Omega_{D}} \frac{c_{\ell}}{2} \text { Fpond }_{\ell} \gamma_{\ell i j} \alpha_{G i j} \leq z, \quad \forall i \in \Omega_{G} \quad: \theta_{i}^{U} \\
& \sum_{\ell \in \Omega_{L}} \sum_{i \in \Omega_{G}} \frac{c_{\ell}}{2} \text { Fpond }_{\ell} \gamma_{\ell i j} \alpha_{D j i} \leq z, \quad \forall j \in \Omega_{D} \quad: \varphi_{j}^{U} \\
& \sum_{\ell \in \Omega_{L}} \sum_{j \in \Omega_{D}} \frac{c_{\ell}}{2} \text { Fpond }_{\ell} \gamma_{\ell i j} \alpha_{G i j} \geq w, \quad \forall i \in \Omega_{G} \quad: \theta_{i}^{L} \\
& \sum_{\ell \in \Omega_{L}} \sum_{i \in \Omega_{G}} \frac{c_{\ell}}{2} \text { Fpond }_{\ell} \gamma_{\ell i j} \alpha_{D j i} \geq w, \quad \forall j \in \Omega_{D} \quad: \varphi_{j}^{L} \\
& z \leq z^{M A X} \quad: \rho^{U} \\
& w \geq w^{M I N} \quad: \rho^{L} \\
& \sum_{j \in \Omega_{D}} \alpha_{G i j}=1, \quad \forall i \in \Omega_{G} \quad: \varepsilon_{i}^{G} \\
& \sum_{i \in \Omega_{G}} \alpha_{D j i}=1, \quad \forall j \in \Omega_{D} \quad: \varepsilon_{j}^{D} \\
& \alpha_{G i j} P_{G i}=\alpha_{D j i} P_{D j}, \quad \forall i \in \Omega_{G}, \forall j \in \Omega_{D} \quad: \tau_{i j} \\
& \alpha_{G i j}, \alpha_{D j i} \in \mathbb{R}_{+}, \quad \forall i \in \Omega_{G}, \forall j \in \Omega_{D} \\
& z, w \in \mathbb{R}
\end{aligned}
$$

Para que o modelo ABTT (5.3)-(5.21) possa ser resolvido, deve ser convertido em um modelo equivalente de um único nível. Neste caso, é utilizada a teoria de dualidade em problemas lineares [49] no nível inferior (5.10)-(5.21). Por esta teoria, a solução ótima de um problema linear (ou problema primal) pode ser acessada resolvendo o conjunto de equações formado por suas restrições originais (ou primais), pelas restrições do problema dual correspondente, e pela relação de dualidade forte que iguala as funções objetivo dos problemas primal e dual. Este conjunto de restrições quando atendidas garantem a solução ótima do problema. Ressalta-se que por o resultado de fluxo de potência ser constante para o nível inferior isoladamente, o modelo TMA é linear, conforme pontuado na Seção 4.2.3 
do Capítulo 4, e a teoria pode ser aplicada. Para tanto, o problema dual do nível inferior é apresentado em (5.22)-(5.32) em função das variáveis duais sinalizadas em (5.11)-(5.19).

\section{Problema dual do nível inferior do modelo ABTT}

$$
\begin{aligned}
& \underset{\substack{\rho^{U}, \rho^{L} \\
\theta_{i}^{U}, \theta_{i}^{L}, \varepsilon_{i}^{G}, \forall i \in \Omega_{G} \\
\varphi_{j}^{U}, \varphi_{j}^{L}, \varepsilon_{j}^{D}, \forall j \in \Omega_{D}}}{\operatorname{maximizar}} y_{T M A-D u a l}=\rho^{L} w^{M I N}-\rho^{U} Z^{M A X}+\sum_{i \in \Omega_{G}} \varepsilon_{i}^{G}+\sum_{j \in \Omega_{D}} \varepsilon_{j}^{D} \\
& \tau_{i j}, \forall i \in \Omega_{G}, \forall j \in \Omega_{D}
\end{aligned}
$$

$\tau_{i j}, \forall i \in \Omega_{G}, \forall j \in \Omega_{D}$

s.a.:

$$
\begin{aligned}
& \varepsilon_{i}^{G}+\tau_{i j} P_{G i}+\left(\theta_{i}^{L}-\theta_{i}^{U}\right) \sum_{\ell \in \Omega_{L}} \frac{c_{\ell}}{2} \text { Fpond }_{\ell} \gamma_{\ell i j} \leq 0, \forall i \in \Omega_{G}, \forall j \in \Omega_{D} \\
& \varepsilon_{j}^{D}-\tau_{i j} P_{D j}+\left(\varphi_{j}^{L}-\varphi_{j}^{U}\right) \sum_{\ell \in \Omega_{L}} \frac{c_{\ell}}{2} \text { Fpond }_{\ell} \gamma_{\ell i j} \leq 0, \forall i \in \Omega_{G}, \forall j \in \Omega_{D}
\end{aligned}
$$

$$
\begin{gathered}
\sum_{i \in \Omega_{G}} \theta_{i}^{U}+\sum_{j \in \Omega_{D}} \varphi_{j}^{U}-\rho^{U}=1 \\
-\sum_{i \in \Omega_{G}} \theta_{i}^{L}-\sum_{j \in \Omega_{D}} \varphi_{j}^{L}+\rho^{L}=-1 \\
\theta_{i}^{U}, \theta_{i}^{L} \in \mathbb{R}_{+}, \quad \forall i \in \Omega_{G} \\
\varphi_{j}^{U}, \varphi_{j}^{L} \in \mathbb{R}_{+}, \quad \forall j \in \Omega_{D} \\
\rho^{U}, \rho^{L} \in \mathbb{R}_{+} \\
\varepsilon_{i}^{G} \in \mathbb{R}, \quad \forall i \in \Omega_{G} \\
\varepsilon_{j}^{D} \in \mathbb{R}, \quad \forall j \in \Omega_{D} \\
\tau_{i j} \in \mathbb{R}, \quad \forall i \in \Omega_{G}, \forall j \in \Omega_{D}
\end{gathered}
$$

Substituindo o nível inferior pelas restrições que garantem a sua solução ótima, o modelo único equivalente para a ABTT é apresentado a seguir. Adicionalmente às restrições já apresentadas, a relação de dualidade forte utilizando as funções objetivo $y_{T M A}$ e $y_{T M A-D u a l}$ é apresentada em (5.35). 


\section{Alocação Binível de Tarifas de Transmissão - Modelo único equivalente}

$$
\begin{aligned}
& \operatorname{maximizar}_{\substack{P_{G i}, \forall i \in \Omega_{G} \\
F_{\ell}, \forall \ell \in \Omega_{L} \\
z, w}} y_{A B T T}=\sum_{\ell \in \Omega_{L}} F_{\ell} \\
& \alpha_{G i j}, \forall i \in \Omega_{G}, \forall j \in \Omega_{D} \\
& \alpha_{D j i}, \forall j \in \Omega_{D}, \forall i \in \Omega_{G} \\
& \rho^{U}, \rho^{L} \\
& \theta_{i}^{U}, \theta_{i}^{L}, \varepsilon_{i}^{G} ; \forall i \in \Omega_{G} \\
& \varphi_{j}^{U}, \varphi_{j}^{L}, \varepsilon_{j}^{D} ; \forall j \in \Omega_{D} \\
& \tau_{i j}, \forall i \in \Omega_{G}, \forall j \in \Omega_{D}
\end{aligned}
$$

s.a.:

Restrições (5.4)-(5.9)

Restrições (5.11)-(5.21)

Restrições (5.23)-(5.32)

$$
\rho^{L} w^{M I N}-\rho^{U} z^{M A X}+\sum_{i \in \Omega_{G}} \varepsilon_{i}^{G}+\sum_{j \in \Omega_{D}} \varepsilon_{j}^{D}=z-w
$$

Em relação à complexidade computacional do modelo único equivalente, ele apresenta $4+n_{L}+4 n_{G}+3 n_{D}+3 n_{G} n_{D}$ variáveis contínuas, e $5+3 n_{L}+$ $5 n_{G}+4 n_{D}+3 n_{G} n_{D}$ restrições. O modelo é do tipo não-linear devido aos diversos produtos de variáveis reais presentes nas restrições. Conforme será abordado na apresentação de resultados (Capítulo 6), o modelo é resolvido usando um solver não-linear voltado para problemas de larga escala.

\section{2.}

\section{Análise de soluções}

Conforme apresentado na Seção 4.2.3 do Capítulo 4, o nível inferior do modelo $\mathrm{ABTT}$ proposto permite inserir limites tarifários máximo $z^{M A X}$ e mínimo $w^{M I N}$. Estes limites têm por objetivo informar ao modelo, a partir de conhecimentos do regulador do sistema, o intervalo no qual os sinais locacionais podem variar sem comprometer os interesses definidos para as tarifas. No modelo ABTT, quanto mais restrito é o intervalo $\left[w^{M I N}, z^{M A X}\right]$, mais restrita é a região viável do problema. Assim, existe uma relação entre o valor ótimo do máximo estresse da rede $\left(y_{A B T T}^{*}\right)$ e os valores de $w^{M I N}$ e $z^{M A X}$. Esta relação é ilustrada na Figura 5.1. Para facilitar a visualização e interpretação, é considerado um valor 
fixo para $W^{M I N}$, e um gráfico bidimensional de $y_{A B T T}^{*}$ em função $z^{M A X}$ é apresentado.

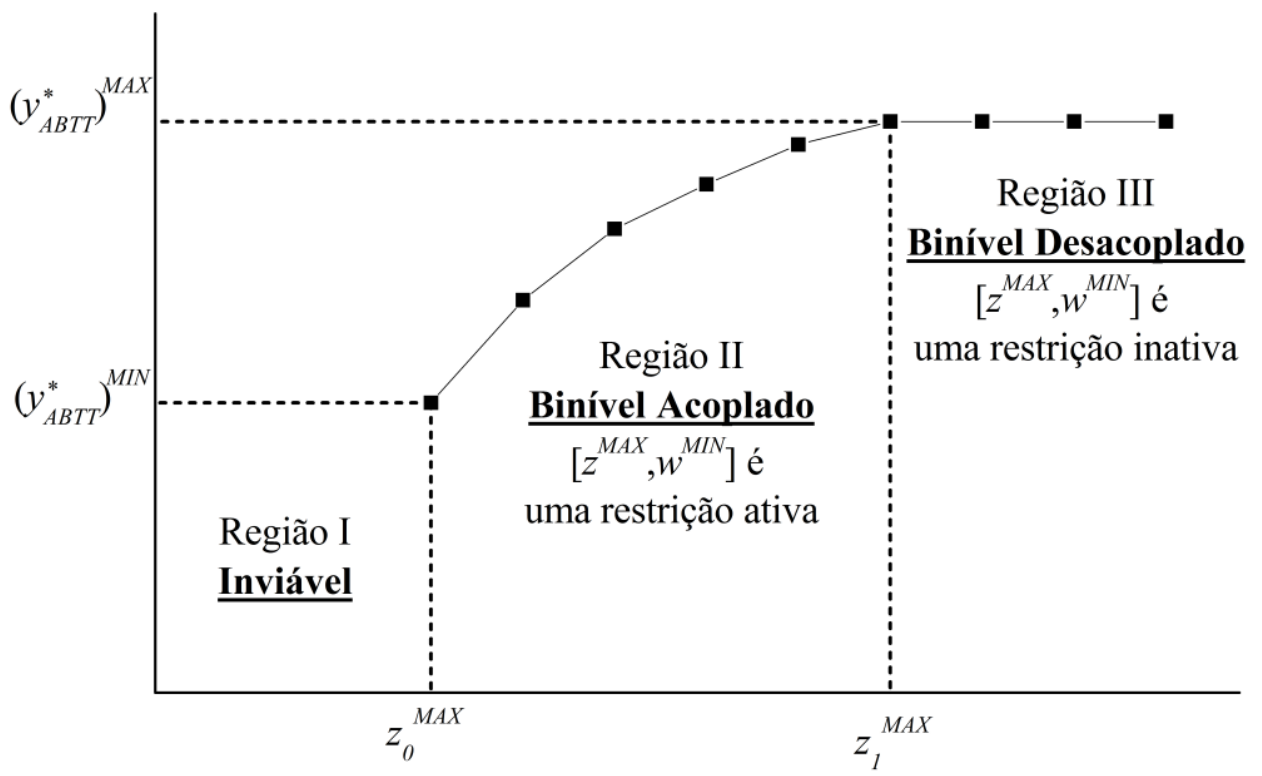

Figura 5.1. Estresse máximo do sistema $y_{A B T T}^{*} \operatorname{como}$ função de $z^{M A X} \operatorname{com} w^{M I N}$ fixo

As soluções ótimas do problema binível podem ser classificadas em três categorias: inviável (região I), binível acoplado (região II) e binível desacoplado (região III). Na região I, não há resultado viável de fluxo de potência (ou de despacho de geração) que permita aos resultados de tarifa estar compreendidos entre $W^{M I N}$ e $z^{M A X}$. A partir de um determinado valor $z_{0}^{M A X}$ para o limite superior $Z^{M A X}$, o problema passa a ser viável e a solução ótima corresponde ao menor valor possível para o nível de máximo estresse do sistema $\left(\left(y_{A B T T}^{*}\right)^{M I N}\right)$. Para limites superiores a $z_{0}^{M A X}$, até atingir o valor $z_{1}^{M A X}$, o problema binível é acoplado e a Figura 5.1 pode ser vista como uma curva de eficiência (ou uma superfície de eficiência, para o caso de $w^{M I N}$ variar) do nível de máximo estresse do sistema em função dos limites de tarifa. Neste caso, os limites tarifários são restrições ativas para a solução ótima, e a interdependência entre os problemas está ativa.

Para valores de $Z^{M A X}$ maiores que $Z_{1}^{M A X}$, os limites não são restritivos o suficiente para influenciar nas decisões ótimas do nível superior. Assim, o binível é desacoplado, e é atingido o máximo valor possível para nível de estresse do sistema $\left(\left(y_{A B T T}^{*}\right)^{M A X}\right)$. Neste caso, o nível inferior não é uma restrição ativa do problema binível, e a solução ótima corresponde aos modelos DPC e TMA (apresentados nos Capítulos 3 e 4) resolvidos separadamente e em sequência. Esta é uma característica vantajosa do método, pois caso o critério estabelecido no 
nível inferior não provoque acoplamento dos dois problemas, o método naturalmente retorna à solução clássica sequencial.

Neste ponto, é importante ressaltar que não é necessário saber a priori em qual região da Figura 5.1 estarão os valores escolhidos para limites de tarifa. O modelo binível proposto é geral o suficiente para capturar as três possibilidades apresentadas para os resultados. Adicionalmente, através de um estudo como o da Figura 5.1 é mensurado o quanto de máximo estresse da rede é comprometido para atender aos limites estabelecidos para as tarifas.

\section{3. \\ Solução única de tarifas}

Em sistemas realistas de médio e grande porte, a aplicação do modelo ABTT proposto apresenta grande quantidade de variáveis. Entre elas os NEFs $\alpha_{G i j}$ e $\alpha_{D j i}$ que juntos tem quantidade igual a $2 n_{G} n_{D}$, sendo $n_{G}$ e $n_{D}$ o número de geradores e demandas, respectivamente. Esta característica pode levar o modelo binível a ter múltiplas soluções ótimas, ou seja, mais de um conjunto de valores de variáveis que levam ao mesmo valor ótimo da função objetivo. Neste sentido, é importante para o método determinar valores únicos de tarifas locacionais, que compõem o resultado final do processo de alocação de custos.

Assim, é proposto um passo extra no processo de alocação de tarifas baseado em otimização lexicográfica [50]. Na otimização lexicográfica, diferentes critérios de otimização são ordenados por prioridade. A solução obtida pelo critério mais importante é restrição para o segundo critério mais importante e assim por diante. Um exemplo de utilização desta técnica na literatura relacionada à tarifação de sistemas de transmissão, é o uso da técnica min-max de otimização presente em alguns métodos revisitados no Capítulo 2.

Neste trabalho, um novo critério é adicionado para definir os valores finais de tarifa locacional. Para manter o critério primordial, que consiste na solução do modelo ABTT, os resultados de despacho de geração $P_{G i}^{*}$ e a amplitude ótima das tarifas $z^{*}$ e $w^{*}$ são mantidos. Com estes valores constantes, a variância das tarifas é minimizada para definir o valor final dos NEFs e consequentemente das tarifas. A minimização da variância segue a mesma ideia da minimização de amplitude das tarifas: aproximar as tarifas de uma alocação do tipo pro-rata tendo como 
restrição o sinal locacional. Neste caso, o sinal locacional se faz presente porque o resultado final dos NEFs é limitado apenas pelas restrições da rede, uma vez que a amplitude tarifária e o despacho de geração são fixos. Outras opções de função objetivo (maximização da variância, e minimização/maximização da média) foram avaliadas, no entanto, a minimização da variância foi a que apresentou melhores resultados em relação à coerência de sinalização locacional.

Como o resultado ótimo do modelo ABTT é garantido, caso os NEFs já sejam únicos e o ótimo do modelo ABTT não seja múltiplo, o resultado original é mantido. A seguir é proposta a formulação do problema de tarifas de mínima variância.

\section{Minimização da variância tarifária}

$$
\begin{aligned}
& \operatorname{minimizar}_{\substack{G i j, \forall i \in \Omega_{G}, \forall j \in \Omega_{D} \\
\alpha_{D j i}, \forall i \in \Omega_{G}, \forall j \in \Omega_{D}}} y_{V A R}=\frac{1}{n_{G}+n_{D}}\left[\sum_{i \in \Omega_{G}}\left(\pi_{G i}^{T M A}-M\right)^{2}+\sum_{j \in \Omega_{D}}\left(\pi_{D j}^{T M A}-M\right)^{2}\right] \\
& \pi_{G i}^{T M A}, \forall i \in \Omega_{G} \\
& \pi_{D j}^{T M A}, \forall j \in \Omega_{D} \\
& M
\end{aligned}
$$

S.a.:

$$
\begin{gathered}
M=\frac{\sum_{i \in \Omega_{G}} \pi_{G i}^{T M A}+\sum_{j \in \Omega_{D}} \pi_{D j}^{T M A}}{n_{G}+n_{D}} \\
\pi_{G i}^{T M A}=\sum_{\ell \in \Omega_{L}} \sum_{j \in \Omega_{D}} \frac{c_{\ell}}{2} F_{p o n d} \gamma_{\ell i j} \alpha_{G i j}, \quad \forall i \in \Omega_{G} \\
\pi_{D j}^{T M A}=\sum_{\ell \in \Omega_{L}} \sum_{i \in \Omega_{G}} \frac{c_{\ell}}{2} F p o n d_{\ell} \gamma_{\ell i j} \alpha_{D j i}, \quad \forall j \in \Omega_{D} \\
\pi_{G i}^{T M A} \leq z^{*}, \quad \forall i \in \Omega_{G} \\
\pi_{D j}^{T M A} \leq z^{*}, \quad \forall j \in \Omega_{D} \\
\pi_{G i}^{T M A} \geq w^{*}, \quad \forall i \in \Omega_{G} \\
\pi_{D j}^{T M A} \geq w^{*}, \quad \forall j \in \Omega_{D} \\
\sum_{j \in \Omega_{D}} \alpha_{G i j}=1, \quad \forall i \in \Omega_{G}
\end{gathered}
$$




$$
\begin{gathered}
\sum_{i \in \Omega_{G}} \alpha_{D j i}=1, \quad \forall j \in \Omega_{D} \\
\alpha_{G i j} P_{G i}^{*}=\alpha_{D j i} P_{D j}, \quad \forall i \in \Omega_{G}, \forall j \in \Omega_{D} \\
\alpha_{G i j}, \alpha_{D j i} \in \mathbb{R}_{+}, \quad \forall i \in \Omega_{G}, \forall j \in \Omega_{D} \\
\pi_{G i} \in \mathbb{R}, \quad \forall i \in \Omega_{G} \\
\pi_{D j} \in \mathbb{R}, \quad \forall j \in \Omega_{D} \\
M \in \mathbb{R}
\end{gathered}
$$

Em (5.36) a expressão da variância das tarifas de geradores e demandas $y_{V A R}$ é minimizada, sendo a média $M$ de todas as tarifas definida na restrição (5.37). As restrições (5.38) e (5.39) inserem as expressões de tarifa de geradores e demandas no modelo. Em (5.40)-(5.43) a amplitude ótima das tarifas é preservada. As demais restrições (5.44)-(5.47) são àquelas relacionadas ao conceito e definição dos NEFs conforme (5.17)-(5.20). Assim, o processo completo de alocação de tarifas proposto neste trabalho é resumido na Figura 5.2.

Inicializações: parâmetros da rede, demanda máxima, $z^{M A X}$ e $w^{M I N}$

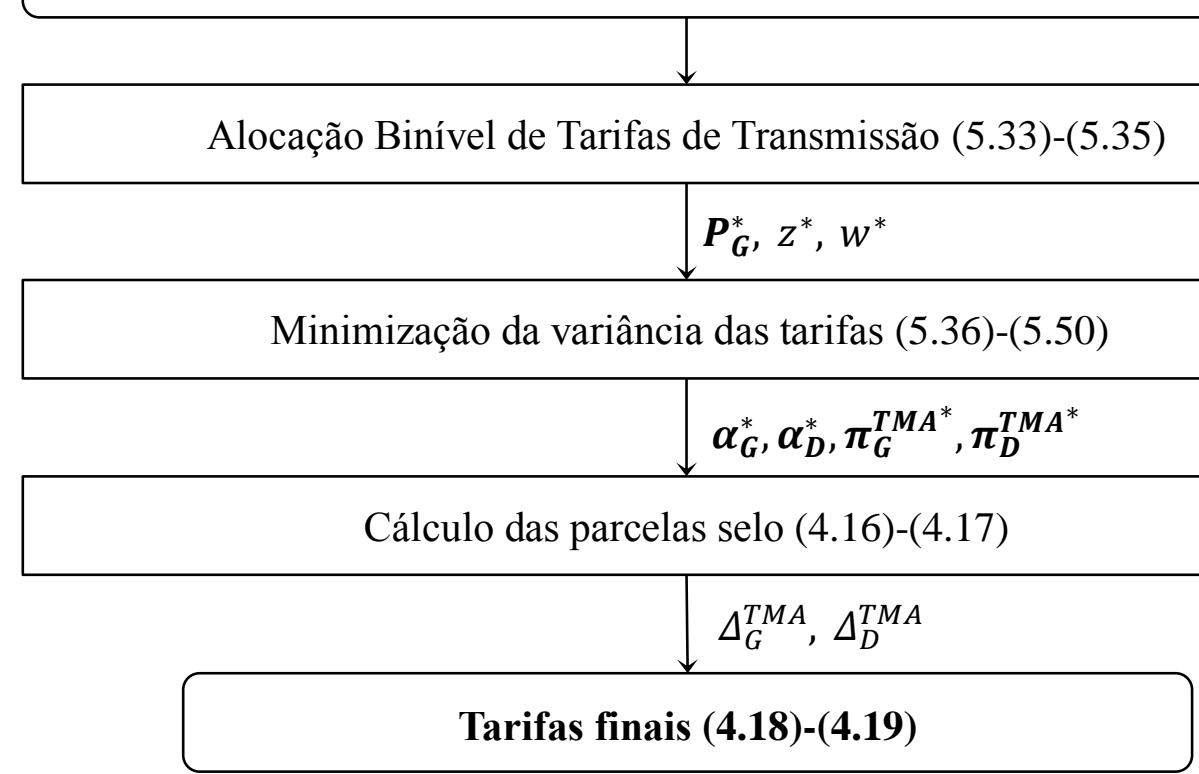

Figura 5.2. Processo de alocação das tarifas de transmissão 


\section{6 \\ Resultados}

Neste capítulo, o processo de alocação proposto no Capítulo 5 é aplicado em sistemas de transmissão de teste, e os resultados obtidos são analisados em detalhes. Primeiramente, um sistema didático de 6 barras é utilizado para explorar a ideia dos NEFs e da decomposição de fluxos. Posteriormente, no sistema IEEE 118 barras, o método proposto é avaliado em um sistema de maior porte, e seus resultados são comparados aos do método Nodal para verificar se os objetivos descritos no Capítulo 1 foram atingidos. No mesmo sistema, diferentes configurações de demanda são consideradas para avaliar a adequação do método em diferentes padrões de sinais locacionais. Além disso, para complementar a análise, o método proposto é comparado com outros métodos de tarifação revisitados no Capítulo 2. Todos os dados dos sistemas utilizados nas simulações são disponibilizados no Apêndice D.

Os problemas de otimização envolvidos no método proposto são resolvidos através do solver não-linear CONOPT [51] utilizado no software General Algebraic Modeling System (GAMS) [52]. A opção por um solver não-linear tem como principal motivo o tempo computacional atrativo quando o método é utilizado em sistemas de médio e grande porte. Neste capítulo, é apresentada uma análise acerca da qualidade da solução (garantia de ótimo global) e do tempo computacional do solver CONOPT.

Para todas as simulações deste capítulo, o método proposto corresponde ao processo de alocação da Figura 5.2 que inclui o modelo ABTT e o problema adicional de minimização de variância. Além disso, o limite mínimo de despacho de geração é tal que $P_{G i}^{M I N}=10 \% \cdot P_{G i}^{M A X}$, de forma que todos os geradores participam do cálculo do caso base de fluxo de potência. Em relação aos fatores de ponderação $F$ pond $d_{\ell}$, é considerado $F_{\ell}^{M I N}=0$. Desta forma, todas as linhas fazem parte da sinalização locacional das tarifas. O computador utilizado para as simulações possui um processador Intel ${ }^{\circledR}$ Core i7 3,4 GHz e 8GB de memória RAM. 


\section{1.}

\section{Sistema de 6 barras}

Nesta seção, o método de alocação proposto é aplicado ao sistema de 6 barras presente na Figura 6.1. São apresentados a demanda máxima $P_{D j}$, e os custos e capacidade das linhas $\left(C_{\ell}^{T} ; \operatorname{Cap}_{\ell}\right)$. Para este sistema, o foco dos resultados são os valores ótimos dos NEFs e a correspondente distribuição de fluxos pelas linhas da rede. Os resultados serão obtidos para os limites $z^{M A X}=7$ e $w^{M I N}=0$, escolhidos arbitrariamente. O tempo de solução do modelo ABTT aplicado ao sistema da Figura 6.1, utilizando o solver CONOPT, é aproximadamente $1 \mathrm{~s}$.

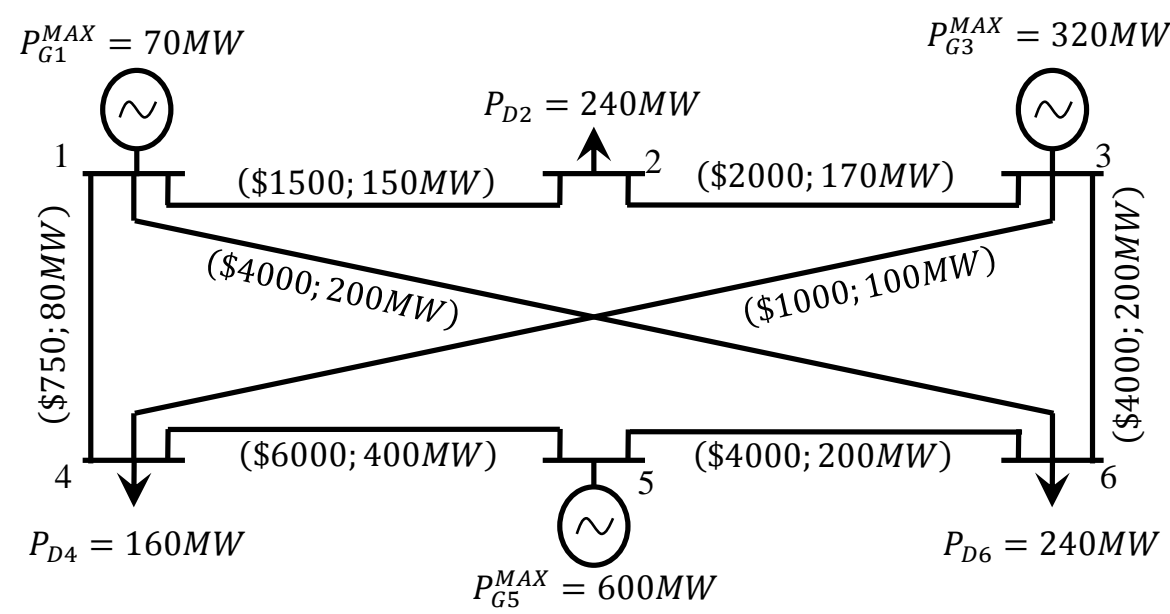

Figura 6.1. Sistema de 6 barras

O valor ótimo do máximo congestionamento do sistema $y_{A B T T}^{*}$ é igual a 723,1 MW que corresponde a 48,2\% da capacidade de transmissão total $\left(\sum_{\ell \in \Omega_{L}} \mathrm{Cap}_{\ell}\right)$. Estes valores são atingidos com um despacho ótimo de geração $P_{G}^{*}=[46,33208,67385,00]$ MW para os geradores 1,3 e 5, respectivamente. Os fluxos de potência correspondentes são apresentados na Tabela 6.1.

As tarifas locacionais ótimas são $\pi_{G}^{T M A^{*}}=[2,964,797,00] \$ / \mathrm{MW}$ para os geradores 1 , 3 e 5. Para as demandas 2 , 4 e $6, \pi_{D}^{T M A^{*}}=[6,204,79$ 7,00] \$/MW. Para as parcelas selo, $\Delta_{G}^{T M A}=\Delta_{D}^{T M A}=12,18 \$ / \mathrm{MW}$. Os valores ótimos dos NEFs $\alpha_{G i j}$ e $\alpha_{D j i}$ são apresentados na Tabela 6.2 e na Tabela 6.3, respectivamente. Para cada NEF é apresentado também o montante de potência referente ao par $(i, j)$.

Nas tabelas é possível ver como as injeções de potência dos geradores se distribuem entre as demandas de forma que as tarifas ótimas sejam obtidas. Como exemplo, na Tabela 6.2, o gerador 1 tem $100 \%$ de sua potência destinada à 
demanda 2, enquanto o gerador 5 divide sua injeção entre todas as demandas nas proporções de $13,1 \%$ para a demanda $2,41,6 \%$ para a demanda 4 e $45,3 \%$ para a demanda 6. Na Tabela 6.3, 100\% da demanda 4 é suprida pelo gerador 5, ao passo que a demanda 2 é suprida por todos os geradores do sistema com 19,3\% oriundos do gerador 1, 59,6\% oriundos do gerador 3 e 21,1\% oriundos do gerador 5 .

Tabela 6.1. Fluxos de potência do sistema de 6 barras

\begin{tabular}{|c|c|c|}
\hline Barra "de" & Barra "para" & Fluxo \\
\hline 1 & 2 & $F_{1-2}=70,00 \mathrm{MW}$ \\
\hline 3 & 2 & $F_{3-2}=170,00 \mathrm{MW}$ \\
\hline 3 & 6 & $F_{3-6}=56,54 \mathrm{MW}$ \\
\hline 4 & 1 & $F_{4-1}=21,93 \mathrm{MW}$ \\
\hline 4 & 3 & $F_{4-3}=17,87 \mathrm{MW}$ \\
\hline 5 & 4 & $F_{5-4}=199,81 \mathrm{MW}$ \\
\hline 5 & 6 & $F_{5-6}=185,19 \mathrm{MW}$ \\
\hline 6 & 1 & $F_{6-1}=1,73 \mathrm{MW}$ \\
\hline
\end{tabular}

Tabela 6.2. Valores de $\alpha_{G i j}$ e $\alpha_{G i j} \cdot P_{G i}$ para o sistema de 6 barras

\begin{tabular}{|c|c|c|c|c|c|c|}
\hline & \multicolumn{2}{|c|}{ Gerador $i=1$} & \multicolumn{2}{|c|}{ Gerador $i=3$} & \multicolumn{3}{|c|}{ Gerador $i=5$} \\
\cline { 2 - 7 } & $\alpha_{G 1 j}$ & $P_{G 1} \cdot \alpha_{G 1 j}$ & $\alpha_{G 3 j}$ & $P_{G 3} \cdot \alpha_{G 3 j}$ & $\alpha_{G 5 j}$ & $P_{G 5} \cdot \alpha_{G 5 j}$ \\
\hline $\begin{array}{c}\text { Demanda } \\
j=2\end{array}$ & 1,000 & $46,33 \mathrm{MW}$ & 0,686 & $143,13 \mathrm{MW}$ & 0,131 & $50,54 \mathrm{MW}$ \\
\hline $\begin{array}{c}\text { Demanda } \\
j=4\end{array}$ & 0,000 & $0,00 \mathrm{MW}$ & 0,000 & $0,00 \mathrm{MW}$ & 0,416 & $160,00 \mathrm{MW}$ \\
\hline $\begin{array}{c}\text { Demanda } \\
j=6\end{array}$ & 0,000 & $0,00 \mathrm{MW}$ & 0,314 & $65,54 \mathrm{MW}$ & 0,453 & $174,46 \mathrm{MW}$ \\
\hline Total & 1,000 & $46,33 \mathrm{MW}$ & 1,000 & $208,67 \mathrm{MW}$ & 1,000 & $385,00 \mathrm{MW}$ \\
\hline
\end{tabular}

Tabela 6.3. Valores de $\alpha_{D j i}$ e $\alpha_{D j i} \cdot P_{D j}$ para o sistema de 6 barras

\begin{tabular}{|c|c|c|c|c|c|c|}
\hline & \multicolumn{2}{|c|}{ Demand $j=2$} & \multicolumn{2}{|c|}{ Demanda $j=4$} & \multicolumn{2}{|c|}{ Demanda $j=6$} \\
\cline { 2 - 7 } & $\alpha_{D 2 i}$ & $P_{D 2} \cdot \alpha_{D 2 i}$ & $\alpha_{D 4 i}$ & $P_{D 4} \cdot \alpha_{D 4 i}$ & $\alpha_{D 6 i}$ & $P_{D 6} \cdot \alpha_{D 6 i}$ \\
\hline $\begin{array}{c}\text { Gerador } \\
i=1\end{array}$ & 0,193 & $46,33 \mathrm{MW}$ & 0,000 & $0,00 \mathrm{MW}$ & 0,000 & $0,00 \mathrm{MW}$ \\
\hline $\begin{array}{c}\text { Gerador } \\
i=3\end{array}$ & 0,596 & $143,13 \mathrm{MW}$ & 0,000 & $0,00 \mathrm{MW}$ & 0,273 & $65,54 \mathrm{MW}$ \\
\hline $\begin{array}{c}\text { Gerador } \\
i=5\end{array}$ & 0,211 & $50,54 \mathrm{MW}$ & 1,000 & $160,00 \mathrm{MW}$ & 0,727 & $174,46 \mathrm{MW}$ \\
\hline Total & 1,000 & $240,00 \mathrm{MW}$ & 1,000 & $160,00 \mathrm{MW}$ & 1,000 & $240,00 \mathrm{MW}$ \\
\hline
\end{tabular}

Além das distribuições de potência, os resultados atendem às restrições (5.17)-(5.19) referentes aos NEFs. Na linha "Total" de ambas as tabelas, verificase que para todos os geradores/demandas, o somatório dos NEFs associados é igual a 1, e consequentemente, $100 \%$ de suas potências é utilizada nas trocas bilaterais. Além disso, comparando as duas tabelas, para cada par $(i, j)$ o montante 
de potência da troca bilateral é o mesmo quando calculado por $P_{G i} \alpha_{G i j}$ ou por $P_{D j} \alpha_{D j i}$. Com todos estes resultados, comprovamos que os NEFs respeitam o balanço de potência do sistema.

Outra análise possível envolvendo o detalhamento dos NEFs é a decomposição de fluxo ótima. Este resultado é obtido através da expressão (4.13) calculada com os valores da solução ótima da alocação de tarifas. Para ilustrar este resultado, são apresentadas na Tabela 6.4 as componentes de fluxo referentes à injeção de potência pelo gerador 5. Para cada linha do sistema, são apresentadas as componentes $F_{\ell}^{5, j}$ provocadas pela troca bilateral do gerador com cada demanda, bem como a componente total $\left(\sum_{(5, j)} F_{\ell}^{5, j}\right)$ provocada pela injeção de $100 \%$ da potência gerada. Componentes com sinal negativo indicam contrafluxos, que contribuíram para aliviar o fluxo total na linha.

Tabela 6.4. Componentes de fluxo provocadas pelo gerador 5 em MW

\begin{tabular}{|c|c|c|c|c|}
\hline & Par $(5,2)$ & Par $(5,4)$ & Par $(5,6)$ & Total \\
\hline Linha 1-2 & $F_{1-2}^{5,2}=17,23$ & $F_{1-2}^{5,4}=-0,42$ & $F_{1-2}^{5,6}=0,91$ & $F_{1-2}^{i=5}=17,72$ \\
\hline Linha 3-2 & $F_{2-3}^{5,2}=33,31$ & $F_{2-3}^{5,4}=0,42$ & $F_{2-3}^{5,6}=-0,91$ & $F_{3-2}^{i=5}=32,83$ \\
\hline Linha 3-6 & $F_{3-6}^{5,2}=-20,74$ & $F_{3-6}^{5,4}=-14,19$ & $F_{3-6}^{5,6}=30,95$ & $F_{3-6}^{i=5}=-3,98$ \\
\hline Linha 4-1 & $F_{1-4}^{5,2}=8,00$ & $F_{1-4}^{5,4}=-8,77$ & $F_{1-4}^{5,6}=19,11$ & $F_{4-1}^{i=5}=18,34$ \\
\hline Linha 4-3 & $F_{3-4}^{5,2}=12,57$ & $F_{3-4}^{5,4}=-13,77$ & $F_{3-4}^{5,6}=30,04$ & $F_{4-3}^{i=5}=28,84$ \\
\hline Linha 5-4 & $F_{4-5}^{5,2}=20,57$ & $F_{4-5}^{5,4}=137,46$ & $F_{4-5}^{5,6}=49,15$ & $F_{5-4}^{i=5}=207,18$ \\
\hline Linha 5-6 & $F_{5-6}^{5,2}=29,97$ & $F_{5-6}^{5,4}=22,54$ & $F_{5-6}^{5,6}=125,31$ & $F_{5-6}^{i=5}=177,82$ \\
\hline Linha 6-1 & $F_{1-6}^{5,2}=9,23$ & $F_{1-6}^{5,4}=8,35$ & $F_{1-6}^{5,6}=-18,20$ & $F_{6-1}^{i=5}=-0,62$ \\
\hline
\end{tabular}

Primeiramente, verifica-se que cada troca bilateral provoca componentes de fluxo em todas as linhas do sistema. Na coluna "Total", as maiores componentes pertencem às linhas 5-4 e 5-6, que estão entre as mais caras do sistema. Nestas linhas, as trocas com a demanda 4 em 5-4, e com a demanda 6 em 5-6, são as que mais contribuem para a componente total. Este resultado está relacionado à tarifa alocada ao gerador 5, que é a mais alta dos resultados de alocação. Adicionalmente, para todos os pares $(5, j)$ há componentes de contrafluxo, sendo que apenas nas linhas 3-6 e 6-1 a componente total é negativa. 


\section{2.}

\section{Sistema de 118 barras}

Nesta seção, o processo de alocação proposto é aplicado ao sistema de 118 barras apresentado na Figura 6.2. O sistema é dividido em 5 áreas para facilitar alterações de demanda e a apresentação de alguns resultados. O objetivo das simulações neste sistema é avaliar os pontos discutidos no Capítulo $1 \mathrm{em}$ um sistema de maior porte. Neste caso, o foco é analisar o despacho de geração ótimo, o máximo estresse do sistema, bem como as tarifas e seus sinais locacionais de acordo com as condições e características da rede. Para tanto, primeiramente, os resultados do método proposto são avaliados em detalhes, e então é feita uma comparação com o método Nodal. Este método é escolhido por ser base para a proposta e por isso apresentar maior semelhança nos sinais locacionais fornecidos, facilitando a comparação. Ainda assim, resultados adicionais comparando o método proposto com outros métodos de alocação de tarifas são apresentados na Seção 6.2.3. Resultados para este sistema são obtidos com tempo de execução de 4 min em média para o modelo ABTT acoplado e 16s para o modelo ABTT desacoplado.

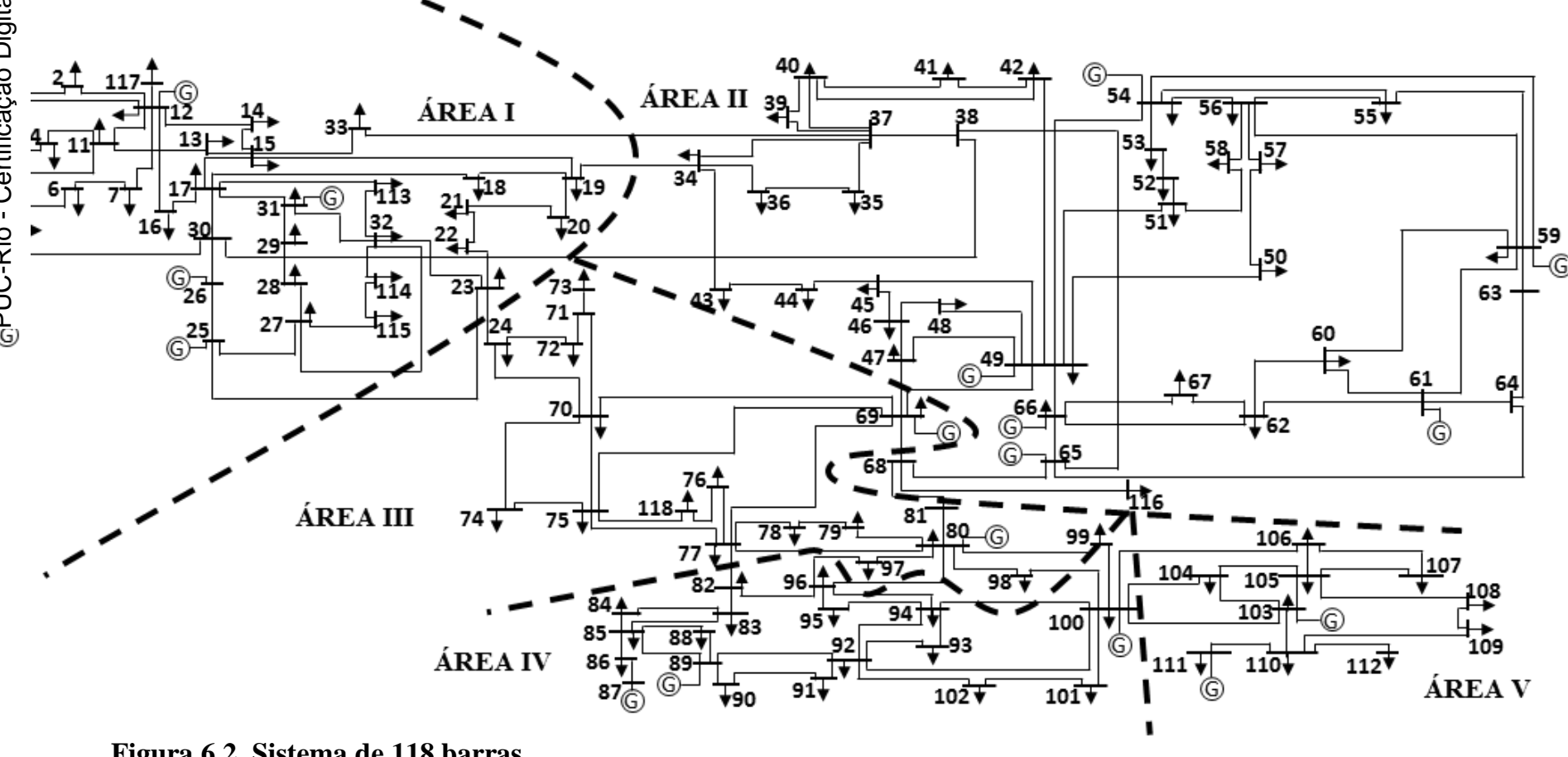

Figura 6.2. Sistema de 118 barras

A alocação de tarifas do sistema é avaliada em duas situações de demanda: na primeira a demanda original é utilizada; na segunda, a demanda das áreas I, II e III, sinalizadas na Figura 6.2, é incrementada em 20\% para simular um sistema 
mais estressado e com menos capacidade ociosa. As áreas I, II e III são escolhidas para deslocar a concentração de demanda do sistema (originalmente localizada na parte inferior da área III e nas áreas IV e V) e provocar um novo padrão de sinais locacionais. Os efeitos do aumento de demanda nas tarifas serão sinalizados ao longo das análises. Para todas as simulações apresentadas nesta seção, geradores e demandas instalados em uma mesma barra foram substituídos pela potência líquida correspondente. Desta forma, todas as tarifas calculadas são nodais.

\subsection{1.}

\section{Avaliação do método proposto}

Conforme abordado na Seção 5.2 do Capítulo 5, há uma relação entre o valor ótimo do máximo estresse do sistema $\left(y_{A B T T}^{*}\right)$ e os limites tarifários $z^{M A X} \mathrm{e}$ $w^{M I N}$. A representação gráfica desta relação ilustrada na Figura 5.1 é reproduzida para o sistema de 118 barras nas duas situações de demanda propostas. A Figura 6.3 apresenta os valores ótimos $y_{A B T T}^{*}$ em função de diferentes valores de $z^{M A X}$. O limite $w^{M I N}=0$ é adotado de forma que todas as tarifas são positivas.

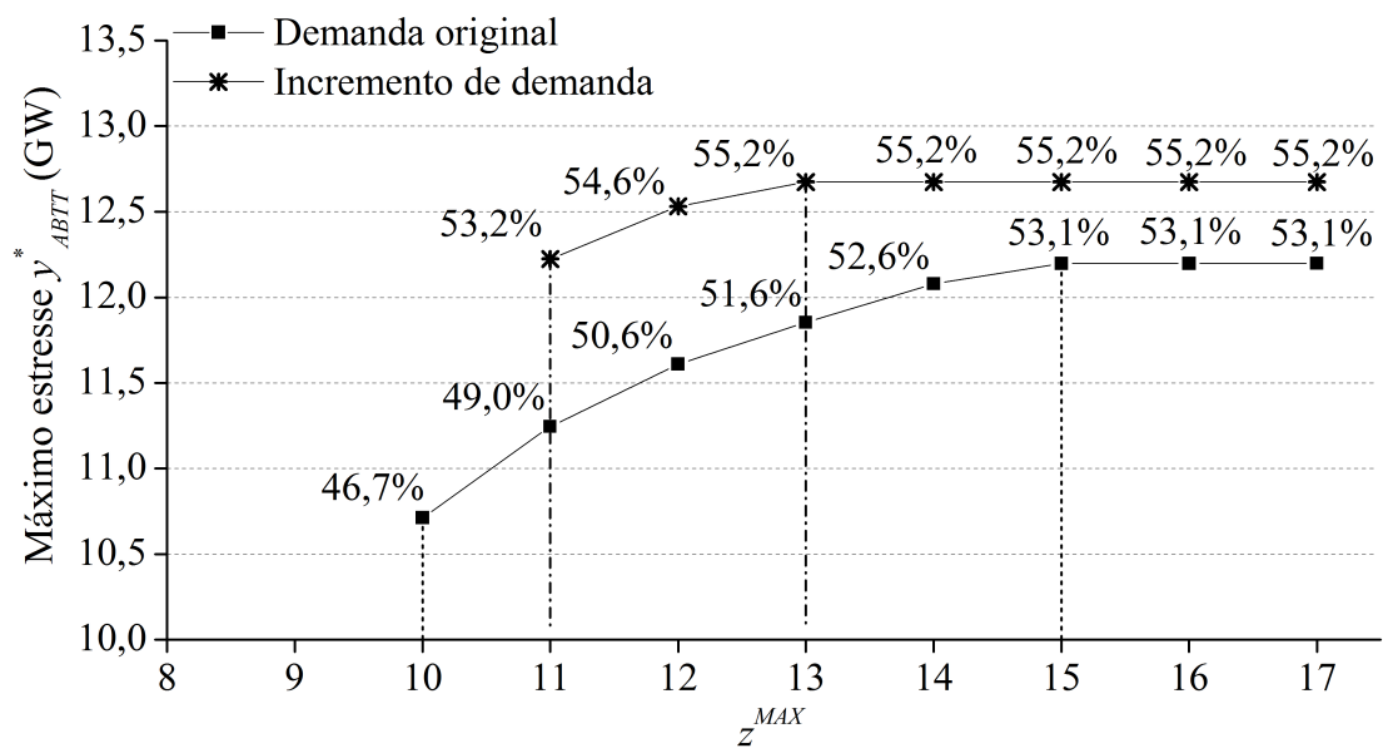

Figura 6.3. Máximo estresse do sistema em função do limite tarifário $z^{M A X}\left(\operatorname{com} w^{M I N}=0\right)$ no sistema de 118 barras

Nas duas curvas apresentadas, cada ponto corresponde a um resultado completo de alocação de tarifas, de acordo com $z^{M A X}$ e $w^{M I N}$. Para cada ponto, é apresentado ainda o percentual da capacidade total do sistema $\left(\sum_{\ell \in \Omega_{L}} \operatorname{Cap} p_{\ell}\right)$ que a maximização do estresse $y_{A B T T}^{*}$ ocupa com os fluxos de potência. Adicionalmente, as linhas pontilhadas verticais delimitam as regiões nas quais o problema é inviável, acoplado, ou desacoplado. 
Primeiramente, algumas características gerais da simulação são pontuadas. O padrão das curvas corresponde à representação da Figura 5.1, confirmando na prática o acoplamento e a interdependência dos níveis do modelo de otimização binível em função dos limites tarifários. Comparando as duas curvas, o aumento de demanda no sistema provoca maior utilização da rede e uma elevação nos valores ótimos $y_{A B T T}^{*}$ para cada $z^{M A X}$. Assim, para análises posteriores de tarifa, podemos dizer que o sistema com incremento de demanda é mais congestionado e possui menos capacidade ociosa em comparação à configuração original de demanda.

Do ponto de vista da tarifa, ao analisar o primeiro resultado viável para as duas condições de demanda, valores de $z^{M A X}$ inferiores a 10 \$/MW na demanda original, e inferiores a 11 \$/MW no incremento de demanda, não conseguem ser atingidos por nenhuma solução viável de fluxo de potência. Comparando os dois resultados, um sistema com menos capacidade ociosa apresenta um valor maior de $Z^{M A X}$ para a primeira solução viável do problema. Além disso, o intervalo de $Z^{M A X}$ para o qual o problema binível é acoplado é mais estreito. Para a demanda original o problema é acoplado em $10 \leq z^{M A X} \leq 15$, enquanto que para o incremento de demanda este intervalo reduz para $11 \leq z^{M A X} \leq 13$. Seguindo esta tendência, em uma situação extrema de um sistema altamente congestionado há a possibilidade de apenas resultados para o problema desacoplado serem viáveis.

Os resultados ótimos de despacho de geração relacionados com cada solução da Figura 6.3, são apresentados na Figura 6.4 para a demanda original e na Figura 6.5 para o incremento de demanda. Nos dois resultados de despacho de geração, é destacado que o despacho ótimo que maximiza o estresse da rede não segue a regra de proporcionalidade da capacidade máxima dos geradores $P_{G}^{M A X}$. Como exemplo, ao comparar os despachos dos geradores 61 e 65 em ambas as figuras, o que possui maior $P_{G}^{M A X}$ recebe um despacho ótimo menor. Também é possível observar quais geradores influenciam mais no resultado de máximo estresse, ao apresentarem maiores variações em seu despacho de acordo com $Z^{M A X}$. É o caso do gerador 59 no sistema com demanda original. Além disso, mudanças nos resultados quando a demanda é incrementada confirmam que as restrições do método proposto permitem que a solução ótima se adapte e se modifique de acordo com as condições e características da rede. 


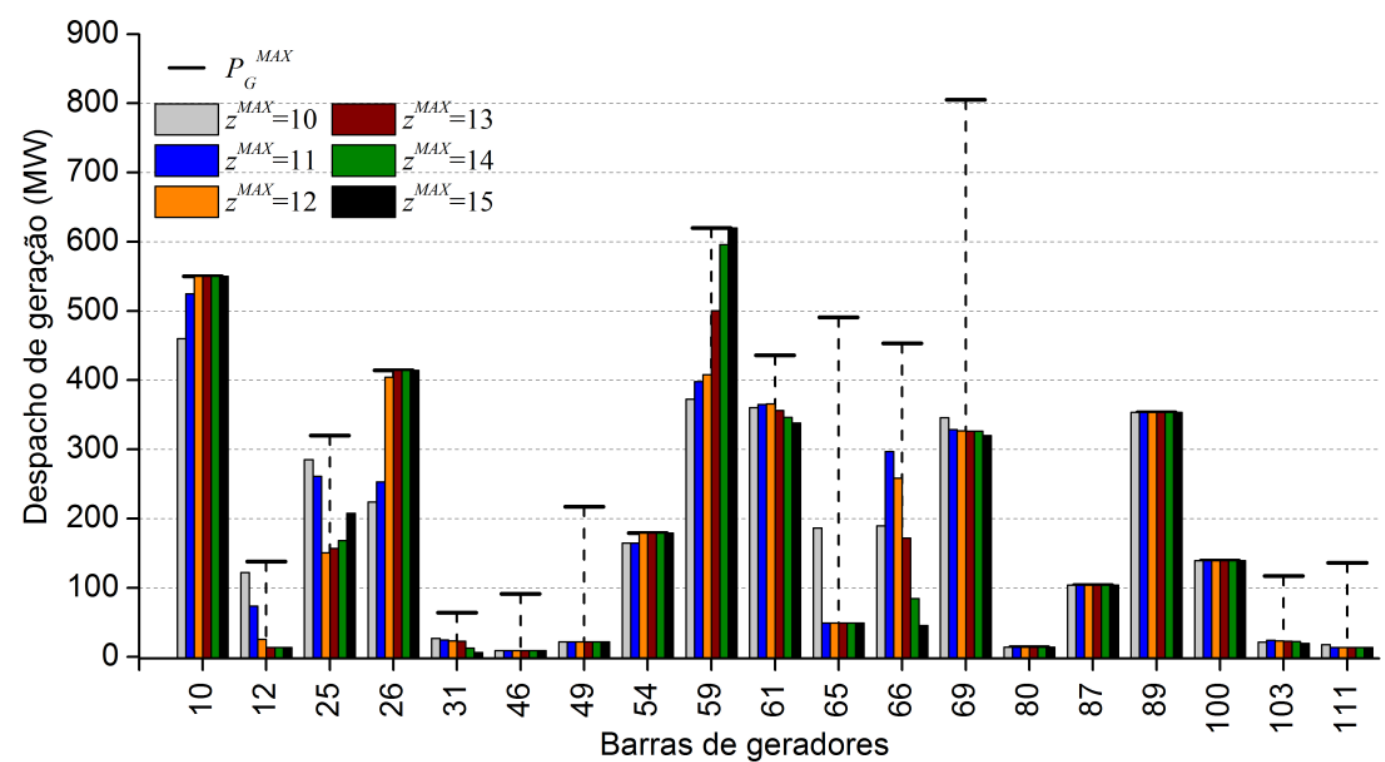

Figura 6.4. Despachos de geração do sistema de 118 barras com demanda original para diferentes valores de $z^{M A X}$ e $w^{M I N}=0$

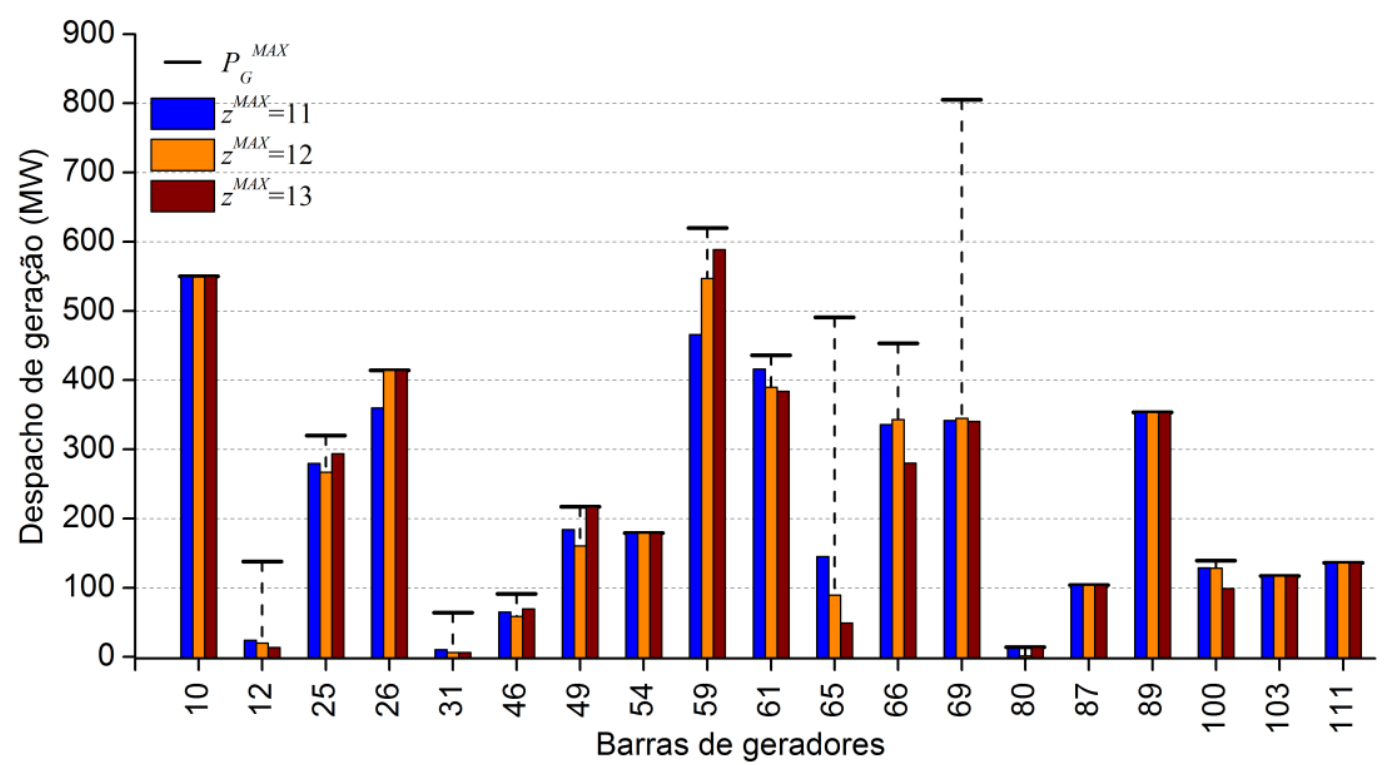

Figura 6.5. Despachos de geração do sistema de 118 barras com incremento para diferentes valores de $z^{M A X}$ e $w^{M I N}=0$

Ainda na Figura 6.4 e Figura 6.5, destacam-se os geradores 10 e 59. Ambos estão isolados da concentração de demanda e juntos suprem em média $29 \%$ da demanda máxima no sistema com demanda original e $26 \%$ no sistema com incremento de demanda. Estes geradores representam a situação descrita no Capítulo 1 e as características de suas tarifas em comparação ao método Nodal serão ressaltadas na Seção 6.2.2.

Finalizando a análise do método isoladamente, os resultados ótimos das tarifas locacionais $\pi_{G i}^{T M A}$ são apresentados para os diferentes valores viáveis de $Z^{M A X}$ com $w^{M I N}=0$. O objetivo é observar e comparar a influência de diferentes limites nos valores de tarifa locacional. A Figura 6.6 é referente ao sistema com 
demanda original e a Figura 6.7 ao com incremento de demanda. Para facilitar a visualização, devido ao volume de resultados, serão incluídas apenas tarifas de geradores. Resultados de tarifa para as demandas são abordados na Seção 6.2.2. Observe que para que seja possível associar os valores de tarifa aos resultados de despacho de geração, as mesmas cores são utilizadas para cada limite $z^{M A X}$.

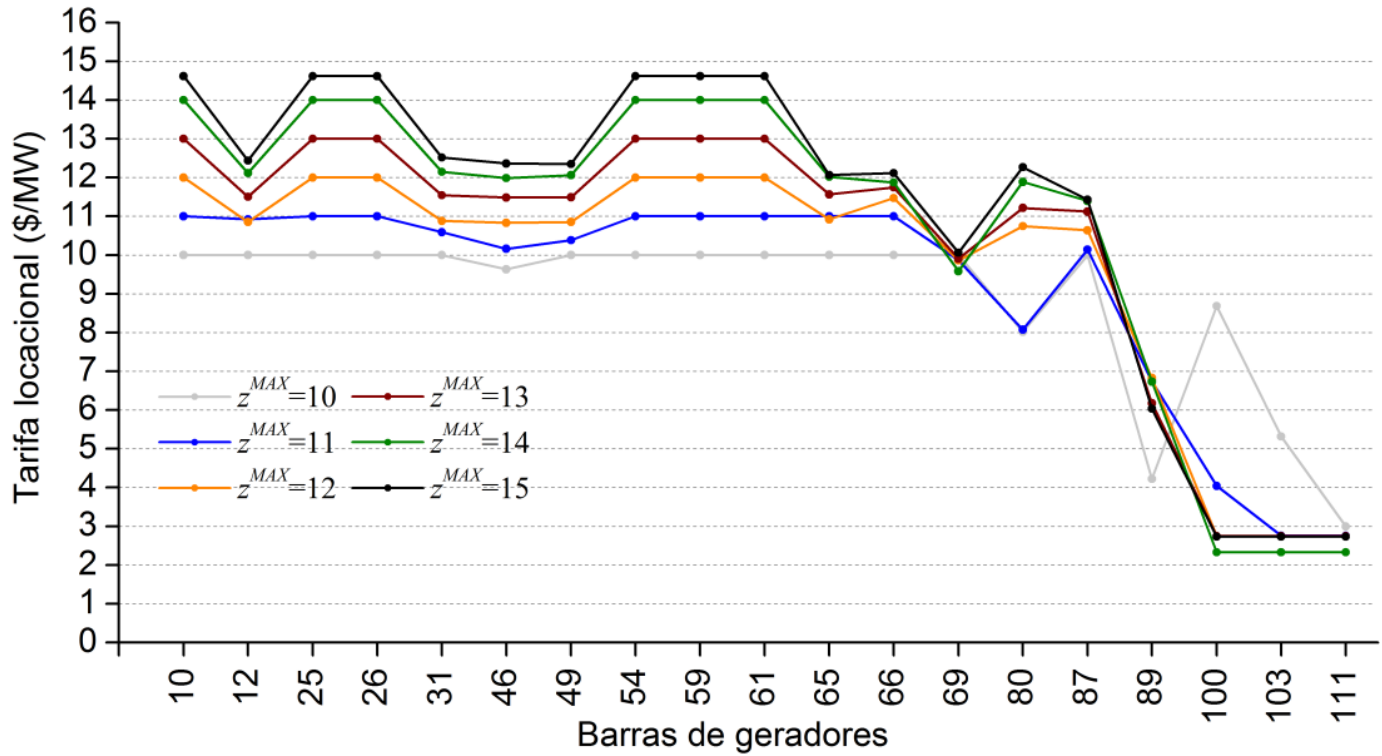

Figura 6.6. Tarifas locacionais de geradores do sistema de 118 barras com demanda original para diferentes valores de $z^{M A X}$ e $w^{M I N}=0$

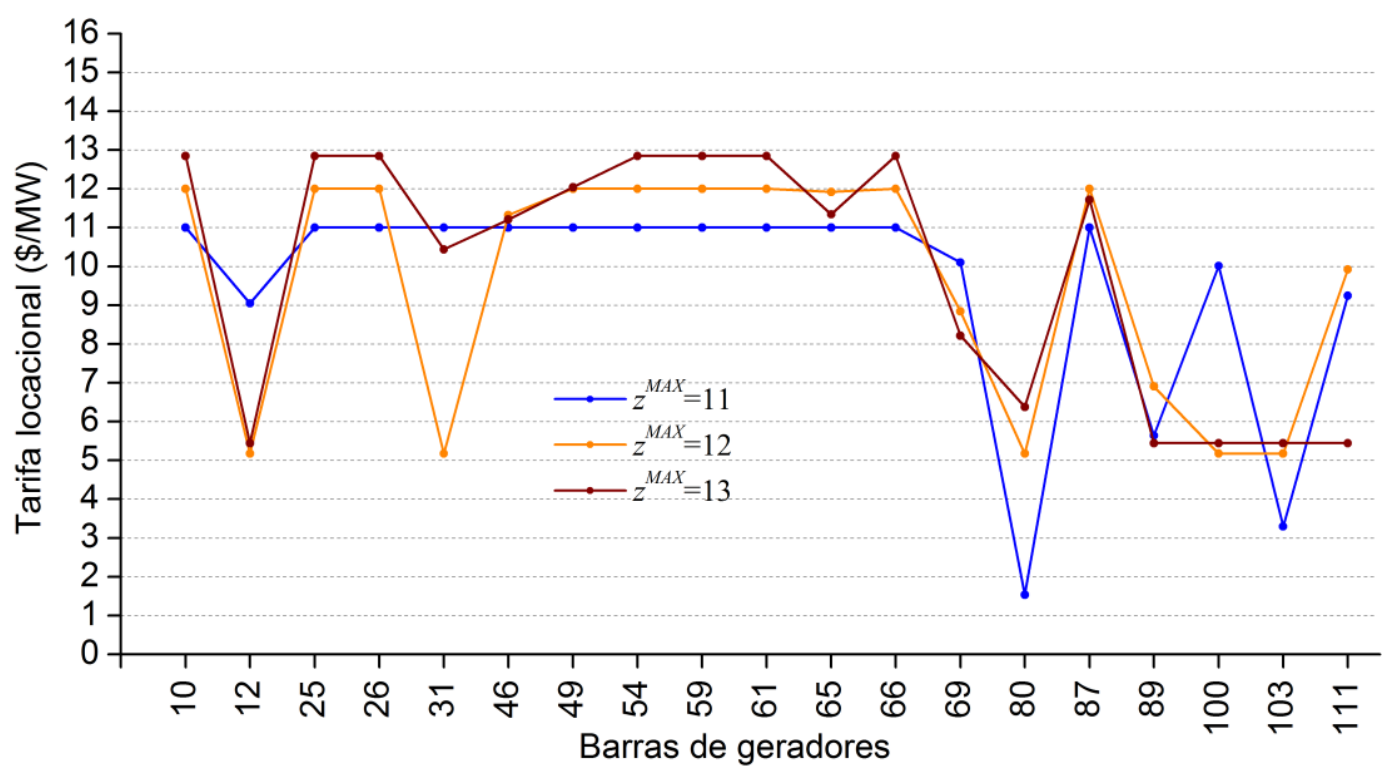

Figura 6.7. Tarifas locacionais de geradores do sistema de 118 barras com incremento de demanda para diferentes valores de $z^{M A X}$ e $w^{M I N}=0$

Em ambas as figuras, são verificadas mudanças nos valores de tarifa para cada $z^{M A X}$ indicando que os limites definidos têm influência no problema de alocação como um todo. Primeiramente, destacam-se os resultados de tarifas para os limites $Z^{M A X}$ nos quais o problema binível é desacoplado. Para $z^{M A X}=15$ na Figura 6.6 e $z^{M A X}=13$ na Figura 6.7, os valores extremos máximo e mínimo das 
tarifas não atingem os limites superior e inferior estabelecidos, logo, ambas as restrições envolvendo $z^{M A X}$ e $w^{M I N}$ estão inativas na solução ótima comprovando o desacoplamento dos níveis do problema de otimização.

Analisando os resultados, o método tende a formar níveis ou grupos de tarifas iguais, principalmente em seus valores extremos nos quais o sinal locacional é mais intenso. Tais valores limitam a minimização da amplitude tarifária de acordo com as restrições (5.11) e (5.13). Na Figura 6.6, para os valores de $Z^{M A X}$ iguais a 15, 1413 e 12, é atribuído o valor máximo de tarifa aos geradores 10, 25, 26, 54, 59 e 61; e é atribuído o valor mínimo de tarifa aos geradores 100, 103 e 111. Conforme será visto na próxima seção, estes geradores possuem intensos sinais locacionais no método Nodal.

Ainda na Figura 6.6, em valores inferiores de $z^{M A X}$, a amplitude tarifária viável fica mais restrita, e a máxima tarifa é atribuída à mais geradores. Em $z^{M A X}=11$, entram para este grupo os geradores 65 e 66 , e em $z^{M A X}=10$ os geradores 12, 31, 49, 65, 66, 69 e 87. Além disso, podem ser observadas diferenças na tendência das tarifas nos geradores 80, 89, 100 e 103. Para explicar tais diferenças, deve-se considerar que cada limite $z^{M A X}$ produz um resultado de despacho de geração, a partir do qual se obtém uma desagregação de fluxos através dos NEFs, e consequentemente um resultado de tarifas. Neste sentido, para $Z^{M A X}$ igual a 10 e 11 , é possível observar alterações expressivas nos despachos de geração na Figura 6.4, mais especificamente nos geradores 12, 25, 59 e 66.

Já para a Figura 6.7 conclusões análogas às anteriores podem ser atribuídas aos resultados. A principal diferença é que por ser uma configuração de demanda que torna o sistema mais congestionado, os sinais locacionais são mais intensos e a diferença entre as tarifas de um mesmo gerador para cada valor de $z^{M A X}$ são maiores. Esta característica é mais acentuada nos geradores 12, 31, 80, 100 e 111.

Um ponto importante desta análise é a sinalização locacional verificada no menor limite viável em ambas as condições de demanda. Para $z^{M A X}=10$ na Figura 6.6 e $z^{M A X}=11$ na Figura 6.7, as tarifas possuem valores diferentes entre si caracterizando a presença de sinais locacionais. Assim, podemos concluir que o resultado com um único nível de tarifa (método Pro-rata) não é uma solução viável para o sistema em estudo, o que é reconhecido e avaliado pelo método 
proposto. Devido às características de adaptação do método, no caso de um sistema que não reflete a necessidade de sinais locacionais (sistemas altamente malhados e com usuários bem distribuídos) uma alocação próxima ao método Pro-rata seria fornecida.

\subsection{2.}

\section{Comparação com o método Nodal}

Nesta seção, as tarifas de geradores e demandas fornecidas pelo método proposto são comparadas com o método Nodal. Todos os resultados se referem às tarifas finais (tarifas locacionais ótimas somadas com as parcelas selo) obtidas do processo descrito na Figura 5.2. Conforme dito na Seção 6.2.1, cada valor de $Z^{M A X}$ e $w^{M I N}$ origina um resultado completo de alocação. Assim, para as análises desta seção são escolhidos os limites $z^{M A X}=12$ e $w^{M I N}=0$, de forma que para as duas configurações de demanda do sistema, o modelo ABTT é acoplado na solução ótima (conforme a Figura 6.3) e a interdependência entre as tarifas e o fluxo de potência está ativa. Resultados do método proposto para o modelo ABTT desacoplado são apresentados na Seção 6.2.3 e comparados com outros métodos de alocação de tarifas.

Os valores de máximo estresse da rede e de despacho de geração correspondentes aos resultados de tarifa estão presentes na Figura 6.3, Figura 6.4 e Figura 6.5 para os limites tarifários mencionados. Nos cálculos de tarifa do método Nodal, o caso base de fluxo de potência utilizado é o obtido na solução ótima do método proposto.

No sistema com demanda original, as parcelas selo no método proposto são $\Delta_{G}^{T M A}=\Delta_{D}^{T M A}=24,24 \$ / \mathrm{MW}$, e no método Nodal são $\Delta_{G}^{N O D A L}=20,27 \$ / \mathrm{MW}$ e $\Delta_{D}^{N O D A L}=27,08 \$ / \mathrm{MW}$. Já no sistema com incremento de demanda, $\Delta_{G}^{T M A}=$ $\Delta_{D}^{T M A}=17,54 \$ / \mathrm{MW}, \Delta_{G}^{N O D A L}=15,14 \$ / \mathrm{MW}$ e $\Delta_{D}^{N O D A L}=21,36 \$ / \mathrm{MW}$. A proximidade no valor das parcelas selo de ambos os métodos indica que existe uma proximidade também na parcela da receita total do sistema remunerada pelas tarifas locacionais. Comparando os resultados para as duas condições de demanda, a parcela selo menor no segundo caso é uma consequência do aumento do máximo estresse do sistema (evidenciado na Figura 6.3). Relembrando que a parcela selo é responsável por cobrir os custos da capacidade ociosa da rede, uma 
demanda maior reduz esta sobrecapacidade e como consequência reduz a parcela selo.

As tarifas de geradores para ambas as condições de demanda são apresentadas na Figura 6.8 para o método proposto e para o método Nodal.

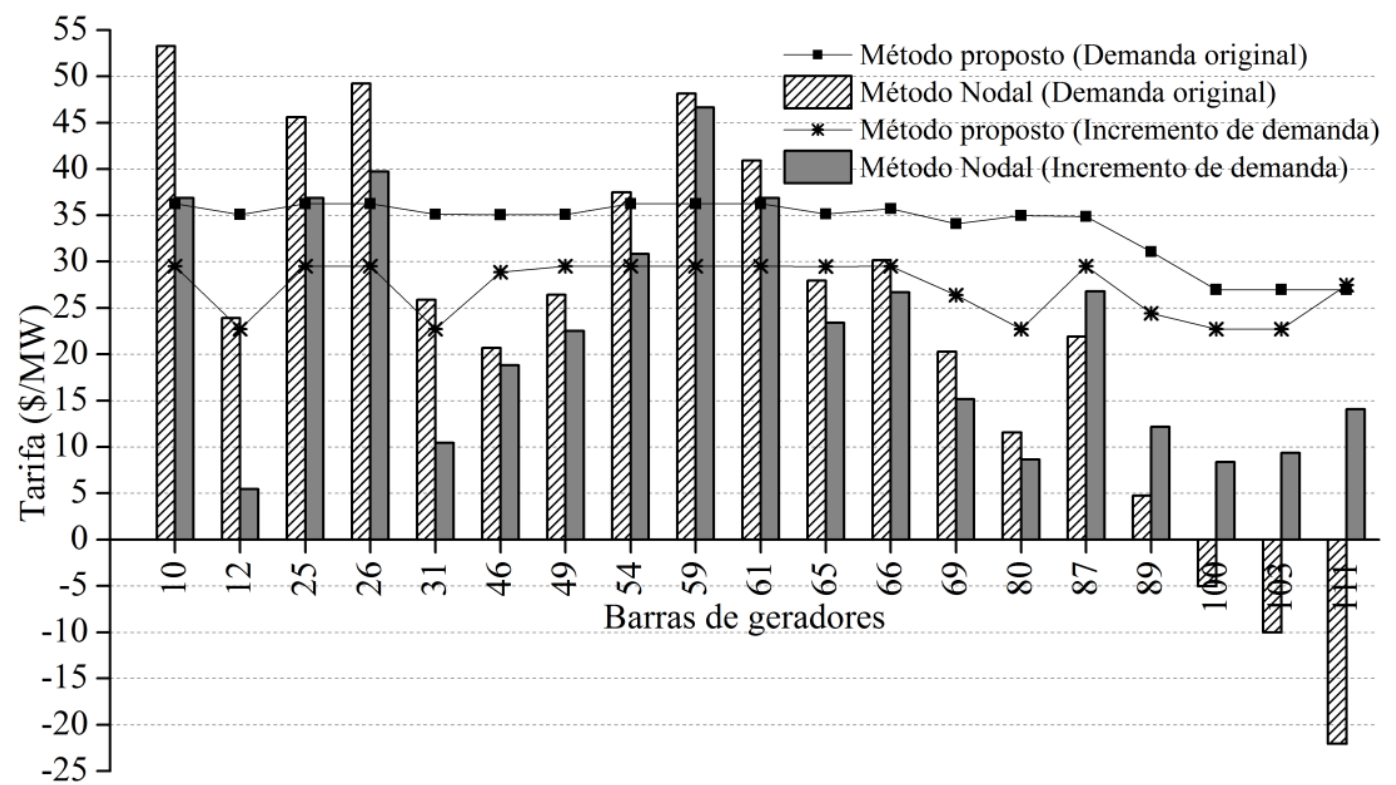

Figura 6.8. Tarifas finais para geradores para o sistema de 118 barras com demanda original e com incremento de demanda $\left(z^{M A X}=12\right.$ e $\left.w^{M I N}=0\right)$

Como já mencionado anteriormente, na Figura 6.8 observa-se que o método proposto tende a produzir grupos ou níveis de tarifa com o mesmo valor. Comparando as alocações do método proposto para as duas condições de demanda, quanto mais congestionado é o sistema, mais fortes são os sinais locacionais. Além disso, a utilização da função objetivo $y_{T M A}$ em (5.10) faz com que em ambos os sistemas haja uma redução da amplitude das tarifas, quando o método proposto é comparado ao método Nodal. Como consequência, as tarifas mais altas, que remetem à motivação apresentada no Capítulo 1, são minimizadas.

No sistema original, o gerador 10 recebe a maior tarifa pelo método Nodal e pelo método proposto. No entanto, no método proposto, a tarifa é menor comparada à obtida no método Nodal. Analisando a coerência dos sinais locacionais, outros geradores que recebem tarifas elevadas no método Nodal, mais especificamente nas barras 25, 26 e 59, também recebem a maior tarifa no método proposto. No extremo oposto, os geradores nas barras 100, 103 e 111 que recebem tarifas negativas para o método Nodal, recebem as menores tarifas no método proposto. Aqui, é destacado que tarifas negativas como as observadas no método Nodal não são viáveis para o método proposto, uma vez que $w^{M I N}=0$. 
Quando a demanda do sistema é incrementada, a capacidade ociosa da rede diminui, as linhas de transmissão são mais bem aproveitadas e, como consequência, a utilização dos mesmos limites tarifários $z^{M A X}=12$ e $w^{M I N}=0$ faz com que o método proposto aloque tarifas menores. Este é um ponto positivo do método porque o quanto mais a capacidade do sistema é utilizada, menores são as tarifas mais elevadas para o mesmo valor de $z^{M A X}$. Neste sistema, a maior tarifa é agora alocada para o gerador 59 no método Nodal e no método proposto. Mas, conforme para o sistema com demanda original, o método proposto oferece uma tarifa reduzida. Em relação aos sinais locacionais gerais, por se tratar de um sistema mais congestionado, estes são mais fortes e uma semelhança maior na tendência das tarifas dos dois métodos pode ser verificada. Mais especificamente, isto ocorre para os geradores 12, 31, 69, 80 e 111. Muito embora os resultados do método Nodal não sejam um alvo a ser alcançado, um sinal locacional semelhante reforça a ideia de que o método proposto garante um sinal locacional coerente, e simultaneamente oferece tarifas com mínima amplitude a partir dos limites tarifários $Z^{M A X}$ e $w^{M I N}$.

Os mesmos pontos analisados para as tarifas dos geradores são agora comentados para as tarifas das demandas. Os resultados são divididos para facilitar a visualização. Na Figura 6.9 inclui tarifas das demandas 1 a 58, e a Figura 6.10 das demandas 59 a 118.

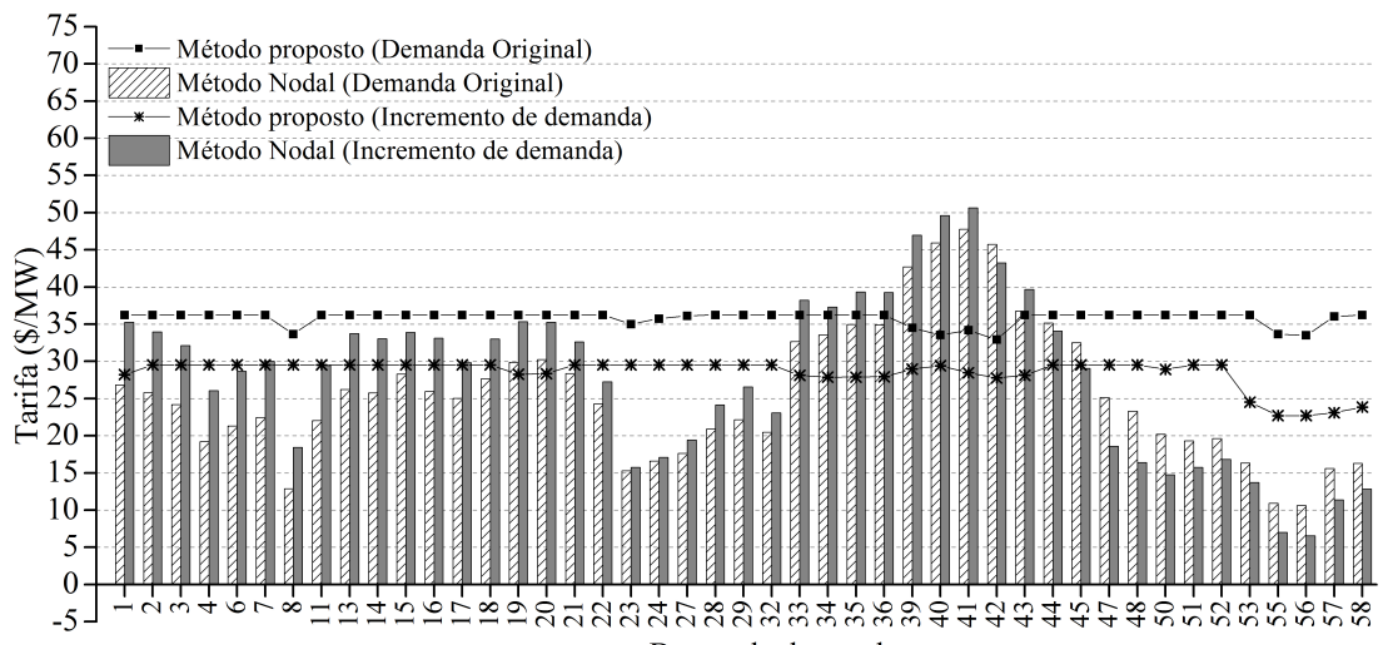

Barras de demanda

Figura 6.9. Tarifas finais para as demandas 1 a 58 para o sistema de 118 barras com demanda original e com incremento de demanda $\left(z^{M A X}=12\right.$ e $\left.w^{M I N}=0\right)$ 


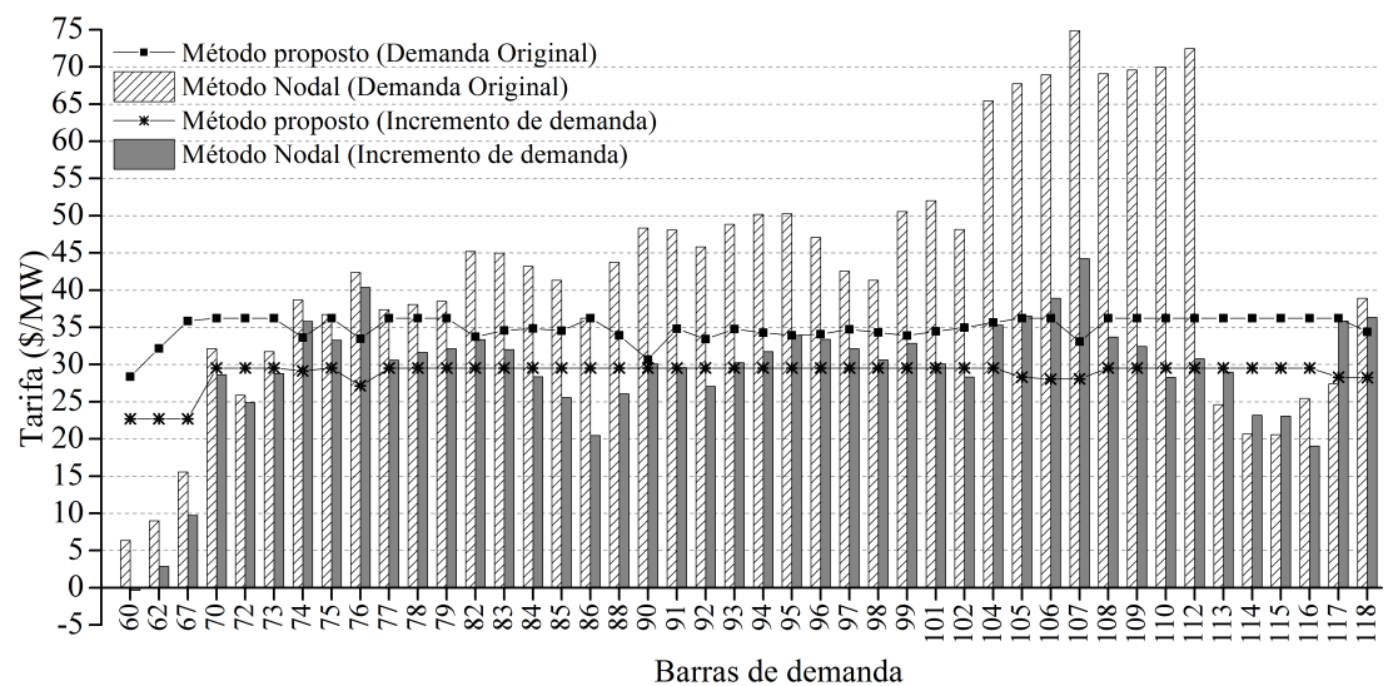

Figura 6.10. Tarifas finais para as demandas 60 a 118 para o sistema de 118 barras com demanda original e com incremento de demanda $\left(z^{M A X}=12\right.$ e $\left.w^{M I N}=0\right)$

No que diz respeito à minimização de amplitude, as características do método proposto verificadas nas tarifas de geradores se repetem para as tarifas de demanda. Sinais locacionais mais intensos são verificados no sistema mais estressado, especificamente nas demandas das barras 53 a 67 onde os menores valores de tarifa ocorrem para ambos os métodos. Em relação aos picos de tarifas no método Nodal, no sistema com demanda original ocorrem nas barras de 104 a 112 com valores ainda mais severos que àqueles alocados aos geradores. No método proposto estas demandas recebem tarifas suavizadas, e que estão entre as maiores tarifas obtidas. Já para o sistema com incremento de demanda, os picos de tarifa se transferem para as barras de 39 a 41 no método Nodal, também sendo minimizadas no método proposto. Com isso, é chamada a atenção para a aplicabilidade do método em qualquer contexto que envolva a necessidade de suavizar sinais locacionais intensos mantendo uma avaliação do uso da rede.

Em relação aos sinais locacionais gerais, o método Nodal e o método proposto apresentam tendências coerentes entre si, com algumas variações que podem ser atribuídas a diferenças no processo de cálculo dos métodos. Tais diferenças incluem, além da otimização e do uso dos NEFs, o cálculo conjunto de tarifas de geradores e demandas. É dado destaque para as tarifas das barras 53 a 67 nas quais o método proposto acompanha a tendência de queda nas tarifas presente no método Nodal.

Para complementar os resultados de tarifas de demanda, algumas estatísticas são apresentadas na Tabela 6.5 para o sistema com incremento de demanda. A ideia é resumir a comparação entre os dois métodos, devido ao grande volume de 
resultados para as tarifas de demanda, e assim reforçar a coerência do método proposto. As áreas sinalizadas na Figura 6.2 são utilizadas para facilitar a divisão das estatísticas em grupos. O mínimo, o máximo, a média, a amplitude e o coeficiente de variação das tarifas de demanda são apresentados. O coeficiente de variação é utilizado como medida de dispersão relativa à média, e é obtido pela razão entre o desvio padrão e a média das amostras de tarifa. Quanto maior é o seu valor, mais as tarifas estão dispersas em torno da média.

Tabela 6.5. Estatísticas das tarifas de demanda para o sistema de 118 barras com incremento de demanda

\begin{tabular}{|c|c|c|c|c|c|}
\hline \multicolumn{7}{|c|}{ Método proposto } \\
\hline & Área I & Área II & Área III & Área IV & Área V \\
\hline Mínima (\$/MW) & 28,12 & 22,71 & 27,15 & 29,53 & 28,06 \\
\hline Máxima (\$/MW) & 29,53 & 29,53 & 29,53 & 29,53 & 29,53 \\
\hline Média (\$/MW) & 29,31 & 26,97 & 29,24 & 29,53 & 29,02 \\
\hline Amplitude (\$/MW) & 1,42 & 6,83 & 2,39 & 0,00 & 1,48 \\
\hline $\begin{array}{c}\text { Coeficiente de } \\
\text { variação }\end{array}$ & $1,71 \%$ & $10,61 \%$ & $2,39 \%$ & $0,00 \%$ & $2,49 \%$ \\
\hline \multicolumn{7}{|c|}{ Método Nodal } \\
\hline \multicolumn{7}{|c|}{ Área II } & Área III & Área IV & Área V \\
\hline Mínima (\$/MW) & 15,74 & $-0,37$ & 17,09 & 20,48 & 28,30 \\
\hline Máxima (\$/MW) & 38,20 & 50,63 & 40,37 & 33,91 & 44,24 \\
\hline Média (\$/MW) & 29,26 & 23,92 & 31,08 & 29,35 & 35,02 \\
\hline Amplitude (\$/MW) & 22,46 & 51,00 & 23,28 & 13,43 & 15,95 \\
\hline $\begin{array}{c}\text { Coeficiente de } \\
\text { variação }\end{array}$ & $19,92 \%$ & $66,50 \%$ & $17,68 \%$ & $12,17 \%$ & $14,24 \%$ \\
\hline
\end{tabular}

Primeiramente, ao comparar os dois métodos em todas as áreas, a amplitude das tarifas no método proposto é menor, conforme evidenciado em resultados anteriores. Adicionalmente, a amplitude de variação do método proposto está contida na amplitude de variação do método Nodal. Estes resultados de amplitude são acompanhados por coeficientes de variação reduzidos no método proposto.

Para os resultados de coeficiente de variação, a área II se destaca com um percentual elevado para o método Nodal. Por se tratar de uma área que abrange um grande território do sistema, é esperado que sinais locacionais muito distintos estivessem presentes, provocando o valor alto para o coeficiente de variação. Esta tendência é acompanhada no método proposto que também apresenta a maior coeficiente na mesma área, no entanto, com um valor muito menor. Já o menor coeficiente de variação ocorre para ambos os métodos na área IV. Destaca-se que apenas para esta área um único nível de tarifa é obtido no método proposto, o que é coerente com o menor coeficiente de variação resultante do método Nodal. 


\subsection{3. \\ Comparação com outros métodos de alocação de tarifas de transmissão}

Nesta seção os resultados de tarifas finais dos métodos ABTT e Nodal, já abordados na Seção 6.2.2, são comparadas a diferentes métodos de alocação de tarifas. São utilizados os métodos Pro rata, Equivalent Bilateral Exchanges (EBE), e Zbus, que estão apresentados com suas características e formulações no Apêndice $\mathrm{B}$ deste documento. O objetivo desta comparação é ilustrar como diferentes métodos com diferentes premissas fornecem tarifas com valores e sinalizações econômicas distintas para um mesmo sistema.

Os métodos citados serão aplicados ao sistema IEEE 118 barras com sua demanda original. Para o método proposto neste trabalho, serão utilizados os limites tarifários $z^{M A X}=15 \$ / \mathrm{MW}$ e $w^{M I N}=0 \$ / \mathrm{MW}$, que faz com que seja resolvido um problema binível desacoplado conforme apresentado na Figura 6.3.

Para os demais métodos mencionados, o resultado de fluxo de potência utilizado, de acordo com as premissas de cada método, é obtido a partir do despacho de geração ótimo fornecido pelo método proposto para os limites tarifários mencionados. Este resultado de despacho de geração pode ser visto na Figura 6.4. Os resultados de tarifas para geradores e demandas são apresentados na Figura 6.11, Figura 6.12 e Figura 6.13.

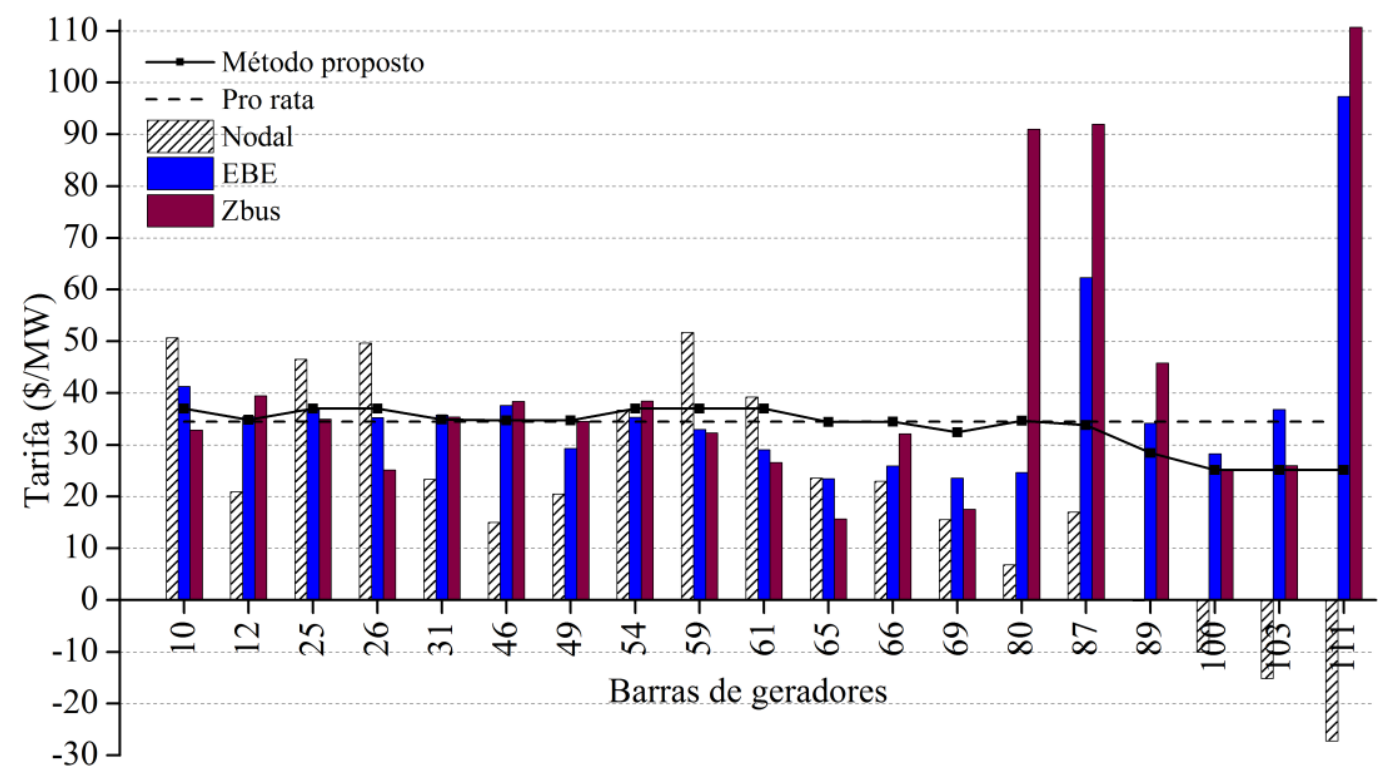

Figura 6.11. Tarifas finais para geradores para o sistema de 118 barras com demanda original $\left(z^{M A X}=15\right.$ e $\left.w^{M I N}=0\right)$ 


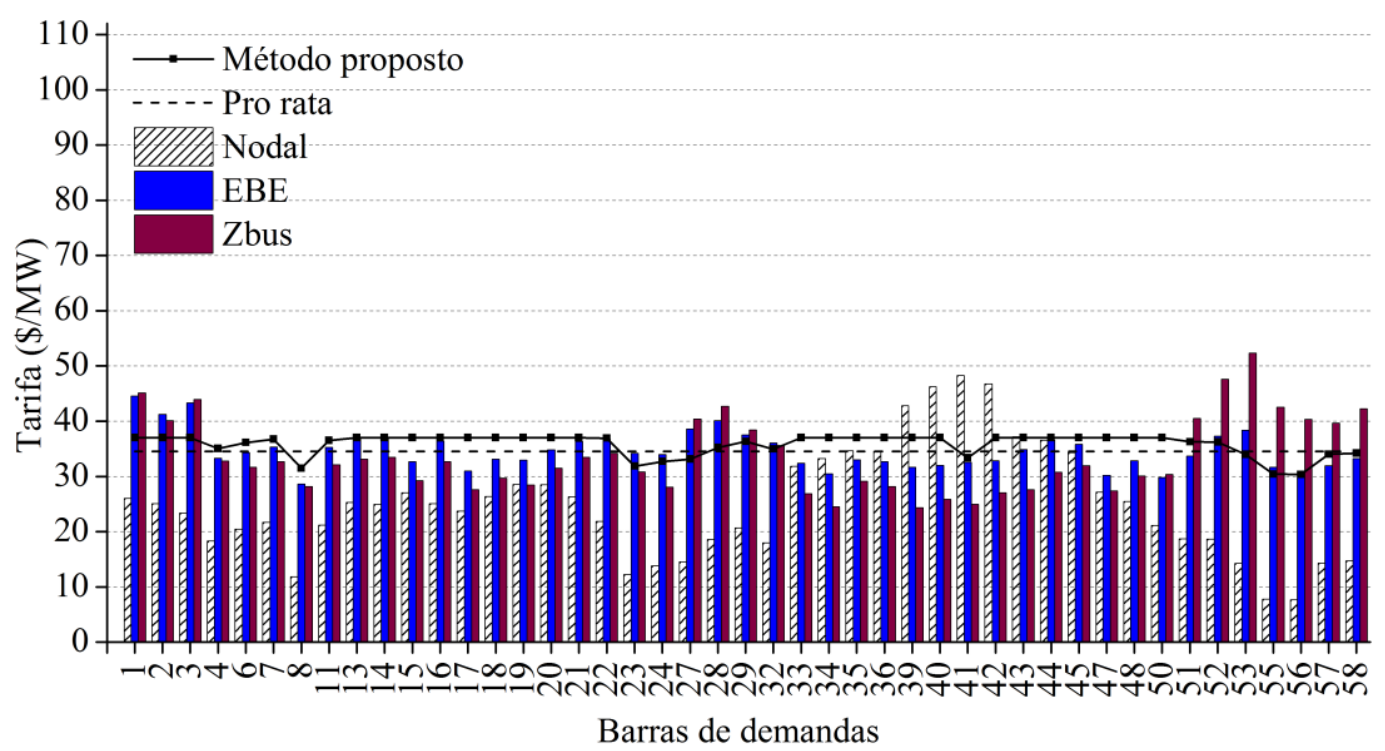

Figura 6.12. Tarifas finais para demandas 1 a 58 para o sistema de 118 barras com demanda original $\left(z^{M A X}=15\right.$ e $\left.w^{M I N}=0\right)$

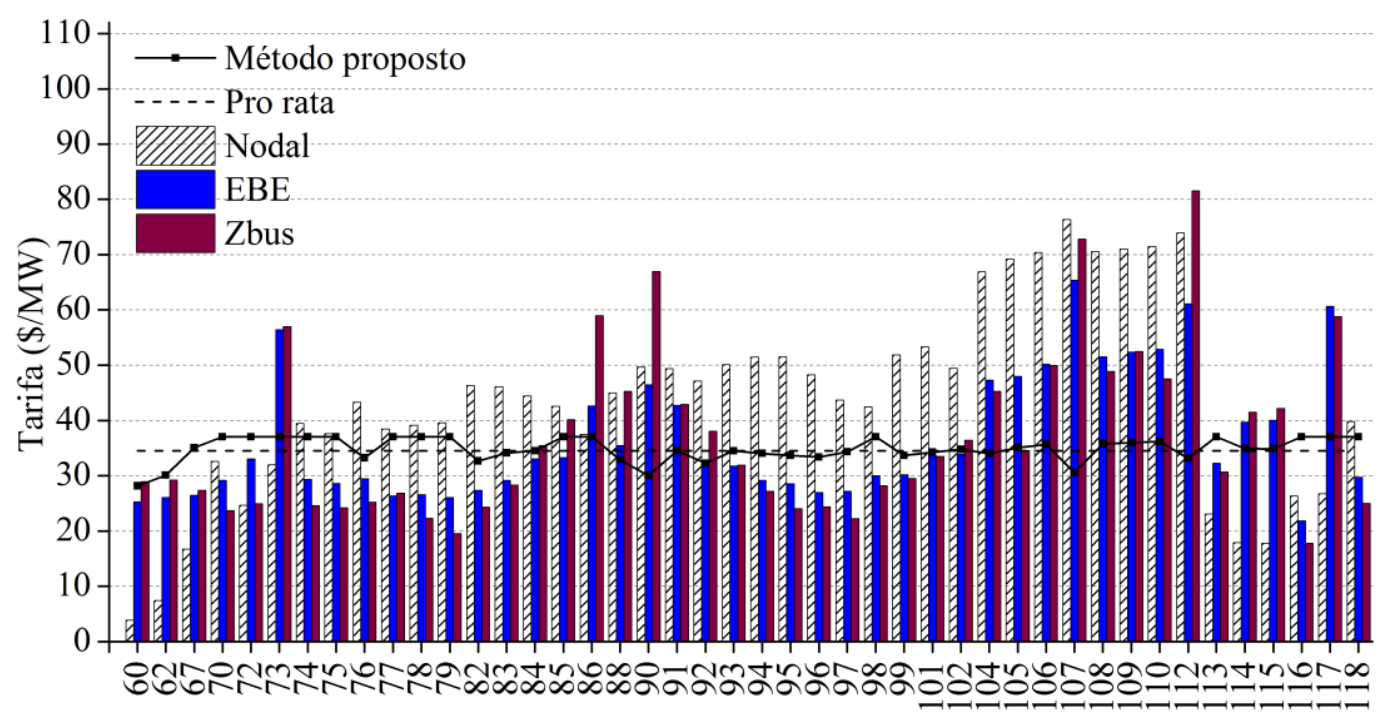

Barras de demandas

Figura 6.13. Tarifas finais para demandas 60 a 118 para o sistema de 118 barras com demanda original $\left(z^{M A X}=15\right.$ e $\left.w^{M I N}=0\right)$

Primeiramente, em complemento às análises realizadas na Seção 6.2.2, ao comparar o método proposto ao método Nodal ressalta-se que mesmo para um resultado ótimo de tarifa do método ABTT oriundo de um modelo binível desacoplado, as características de redução de pico de tarifa e sinalização locacional coerente se mantém. Em uma comparação geral de todos os métodos, conforme esperado, semelhanças e diferenças são verificadas nos resultados apresentados.

Como exemplo de característica de um dos métodos que pode ser notada nos resultados, no método Zbus destacam-se as elevadas tarifas dos geradores $87 \mathrm{e}$ 111, ambos conectados ao sistema por linhas de transmissão de custo elevado 
(conforme pode ser visto nos dados de simulação presentes no Apêndice D). Também é o caso do gerador 80 que está conectado à rede por algumas linhas de custo acima da média do restante do sistema. Usuários nestas situações tendem a receber parcelas de custo elevadas, devido à tendência do método de alocar a maior parte dos custos de uma linha de transmissão a usuários diretamente conectados a ela.

\subsection{4. Desempenho computacional}

Conforme mencionado no Capítulo 5, o processo de alocação de tarifas de transmissão proposto neste trabalho é formado por dois problemas de otimização não-lineares devido a presença de produtos entre variáveis de decisão reais. Neste tipo de modelo, os algoritmos robustos e de alta eficiência desenvolvidos para programação linear não podem ser utilizados. No caso de não-linearidades em problemas de otimização, os procedimentos de solução usuais envolvem a representação ou aproximação por um modelo linear, ou o uso de métodos (solvers) específicos que podem apresentar limitações conforme será abordado ao longo desta seção [53]. Neste trabalho foi feita a opção pelo solver CONOPT que se mostrou ser a alternativa mais eficiente para alcançar as soluções ótimas dos problemas propostos. Assim, esta seção tem como objetivo justificar o uso de tal solver, bem como avaliar se a solução fornecida por ele é satisfatória para o problema de alocação de tarifas proposto. Dado este objetivo, as análises serão feitas sobre o modelo ABTT (5.33)-(5.35), e as conclusões obtidas podem ser estendidas ao modelo de minimização de variância das tarifas (5.36)-(5.50).

Inicialmente, para a solução dos modelos, foi feita a tentativa de linearizar os produtos de variáveis de decisão reais através de manipulações matemáticas nas restrições, que buscavam substituir termos não-lineares por polinômios lineares, de forma que o conjunto viável do problema fosse mantido. No entanto, não foi possível chegar a um modelo que pudesse ser resolvido através de algoritmos de solução para modelos lineares.

Para o modelo ABTT, uma alternativa é aplicar o método de Expansão Binária [54] que converte o modelo não-linear em um modelo Linear Inteiro Misto (LIM). Dado um produto de duas variáveis reais, o método transforma o intervalo contínuo viável de uma delas em um intervalo discreto com valores 
espaçados por uma constante $\delta$, e representados em função de variáveis de decisão binárias. Desta forma, o produto entre duas variáveis reais é substituído por produtos entre uma variável real e variáveis binárias, o que pode ser tratado por restrições lineares de forma que o problema final seja do tipo LIM. No modelo ABTT, esta discretização pode ser aplicada à variável $P_{G i}$ já que ela faz parte de todas as não-linearidades do modelo. Quanto menor for a constante $\delta$ que separa os valores do intervalo discreto, mais precisa é a aproximação ao intervalo contínuo original. Em contrapartida, uma maior quantidade de variáveis binárias é necessária.

Ainda que matematicamente aplicável, a inserção de variáveis binárias no modelo proposto compromete o seu uso em sistemas de transmissão reais de grande porte devido ao tempo e esforço computacionais no processo de solução. Conforme será ilustrado ao longo desta seção, com o aumento da quantidade de geradores do sistema a que se aplica o modelo, e consequente aumento na quantidade de variáveis binárias, há um crescimento acentuado no tempo total de solução.

Assim, para as simulações apresentadas neste trabalho, foi utilizado solver não-linear CONOPT [51]. A principal vantagem na utilização deste tipo de solver está no tempo computacional atrativo, viabilizando a utilização do método em qualquer sistema. O solver é baseado no algoritmo do Gradiente Reduzido Generalizado (GRG) [53], que de maneira geral, realiza um processo iterativo no qual a cada iteração valor das variáveis é modificado em função do gradiente reduzido de um grupo de variáveis não-básicas (selecionadas através da jacobiana da matriz de restrições), comparado a uma tolerância preestabelecida. Se os gradientes calculados são inferiores a tal tolerância, o resultado ótimo final do problema foi atingido ${ }^{1}$. No solver CONOPT, modificações adicionais no algoritmo GRG aumentam a eficiência em modelos de larga escala [54,55]. Entre outras indicações, o solver apresenta alto desempenho em modelos esparsos (a maioria das restrições é função de uma parcela pequena do total de variáveis de decisão) que é o caso dos modelos propostos. Apesar das vantagens pontuadas, o solver CONOPT, e a maioria dos solvers não-lineares voltados para modelos de grande porte, apresentam como desvantagem a possibilidade de obter um ótimo

\footnotetext{
${ }^{1}$ Para todas as simulações deste capítulo, a tolerância utilizada para a convergência do algoritmo GRG foi de $10^{-7}$.
} 
local como resultado final da otimização. Neste sentido, é de grande importância que seja fornecida ao solver um ponto inicial que contribua para que a solução final seja o ótimo global, ou esteja satisfatoriamente próxima a ele. Para tanto, o conjunto de variáveis deve ser inicializado com valores que sejam viáveis, ou que estejam próximos da viabilidade, além de estarem na vizinhança do ótimo global desejado [51,53].

Neste trabalho, o ponto inicial fornecido para o solver é obtido a partir de soluções parciais do próprio modelo de otimização. Para o modelo ABTT (5.33)(5.35), a inicialização das variáveis é obtida dos níveis superior e inferior resolvidos separadamente. O modelo DPC (3.4)-(3.10), é resolvido e são obtidas soluções para as variáveis $P_{G i}$ e $F_{\ell}$. Então, o modelo TMA (4.20)-(4.31) e seu dual correspondente (5.22)-(5.32) são resolvidos com $P_{G i}$ e $F_{\ell}$ fixos na solução obtida anteriormente. Ressalta-se que, nesta solução sequencial, todos os modelos são problemas de programação linear solucionados em baixo tempo computacional.

No caso de os limites $z^{M A X}$ e $w^{M I N}$ escolhidos serem inviáveis para a solução do modelo TMA isoladamente, estes limites podem ser relaxados para que uma solução inicial possa ser obtida. Além disso, se a solução ótima do modelo ABTT corresponder a um binível desacoplado, a solução inicial fornecida já é a solução ótima global desejada, conforme abordado no Capitulo 5 (seção 5.2). Para o modelo de minimização da variância tarifária (5.36)-(5.50) todas as variáveis são inicializadas com a solução ótima do modelo ABTT.

Para verificar o bom desempenho do solver CONOPT, com o uso da solução inicial mencionada, seu resultado final deve ser comparado ao ótimo global do problema. Para tanto, seu resultado é comparados à solução fornecida pelo modelo LIM via Expansão Binária mencionado anteriormente. Dois pontos são avaliados: a qualidade da solução em relação ao ótimo global fornecido pelo modelo linearizado, e o ganho em tempo computacional. Em ambas as soluções será utilizado o software GAMS [52], com o solver CONOPT para o modelo nãolinear e o solver CPLEX [56] para o modelo LIM. O solver CPLEX utiliza o algoritmo branch and cut [57] que através de uma árvore de busca resolve subproblemas do modelo original, atualizando ao longo do processo a melhor solução inteira encontrada e o melhor limite superior da função objetivo (no caso de problemas de maximização). A diferença entre estes dois valores é definida como gap de otimalidade. Muito embora a otimalidade da solução do problema 
LIM seja matematicamente comprovada apenas para gap $=0$, é usual admitir uma tolerância principalmente para problemas com elevado tempo de execução. O modelo ABTT linearizado inteiro misto é apresentado no Apêndice C deste documento.

Para avaliar a qualidade da solução fornecida pelo solver CONOPT, é utilizado o sistema de 6 barras apresentado na Figura 6.1. Para que o processo de discretização da Expansão Binária tenha um alto grau de precisão, o intervalo $\delta$ da discretização da variável $P_{G i}$ é em torno de 0,5 MW. Tal configuração acarreta uma grande quantidade de variáveis binárias para cada $P_{G i}$, no entanto, como o sistema de 6 barras é pequeno e contém apenas 3 geradores, o modelo é resolvido em tempo reduzido. A comparação dos resultados para as principais variáveis do modelo ABTT é apresentada na Tabela 6.6.

Tabela 6.6. Comparação de resultados do modelo ABTT para o sistema de 6 barras com $z^{M A X}=7$ e $w^{M I N}=0$

\begin{tabular}{|c|c|c|}
\hline & $\begin{array}{c}\text { Modelo Não-linear } \\
\text { (solver CONOPT) }\end{array}$ & $\begin{array}{c}\text { Modelo LIM por Expansão } \\
\text { Binária } \\
\text { (solver CPLEX) }\end{array}$ \\
\hline$y_{A B T T}^{*}$ & 723,06 & $722,71($ com $g a p=0,95 \%)$ \\
\hline$z^{*} ; w^{*}$ & 7,$000 ; 2,958$ & 6,$999 ; 2,961$ \\
\hline$P_{G 1}^{*} ; P_{G 3}^{*} ; P_{G 5}^{*}$ & 46,$330 ; 208,669 ; 385,002$ & 46,$375 ; 208,625 ; 384,844$ \\
\hline$\alpha_{G 12}^{*} ; \alpha_{G 14}^{*} ; \alpha_{G 16}^{*}$ & 1,$00 ; 0 ; 0$ & 1,$00 ; 0 ; 0$ \\
\hline$\alpha_{G 32}^{*} ; \alpha_{G 34}^{*} ; \alpha_{G 36}^{*}$ & 0,$686 ; 0 ; 0,314$ & 0,$686 ; 0 ; 0,314$ \\
\hline$\alpha_{G 52}^{*} ; \alpha_{G 54}^{*} ; \alpha_{G 56}^{*}$ & 0,$131 ; 0,416 ; 0,453$ & 0,$131 ; 0,415 ; 0,454$ \\
\hline$\alpha_{D 21}^{*} ; \alpha_{D 23}^{*} ; \alpha_{D 25}^{*}$ & 0,$193 ; 0,596 ; 0,211$ & 0,$193 ; 0,597 ; 0,210$ \\
\hline$\alpha_{D 41}^{*} ; \alpha_{D 43}^{*} ; \alpha_{D 45}^{*}$ & $0 ; 0 ; 1,00$ & $0 ; 0 ; 1,00$ \\
\hline$\alpha_{D 61}^{*} ; \alpha_{D 63}^{*} ; \alpha_{D 65}^{*}$ & $0 ; 0,273 ; 0,727$ & $0 ; 0,273 ; 0,727$ \\
\hline
\end{tabular}

Em uma comparação geral dos resultados apresentados, os dois métodos fornecem soluções muito semelhantes e próximas. A maior diferença absoluta ocorre na função objetivo $y_{A B T T}^{*}$, e é igual a 0,35 $\mathrm{MW}$, o que corresponde a $5 \cdot 10^{-6} \%$ da solução fornecida pelo solver CPLEX no modelo LIM. Ressalta-se também que o modelo ABTT é acoplado para os limites $Z^{M A X}$ e $w^{M I N}$ utilizados, assim, a solução inicial fornecida para ambos os métodos não é a solução ótima final.

Para analisar o solver CONOPT em relação ao tempo computacional, novamente sua solução é comparada àquela fornecida pelo modelo LIM. Para tanto, o sistema de 6 barras é replicado sequencialmente formando sistemas de 12, 
18, 24 e 30 barras. Em cada sistema, linhas são incluídas para conectar o bloco adicional de 6 barras à rede já existente. Assim, são obtidas simulações com complexidades diferentes, sendo possível mensurar o ganho em tempo de execução que é fornecido pelo solver não-linear. Além disso, para assegurar a qualidade da solução do solver CONOPT, são apresentados os valores da função objetivo $y_{A B T T}^{*}$.

Nestas simulações, para a Expansão Binária, o intervalo $\delta$ da discretização da variável $P_{G i}$ é $10 \mathrm{MW}$, de forma a controlar a quantidade de variáveis binárias. A exceção é o sistema de 6 barras, para o qual a solução com $\delta \cong 0,5 \mathrm{MW}$ foi apresentada na Tabela 6.6. Novamente, os limites tarifários $Z^{M A X}$ e $w^{M I N}$ são escolhidos de forma que o modelo ABTT seja sempre um problema binível acoplado, e a inicialização das variáveis não corresponda ao ótimo do problema. $\mathrm{Na}$ Tabela 6.7 são apresentados os tempos computacionais, o valor da função objetivo $y_{A B T T}^{*}$ para ambos os modelos e respectivos solvers. Especialmente para o modelo LIM, é apresentada a quantidade de variáveis binárias de cada simulação e o gap referente à solução ótima.

Tabela 6.7. Comparação de tempo de execução entre o modelo não-linear (solver CONOPT) e o modelo LIM via Expansão Binária (solver CPLEX) para o método ABTT

\begin{tabular}{|c|c|c|c|c|c|c|}
\hline \multirow{2}{*}{ Sistema } & \multicolumn{2}{c|}{$\begin{array}{c}\text { Modelo Não-linear } \\
\text { (solver CONOPT) }\end{array}$} & \multicolumn{3}{|c|}{$\begin{array}{c}\text { Modelo LIM via Expansão Binária } \\
\text { (solver CPLEX) }\end{array}$} \\
\cline { 2 - 7 } & Tempo & $\left(y_{A B T T}^{*}\right)_{N L}$ & Tempo & $\begin{array}{c}\mathrm{N}^{0} \text { de } \\
\text { variáveis } \\
\text { binárias }\end{array}$ & gap & $\left(y_{A B T T}^{*}\right)_{L I M}$ \\
\hline $\begin{array}{c}6 \text { barras } \\
\text { geradores } \\
3 \text { demandas }\end{array}$ & $1 \mathrm{~s}$ & $723,06 \mathrm{MW}$ & $1 \mathrm{~s}$ & 29 & $0,95 \%$ & $722,71 \mathrm{MW}$ \\
\hline $\begin{array}{c}12 \text { barras } \\
6 \text { geradores } \\
6 \text { demandas }\end{array}$ & $2 \mathrm{~s}$ & $1550,66 \mathrm{MW}$ & $2 \mathrm{~min}$ & 34 & $0,98 \%$ & $1540,60 \mathrm{MW}$ \\
\hline $\begin{array}{c}18 \text { barras } \\
9 \text { geradores } \\
9 \text { demandas }\end{array}$ & $5 \mathrm{~s}$ & $2342,69 \mathrm{MW}$ & $1 \mathrm{~h} 2 \mathrm{~min}$ & 51 & $0,99 \%$ & $2321,55 \mathrm{MW}$ \\
\hline $\begin{array}{c}24 \text { barras } \\
12 \text { geradores } \\
12 \text { demandas }\end{array}$ & $9 \mathrm{~s}$ & $3194,52 \mathrm{MW}$ & $40 \mathrm{~h}$ & 68 & $1,62 \%$ & $3151,41 \mathrm{MW}$ \\
\hline $\begin{array}{c}30 \text { barras } \\
15 \text { geradores } \\
15 \text { demandas }\end{array}$ & $15 \mathrm{~s}$ & $4071,83 \mathrm{MW}$ & $93 \mathrm{~h}$ & 85 & $1,72 \%$ & $4007,79 \mathrm{MW}$ \\
\hline
\end{tabular}

Nos resultados apresentados na Tabela 6.7 fica evidente o ganho em tempo computacional oferecido pelo solver CONOPT, principalmente a partir do sistema de 18 barras. Além disso, observa-se o crescimento acentuado de tempo 
computacional para a solução do modelo LIM via Expansão Binária. Complementando o resultado apresentado na Tabela 6.6, os valores da função objetivo $y_{A B T T}^{*}$ são próximos para ambos os métodos de solução, com as diferenças provocadas principalmente pela precisão aplicada ao processo de expansão binária $(\delta \cong 10 \mathrm{MW})$. Pelo mesmo motivo, o solver CONOPT apresenta melhores resultados em todas as simulações. Lembrando que o problema resolvido é de maximização, para os cinco sistemas $\left(y_{A B T T}^{*}\right)_{N L}>$ $\left(y_{A B T T}^{*}\right)_{L I M}$. 


\section{7 \\ Conclusões}

Neste trabalho foi proposto um método de alocação de tarifas de transmissão que, em um problema de otimização binível, caracteriza a interdependência entre os problemas de definição do caso base de fluxo de potência e de cálculo das tarifas. Tal relação tem origem na multiplicidade de soluções viáveis inerentes a cada problema. No caso do problema de fluxo de potência, dentre todas as soluções de despacho de geração possíveis, deve ser escolhida aquela que melhor recupera o estado do sistema para o qual se quer calcular as tarifas de transmissão. Tal solução é obtida em um problema de otimização no qual o estado desejado é representado na função objetivo, tendo como restrições os limites de geração e transmissão do sistema.

Já para o cálculo dos valores de tarifa, a multiplicidade reside nas diferentes formas possíveis de decompor os fluxos nas linhas de transmissão (oriundos do resultado de fluxo de potência) e atribuir cada componente aos usuários da rede. Neste conjunto viável de soluções, deve ser escolhida aquela que melhor representa os critérios e objetivos definidos para as tarifas. Novamente, um problema de otimização é utilizado como critério desejado representado na função objetivo e nas restrições.

Neste contexto, é proposta uma estrutura geral de um modelo de otimização binível, no qual o problema de cálculo das tarifas (nível inferior) é uma restrição na definição do conjunto viável do problema de fluxo de potência (nível superior). Nesta estrutura, diretrizes distintas para ambos os problemas podem ser incorporadas através das funções objetivo e restrições, sendo uma abordagem flexível a diferentes tipos de sistemas de transmissão. Neste trabalho, a estrutura geral é particularizada para atender ao contexto prático de minimizar o impacto dos sinais locacionais fornecidos por um método baseado em CMLP para geradores renováveis distantes dos grandes centros de demanda, como ocorre no sistema de transmissão brasileiro. O método proposto de Alocação Binível de Tarifas de Transmissão (ABTT) representa no nível superior a situação de 
máximo estresse da rede, decidindo as soluções de despacho de geração que maximizam os fluxos nas linhas, suprindo a demanda máxima do sistema. O objetivo consiste em calcular as tarifas na situação de pior caso de uso do sistema. O modelo do nível superior é nomeado como Despacho de Geração de Pior Caso (DPC). Para o nível inferior, é proposto o modelo de Tarifação de Mínima Amplitude (TMA), que minimiza a amplitude tarifária, respeitando limites mínimo $Z^{M I N}$ e máximo $Z^{M A X}$ predefinidos. Tal critério busca minimizar a severidade das maiores tarifas do sistema, mantendo a coerência geral do sinal locacional em todo o sistema. O cálculo das tarifas é inspirado no método Nodal utilizado no Brasil, com a inserção dos fatores de intercambio nodal (NEF) que generalizam a formulação das tarifas, e permitem aplicar um modelo de otimização na alocação. Esta generalização também faz com que o modelo seja totalmente independente da escolha da barra de referência para as tarifas locacionais e parcelas selo.

Dada a solução ótima fornecida pelo modelo binível, é salientado que devido a possível grande quantidade de variáveis de decisão, o problema pode apresentar múltiplas soluções ótimas. Assim, utilizando o conceito de otimização lexicográfica, é proposto um passo extra no processo de alocação. O problema adicional minimiza a variância das tarifas, respeitando os resultados de despacho de geração e amplitude tarifária oriundos do modelo ABTT.

Definido o processo completo de alocação de tarifas de transmissão, simulações foram realizadas para dois sistemas teste: um sistema didático de 6 barras, e o sistema IEEE 118 barras. Dos resultados apresentados, as principais conclusões obtidas são listadas a seguir:

- As restrições formuladas para as variáveis NEF $\alpha_{G i j}$ e $\alpha_{D j i}$ (decisão no nível inferior do modelo ABTT), que definem as trocas bilaterais de potência entre os usuários, respeitam adequadamente a solução de fluxo de potência do nível superior;

- As componentes de fluxo obtidas através dos NEFs ótimos podem ser negativas (componentes de contrafluxo) ou positivas, o que contribui para sinalizar através das tarifas os pontos benéficos para a instalação de novos usuários no sistema; 
- A interdependência entre os problemas é constatada e pode ser representada graficamente. Tal representação, evidencia a relação e acoplamento dos níveis de otimização na solução ótima, e também permite avaliar o quanto o nível superior que soluciona o fluxo de potência é afetado pelo critério das tarifas;

- O método proposto se adequa a condições e características do sistema tanto para o despacho de geração, como para o cálculo das tarifas. Como exemplo, em um sistema mais estressado, o intervalo de valores viáveis para os limites $z^{M A X}$ e $w^{M I N}$ é mais limitado;

- Em relação ao máximo estresse da rede, os resultados de despacho de geração obtidos apontam a solução ótima não corresponde à prática de despacho proporcional a capacidade máxima dos geradores;

- Em relação à presença de sinal locacional e diferenciação entre as tarifas, o método leva em conta as características da rede fornecendo a mínima amplitude tarifária ótima. Como exemplo, dadas às características do sistema IEEE 118 barras, a alocação do tipo Pro-rata (amplitude tarifária igual à zero) não é uma solução viável do método proposto. Além disso, quanto mais estressado é o sistema, maior é a diferenciação entre as tarifas;

- Em comparação ao método Nodal tradicional, os picos de tarifa para geradores e demandas são consideravelmente reduzidos pela minimização de amplitude presente no método proposto;

- Em relação à coerência dos sinais locacionais, comparações do método proposto com o método Nodal no sistema IEEE 118 barras apontam semelhanças na tendência das tarifas principalmente para as tarifas dos geradores, ainda que a formulação dos dois métodos seja diferente. Nas tarifas das demandas algumas diferenças nas tendências são verificas, no entanto, uma análise das estatísticas das tarifas por áreas do sistema mostra uma coerência geral dos resultados do método proposto;

- O problema binível ser acoplado ou desacoplado (em função de $z^{M A X}$ e $w^{M I N}$ escolhidos) não altera as características do método proposto em relação à minimização de amplitude e sinalização locacional;

- A solução do método proposto através do solver não-linear CONOPT garante sua aplicabilidade em sistemas de médio e grande porte, com solução ótima global e tempo computacional de solução reduzido. 


\section{8 \\ Trabalhos futuros}

Este capítulo se dedica a apresentar potenciais frentes de pesquisa para novas aplicações e evolução do trabalho apresentado. A ideia geral é utilizar os pontos fortes, as hipóteses e características do método de ABTT proposto neste trabalho para contribuir positivamente com dificuldades existentes em problemas relevantes de sistemas de transmissão. Aqui são propostas aplicações na alocação de tarifas pelo uso de sistemas de transmissão multiárea, e nas decisões de expansão do sistema de transmissão. Cada uma das ideias é apresentada nas seções a seguir de maneira geral e com as respectivas expectativas de vantagens na utilização do método.

\section{1.}

\section{Aplicação da alocação binível de tarifas de transmissão em sistemas multiárea}

Sistemas multiárea são definidos como redes extensas que possuem múltiplas interligações entre áreas dispersas, países ou organizações regionais de transmissão. A alocação de tarifas pelo uso deste tipo de sistemas envolve algumas particularidades. Primeiramente, cada usuário faz uso, além da sua própria área, das linhas de interligação (LI) e das áreas externas, conforme ilustrado na Figura 8.1. Como consequência, cada área deve receber uma parcela do custo de operação e manutenção das instalações externas. Neste caso, a alocação de tarifas ideal consideraria um sistema único que contém todas as áreas e interligações. Entretanto, tal abordagem não é bem aceita na prática, pois, por motivos comerciais e políticos, as informações da rede de cada área não são facilmente disponibilizadas. 


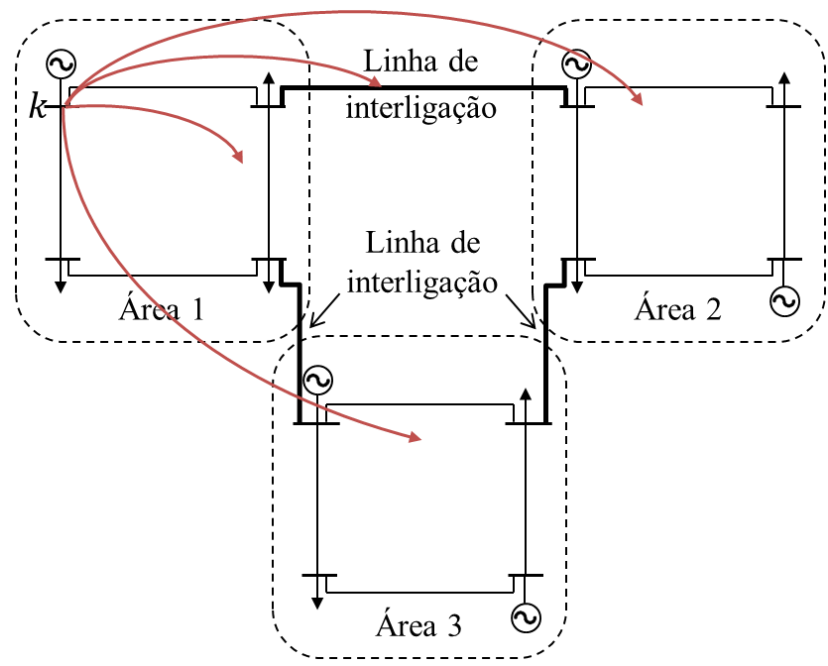

Figura 8.1. Representação de um sistema multiárea

Desta forma, o problema consiste em alocar tarifas pelo uso do sistema multiárea através de uma metodologia que se aproxime da alocação em um sistema único, tendo em vista a limitação existente no compartilhamento de informações da rede e a autonomia das áreas. Neste contexto, a flexibilidade do modelo matemático do método ABTT, bem como as características dos resultados fornecidos, podem contribuir para o objetivo da tarifação de sistemas multiárea. A seguir, é apresentada a ideia geral de tal aplicação do método proposto. Primeiramente, são propostas as seguintes hipóteses:

- O compartilhamento de informações de cada área se reduz ao seu equivalente de rede nas barras de fronteira (conforme adotado em outras propostas $[33,59])$ e aos valores limites máximo e mínimo de geração total sobressalente (capacidade de geração não utilizada pela demanda da área). Estudos realizados em [60, 61] indicam equivalentes do tipo REI (radial equivalent independent) como o mais adequado para a alocação de tarifas em sistemas multiárea;

- A tarifa de cada usuário do sistema multiárea é composta por três parcelas: $t^{A I}$ pelo uso da área interna (área da qual faz parte), $t^{A E}$ pelo uso das áreas externas, e $t^{L I}$ pelo uso das linhas de interligação;

- Há um operador independente (OI) para tratar da alocação de custos das interligações entre áreas [33].

A partir destas hipóteses, o processo de ATT se divide em duas partes: (i) alocação de tarifas pelo uso das interligações por parte de todo o sistema, (ii) 
alocação de tarifas pelo uso de cada área por parte de seus próprios usuários e por parte de áreas externas. Na primeira, o OI em posse dos equivalentes e limites de geração de todas as áreas, conforme representado na Figura 8.2, aloca os custos das linhas de interligação, através do método ABTT. Neste caso, o OI define os limites tarifários $z^{M A X}$ e $w^{M I N}$ que serão válidos para todas as áreas. Como resultado, cada equivalente de área recebe uma tarifa $t^{L I}$ a ser partilhada entre os usuários da área correspondente. Além disso, são obtidos os fluxos de máximo estresse em cada interligação que serão mantidos nas próximas etapas de alocação. É esperado que a manutenção dos fluxos nos elementos comuns a todas as áreas contribua para a aproximação da alocação para o sistema completo.

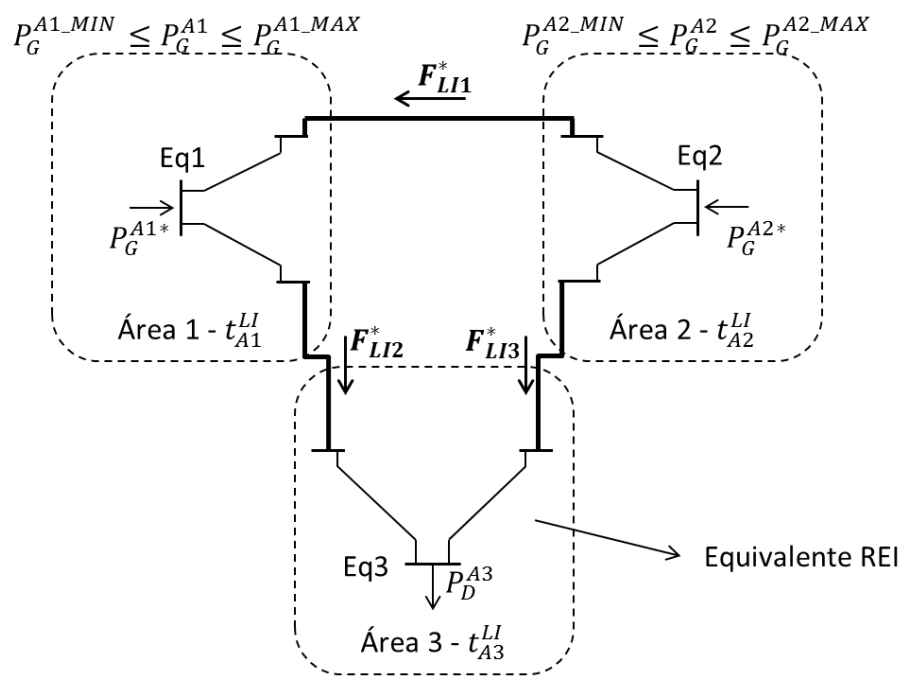

Figura 8.2. Sistema multiárea equivalente para alocação de tarifas pelo uso das LI

$\mathrm{Na}$ segunda, as tarifas de uso de cada área são definidas pelo respectivo regulador que utiliza equivalentes de rede das áreas externas e seus limites de geração, formando um sistema conforme ilustrado na Figura 8.3.

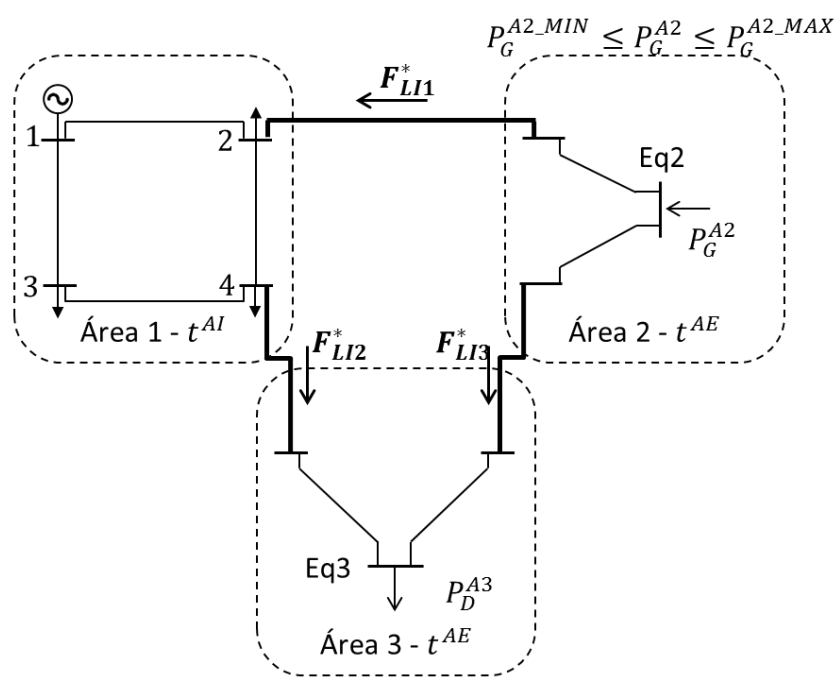

Figura 8.3. Sistema multiárea para alocação de custos da área interna 
O método ABTT é aplicado com restrições adicionais no nível superior para manter os fluxos das linhas de interligação obtidos pelo OI. Neste passo, as tarifas $t^{A I}$ são obtidas para os usuários pertencentes à área interna e as $t^{A E}$ para os equivalentes das áreas externas. Devido aos objetivos do método, usuários isolados, que em sistemas multiárea tenderiam a sofrer um impacto ainda maior no sinal locacional das tarifas, têm penalização minimizada. É possível também que, devido à minimização da amplitude de variação tarifária, haja uma tendência para que as trocas que envolvem os equivalentes de áreas externas (obtidas pelos NEFs ótimos) ocorram majoritariamente para usuários próximos às barras de fronteira.

Para finalizar o processo de alocação, após a aplicação do método nos sistemas ilustrados, as tarifas alocadas a equivalentes de área $\left(t^{L I}\right.$ e $\left.t^{A E}\right)$ devem ser distribuídas aos respectivos usuários. Propostas presentes na literatura indicam uma divisão pro-rata entre todos os geradores e demandas [33]. No entanto, a informação presente nos fatores $\beta_{\ell b}$ (sensibilidade de fluxo das linhas de transmissão $\ell$ com respeito à injeção em uma barra $b$ ) pode fornecer uma solução mais apurada. A ideia é que para uma barra, a cota de custos pelo uso de elementos externos a sua área seja diretamente proporcional ao impacto do fluxo que esta barra causa nas linhas conectadas às barras de fronteira. Assim, a divisão das tarifas alocadas aos equivalentes depende apenas dos parâmetros do sistema.

\section{2. Utilização do sinal locacional ótimo para decisões de planejamento do sistema}

Em função do planejamento descentralizado do sistema de transmissão, no qual os geradores e demandas podem estar alocados em qualquer ponto do sistema, podendo ou não ser orientados e incentivados a partir das tarifas de transmissão, há grandes desafios associados ao planejamento da expansão do sistema de transmissão. A decisão de construção de linha(s) ou reforços adicionais passa pela decisão dos geradores de se instalar em diferentes pontos do sistema e que, por sua vez, podem influenciados ou incentivados pelas tarifas de transmissão caso estas estejam adequadas às características do sistema. Desta forma, pode ser pensado um cálculo integrado dos problemas de planejamento e tarifação considerando as sinalizações e interdependência de ambos. Esta estrutura 
seria uma evolução do modelo proposto na qual todos os âmbitos interdependentes, além de despacho de geração e tarifa, são considerados em um modelo único. Tal ideia é representada na Figura 8.4. Sendo $L_{L T}^{*}$ e $C a p_{L T}^{*}$ a localização e capacidade das linhas de transmissão planejadas; $L_{G}^{*}$ e $P_{G}^{M A X^{*}}$ a localização e potência máxima dos geradores planejados; e $t_{G}^{*}$ e $t_{D}^{*}$ as tarifas ótimas para geradores e demandas.

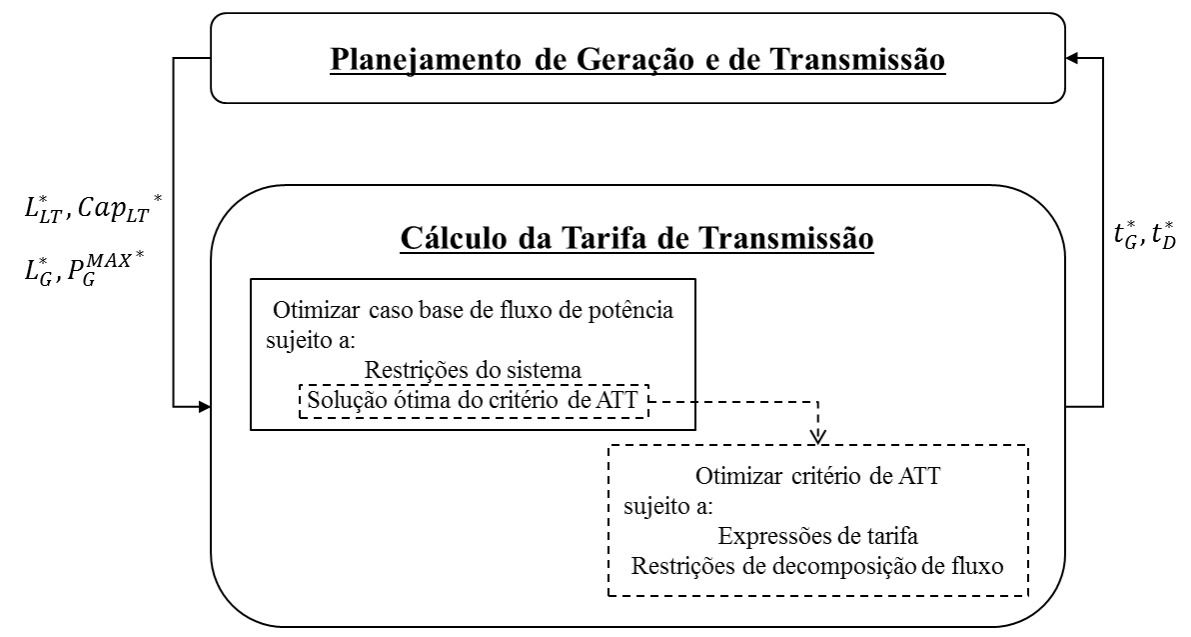

Figura 8.4. Estrutura de alimentação de variáveis entre os problemas de tarifação e planejamento de geração e de transmissão

Conforme explorado ao longo deste documento, a estrutura geral binível proposta (Figura 1.2) possui flexibilidade para incorporar objetivos que fazem da alocação de tarifas o mais adequada possível às características físicas e econômicas do sistema. Tal adequação pode se traduzir em tarifas de mínima amplitude como restrição de um despacho de máximo estresse, como neste trabalho, ou em qualquer outro objetivo justificável. Com esta abordagem de alocação de tarifas, espera-se que seus valores ótimos sejam eficientes em servir como orientadores nas decisões de planejamento e investimentos na expansão de geração e transmissão do sistema. Além disso, espera-se que a consideração de um planejamento conjunto de expansão de geração e de expansão de transmissão conforme representado na Figura 8.4 contribua para um planejamento eficiente do sistema como um todo. A partir da ideia inicial proposta, é necessário desenvolver funções que representem o acoplamento entre os problemas de planejamento e tarifação com as respectivas variáveis, bem como é preciso avaliar a complexidade matemática da proposta para que possa ser aplicada na prática em sistemas reais. 


\section{Referências bibliográficas}

1. FERREIRA, R. S.; RUDNICK, H.; BARROSO, L. The Expansion of Transmission: The Challenges Faced in South America. IEEE Power and Energy Magazine, v. 14, n. 4, p. 54-64, jul./ago 2016.

2. PAN, J. et al. Review of Usage-Based Transmission Cost Allocation Methods under Open Access. IEEE Transactions on Power Systems, v.15, n.4, p. 1218-1224, nov. 2000.

3. LIMA, D. A.; PADILHA FELTRIN, A.; CONTRERAS, J. An overview on network cost allocation methods. Electric Power Systems Research, v. 79, p. 750-758, dez. 2008.

4. ILIC, M.; GALIANA, F.; FINK, L. Power Systems Restructuring: Engineering and Economics. New York: Springer, 1998, 559p.

5. SARAIVA, J. P. T; DA SILVA, J. L P. P.; DE LEÃO, M. T. P. Mercados de Electricidade - Regulação e Tarifação de Uso de Redes. Porto: FEUPedições, 2002. 293 p.

6. BARROSO, L. A. et al. Transmission Structure in Brazil: Organization, Evaluation and Trends. In: IEEE Power Engineering Society General Meeting 2004, Denver, Colorado USA. Anais eletrônicos... Disponível em: < http://ieeexplore.ieee.org/document/1373069/?part=1>. Acesso em: 23 out. 2016.

7. CAIN, M. B.; O’NEILL, R. P.; CASTILLO, A., History of Optimal Power Flow and Formulations, Disponível em: < http://www.ferc.gov/industries/electric/indus-act/market-planning/opfpapers/acopf-1-history-formulation-testing.pdf >. Acessado em: 21 set. 2016.

8. SING, A. et al. Optimal power flow analysis of a Switzerland's transmission system for long-term capacity planning. Renewable and Sustainable Energy Reviews, v. 34, p 596-607, jun. 2014.

9. DE SOUZA A. M.; DE SOUSA, V. A.; DA COSTA, G. R. M., Optimal Power Flow: a Tool for Managing the Transmission Congestion. In: IEEE Power Engineering Society General Meeting 2004, Denver, Colorado USA. Anais eletrônicos... Disponível em: <http://ieeexplore.ieee.org/abstract/document/1372939/ >. Acesso em: 21 set. 2016.

10. HOGAN, W. W. Financial Transmission Right Formulations. Disponível em: $<$ https://www.hks.harvard.edu/hepg/Standard_Mkt_dsgn/Hogan\%20paper \%20FTR_formulations_033102.pdf>. Acesso em: 23 set. 2016.

11. REDDY, S. S.; BIJWE, P. R.; ABHYANKAR ,A. R. Optimal Posturing in Day-Ahead Market Clearing for Uncertainties Considering Anticipated RealTime Adjustment Costs. IEEE Systems Journal, v. 9, n. 1, p. 177-190. Mar. 2015.

12. SOLER, E. M. Resolução do problema de fluxo de potência ótimo com variáveis de controle discretas. São Carlos, 2011. 108p. Tese (Doutorado em 
Engenharia Elétrica e Área de Concentração em Sistemas Elétricos de Potência). Escola de Engenharia de São Carlos da Universidade de São Paulo.

13. SUBBA RAO, N. V.; KESAVA RAO, G.; SIVANAGARAJU, S. Transmission Loss allocation with Optimal Power Flow using Gravitational Search Algorithm. International Journal of Innovative Research in Electrical, Electronics, Instrumentation and Control Engineering, v. 2, ed. 10, p. 2117-2126, out. 2014.

14. FERREIRA, J. et al. Transmission Costs Allocation Based on Optimal Redispatch. In: 8th International Conference on the European Energy Market (EEM) 2011, Zagreb, Croácia. Anais eletrônicos... Disponível em: <http://ieeexplore.iee.. rg/stamp/stamp.jsp?arnumber=5953058\&tag=1>. Acesso em: 26 set. 2016.

15. BAKIRTZIS, A. et al. Comparison of two methods for long-run marginal cost-based transmission use-of-system pricing. IEE Proceedings Generation, Transmission and Distribution, v. 148, n. 4, p. 477-481, jul. 2001.

16. ABHYANKAR, A. R.; SOMAN, S. A.; KHAPARDE, S. A. Optimization approach to real power tracing: an application to transmission fixed cost allocation. IEEE Transactions on Power Systems, v. 21, n. 3, p. 1350-1361, ago. 2006.

17. TELLES, E.; LIMA, D. A. Transmission Tariff Allocation under High Renewable Source Penetration and Congestion Conditions. In: $18^{\text {th }}$ Power Systems Computation Conference 2014, Wroclaw, Polônia. Anais eletrônicos... Disponível em: <http://ieeexplore.ieee.org/stamp/stamp.jsp?tp=\&arnumber=7038491\&tag=1> . Acesso em: 27 mar. 2016.

18. SUPERINTENDÊNCIA DE REGULAÇÃO DOS SERVIÇOS DE TRANSMISSÃO - STR/ANEEL. Manual da metodologia nodal para cálculo de tarifas de uso dos sistemas elétricos. Brasília, DF, 1999. Disponível em: <http://www.aneel.gov.br/arquivos/PDF/Metodologia_completa.pdf >. Acesso em: 27 mar. 2016.

19. EMPRESA DE PESQUISA ENERGÉTICA - EPE. Balanço energético nacional 2015 - Ano base 2014. Brasília, DF, 2015. Disponível em: <https://ben.epe.gov.br/downloads/Relatorio_Final_BEN_2015.pdf >. Acesso em: 27 mar. 2016.

20. MINISTÉRIO DE MINAS E ENERGIA - SECRETARIA DE PLANEJAMENTO E DESENVOLVIMENTO ENERGÉTICO. Plano Nacional de Expansão de Energia 2024. Brasília, DF, 2015. Disponível em: <http://www.epe.gov.br/PDEE/Relat\%C3\%B3rio\%20Final\%20do\%20PDE\% 202024.pdf>. Acesso em: 27 mar. 2016.

21. AGÊNCIA NACIONAL DE ENERGIA ELÉTRICA SUPERINTENDÊNCIA DE GESTÃO TARIFARIA. Nota Técnica $n^{\circ}$ 162/2015-SGT/ANEEL - Estabelecimento das tarifas de uso do sistema de transmissão - TUST para o ciclo 2015-2016. Brasília, 19 jun. 2015. Disponível em: <http://www2.aneel.gov.br/aplicacoes/audiencia/arquivo/2015/023/resulta do/ntecnica_162_sic_11652015_-2015-sgt_tust-_2015-2016-denis-andrerky.pdf>. Acesso em: 27 mar. 2016.

22. AGÊNCIA NACIONAL DE ENERGIA ELÉTRICA. Resolução normativa ${ }^{\circ}$ 77. Brasil, 18 ago. 2004. Disponível em: 
<http://www.aneel.gov.br/cedoc/bren2004077.pdf >. Acesso em: 27 mar. 2016.

23. AGÊNCIA NACIONAL DE ENERGIA ELÉTRICA - ANEEL. Resolução Normativa $\mathrm{n}^{\circ}$ 559. Brasil, 27 jun. 2013. Disponível em: <http://www2.aneel.gov.br/cedoc/ren2013559.pdf>.

24. TELLES, E. et al. Min-max long run marginal cost to allocate transmission tariffs for transmission users. Electric Power Systems Research, v. 101, p. 25-35, ago. 2013.

25. ILIA, M. D. et al. Toward regional transmission provision and its pricing in New England. Utilities Policy, v. 6, n. 3, p. 245-256, 1997.

26. SHIRMOHAMMADI, D. et al. Evaluation of transmission network capacity use for wheeling transactions. IEEE Transactions on Power Systems, v. 4, n. 4, p. 1405-1412, out. 1989.

27. KUMAR, N.; REDDY, Y.R.V.; DAS, D.; PADHY, N.P. Allocation of Transmission Charge by using MVA-Mile Approaches for Restructured Indian Power Utility. In: IEEE Power Engineering Society General Meeting 2011, Detroit Michigan, Estados Unidos. Anais eletrônicos... Disponível em: <http://ieeexplore.ieee.org/stamp/stamp.jsp?arnumber=6039507>. Acesso em: 27 mar. 2016.

28. LIMA, J. W. M. Allocation of transmission fixed charges: an overview. IEEE Transactions on Power Systems, v. 11, n. 3, p. 1409-1418, ago. 1996.

29. BIALEK, J. Topological generation and load distribution factors for supplement charge allocation in transmission open access. IEEE Transactions on Power Systems, v. 12, n. 3, p. 1185-1193, ago 1997.

30. DA SILVA, A. M. L.; COSTA, J. G. C.; LIMA, L. H. L. A new methodology for cost allocation of transmission systems in interconnected energy markets. IEEE Transactions on Power Systems, v. 28, n. 2, p. 740-748, maio 2013.

31. MARANGON LIMA, L. M. Aprimoramento da Metodologia Nodal para Tarifação do Uso de Sistemas de Transmissão. Itajubá, 2007. 96p. Dissertação (Mestrado em Ciências em Engenharia Elétrica e Área de Concentração em Sistemas Elétricos de Potência). Universidade Federal de Itajubá.

32. GALIANA, F. D.; CONEJO, A. J.; GIL, H. A. Transmission network cost allocation based on equivalent bilateral exchanges. IEEE Transactions on Power Systems, v. 18, n. 4, p. 1425-1431, nov. 2003.

33. GIL, H. A.; GALIANA, F. D.; CONEJO, A. J. Multiarea transmission network cost allocation. IEEE Transactions on Power Systems, v. 20, n. 3, p.1293-1301, ago. 2005.

34. CONEJO, A. J. et al. Zbus transmission network cost allocation. IEEE Transactions on Power Systems, v. 22, n. 1, p. 342-349, fev. 2007.

35. MOLINA, Y.P.; SAAVEDRA, O. R.; PORTUGAL, C. Allocation of transmission network cost using modified Zbus matrix. Electric Power and Energy Systems, v. 63, p. 323-330, jul. 2014.

36. NIKOUKAR, J.; HAGHIFAM, M.R.; PARASTAR, A. Transmission cost allocation based on the modified Z-bus. Electric Power and Energy Systems, v. 42, p. 31-37, mai. 2012.

37. CHOUDHURY, N. B. D.; GOSWAMI, S. K. "Fair allocation of transmission ancillary service cost using game theory: A preliminary study". In: Australasian Universities Power Engineering Conference (AUPEC), Christchurch 2010, Nova Zelândia. Anais eletrônicos... Disponível em: 
$<$ http://ieeexplore.ieee.org/stamp/stamp.jsp?arnumber=5710698>. Acessado em: 19 out. 2016.

38. ZOLEZZI, J. M. ; RUDNICK, H. "Transmission Cost Allocation by Cooperative Games and Coalition Formation". IEEE Transactions on Power Systems, v. 17, n. 4, p.1008-1015, nov. 2002.

39. JUNQUEIRA, M. et al. An aumann-shapley approach to allocate transmission service cost among network users in electricity markets. IEEE Transactions on Power Systems, v. 22, n. 4, nov. 2007.

40. KIRSCHEN, D.; GORAN, R. A.; STRBAC. Contributions of individual generators to loads and flows. IEEE Transactions on Power Systems, v. 12, n. 1, p.52-60, fev. 1997.

41. TELLES, E; LIMA, D. A.; CONTRERAS, J.;ALGUACIL, N. (no prelo) "A New Transmission Tariff Allocation Model based on Bilevel Programming". IEEE Transactions on Power Systems.

42. OÑATE, Y. P.; RAMIREZ J. M.; COELLO, C. A. C. An optimal power flow plus transmission costs solution. Electric Power Systems Research, v. 79, p. 1240-1246, abr. 2009.

43. ABHYANKAR, R.; SOMAN, S. A.; KHAPARDE, S. A. Min-max fairness criteria for transmission fixed cost allocation. IEEE Transactions on Power Systems, v. 22, n. 4, p. 2094-2104, nov. 2007.

44. RAO, M. S. S. et al. Min-max fair power flow tracing for transmission system usage cost allocation: a large system perspective. IEEE Transactions on Power Systems, v. 25, n. 3, p. 1457-1468, ago. 2010.

45. ABHYANKAR, A. R.; KHAPARDE, S. A. Electricity transmission pricing: Tracing based point-of-connection tariff. International Journal of Electrical Power and Energy Systems, n. 31, p.59-66, 2009.

46. RAO, M. S. S.; SOMAN, S. A. Marginal pricing of transmission services using min-max fairness policy", IEEE Transactions on Power Systems, v. 30, n. 2, p. 573-584, mar. 2015.

47. PEREZ-ARRIAGA, I. J. et al. Marginal pricing of transmission services: An analysis of cost recovery. IEEE Transactions on Power Systems, v. 10, n. 1, p. 546-553, fev. 1995.

48. MONTICELLI, A. J. Fluxo de carga em redes de energia elétrica. São Paulo: Edgard Blücher, 1983. 164 p.

49. CHVATAL, V. Linear Programming. New York: W. H. Freeman and Company, 1983. $478 \mathrm{p}$.

50. ZYKINA, A. V. A lexicographic optimization algorithm, Automation and Remote Control, v. 65, n. 3, p. 363-368, 2004.

51. DRUD, A. GAMS Documentation - CONOPT. Disponível em: $<$ https://www.gams.com/help/index.jsp?topic=\%2Fgams.doc\%2Fsolvers $\% 2 \mathrm{Fi}$ ndex.html >. Acesso em: 27 mar. 2016.

52. GENERAL ALGEBRAIC MODELING SYSTEM (GAMS) Software, version 24.02. GAMS Development Corporation. Disponível em: <https://www.gams.com/>. Acesso em: 27 mar. 2016.

53. BAZARAA, M. S.; SHERALI, H. D.; SHETTY, C. M. Nonlinear Programming Theory and Algorithms, 3 ed. New Jersey: John Wiley \& Sons 2006. 872 p.

54. DRUD, A. S. A GRG Code for Large Sparse Dynamic Nonlinear Optimization Problems. Mathematical Programming, n.31, p.153-191, 1985. 
55. DRUD, A. S. CONOPT - A Large-Scale GRG Code. ORSA Journal on Computing, n. 6, p. 207-216, 1992.

56. GAMS Documentation - CPLEX 12.6. Disponível em: $<$ https://www.gams.com/help/index.jsp?topic=\%2Fgams.doc\%2Fsolvers $\% 2 \mathrm{Fi}$ ndex.html>. Acesso em: 27 mar. 2016.

57. WOLSEY, L. A. Integer Programming, 1ed. New York: John Wiley \& Sons, 1998. $288 \mathrm{p}$.

58. PEREIRA, M. V. et al. Strategic bidding under uncertainty: A binary expansion approach. IEEE Transactions on Power Systems, v. 20, n. 1, p. 180-188, feb. 2005.

59. LIMA, D. A. et al. Network reduction schemes for transmission cost allocation in multi-area systems. In: IEEE Power Engineering Society PowerTech 2011, Trondheim, Noruega. Anais eletrônicos... Disponível em: <http://ieeexplore.ieee.org/abstract/document/6019453/>. Acesso em: 27 mar. 2016.

60. PARRA, J. C. V. Alocação de Custos pelo Uso do Sistema de Transmissão em Sistemas Multiárea. Rio de Janeiro, 2014. 124p. Dissertação (Mestrado em engenharia elétrica) - Departamento de Engenharia Elétrica, Pontifícia Universidade Católica do Rio de Janeiro.

61. LIMA, D. A.; PARRA, J. C. V. Comparison of transmission cost allocation methods in a multi-area framework. In: IEEE Power Engineering Society General Meeting 2014, Washington, Estados Unidos. Anais eletrônicos... Disponível em: <http://ieeexplore.ieee.org/stamp/stamp.jsp?tp=\&arnumber=6939791> . Acesso em: 27 mar. 2016.

62. ELGERD, O. I. Introdução à teoria de sistemas de energia elétrica. São Paulo: McGraw-Hill do Brasil, 1978. 


\section{Apêndice A \\ Matriz de sensibilidade de fluxos}

Neste Apêndice é apresentado o procedimento para o cálculo da matriz de sensibilidade de fluxos $\boldsymbol{\beta}$ utilizada nos Capítulos 3 e 4 para a formulação dos fluxos de potência DC, das tarifas do método Nodal e das tarifas do método proposto de Tarifação de Mínima Amplitude (Seção 4.2.2). Conforme mencionado no Capítulo 3, a matriz sensibilidade fornece a variação de fluxo nas linhas do sistema dada uma variação de injeção/extração de potência em uma barra [18]. Cada elemento da matriz pode ser representado por (A.1).

$$
\beta_{\ell b}=\frac{\Delta F_{\ell}}{\Delta P_{b}}, \quad \forall \ell \in \Omega_{L}, \forall b \in \Omega_{B}
$$

Assim, busca-se uma matriz que relacione os fluxos através das linhas com as injeções de potência nas barras. Para tanto, primeiramente considera-se a aplicação da primeira lei de Kirchhoff a cada barra do sistema de transmissão.

$$
\left[\begin{array}{c}
P_{1} \\
P_{2} \\
\vdots \\
P_{k} \\
\vdots \\
P_{n}
\end{array}\right]=\left[\begin{array}{c}
F_{1-2}+F_{1-3}+\cdots+F_{1-k}+\cdots+F_{1-n} \\
F_{2-1}+F_{2-3}+\cdots+F_{2-k}+\cdots+F_{2-n} \\
\vdots \\
F_{k-1}+F_{k-2}+\cdots+F_{k-m}+\cdots+F_{k-n} \\
\vdots \\
F_{n-1}+F_{n-2}+\cdots+F_{n-k}+\cdots+F_{n-m}
\end{array}\right]
$$

Considerando as simplificações do fluxo de potência DC [48], as perdas elétricas nas linhas de transmissão são desprezadas, e o fluxo de potência através de uma linha entre as barras $m$ e $k$ quaisquer respeita a seguinte relação: $F_{k-m}=$ $-F_{m-k}$. Com isso, (A.2) é reescrita na formulação apresentada em (A.3)-(A.4).

$$
\begin{gathered}
{\left[\begin{array}{c}
P_{1} \\
P_{2} \\
\vdots \\
P_{k} \\
\vdots \\
P_{n}
\end{array}\right]=\left[\begin{array}{cccccc}
1 & 1 & \ldots & 0 & \ldots & 0 \\
-1 & 0 & \cdots & 0 & \ldots & 0 \\
\vdots & \vdots & \vdots & \vdots & \vdots & \vdots \\
0 & 0 & \cdots & 1 & \ldots & 0 \\
\vdots & \vdots & \vdots & \vdots & \vdots & \vdots \\
0 & 0 & \cdots & 0 & \ldots & 1
\end{array}\right] \cdot\left[\begin{array}{c}
F_{1-2} \\
F_{1-3} \\
\vdots \\
F_{k-m} \\
\vdots \\
F_{n-m}
\end{array}\right]} \\
\boldsymbol{P}=\boldsymbol{A} \boldsymbol{F}
\end{gathered}
$$


Sendo $\boldsymbol{A}$ a matriz de incidência nodal do sistema de transmissão. Esta matriz informa quais linhas estão diretamente conectadas a cada barra $k$ do sistema. Além disso, o sinal dos termos não-nulos indicam, para cada linha, o sentido de fluxo adotado como positivo. Para as linhas de transmissão que possuem o sentido de fluxo bem definido, esta adoção representa o sentido real do fluxo de potência. Assim, a matriz possui dimensão $n_{B} \times n_{L}$ e sua regra de construção, para cada elemento $a_{k \ell}$, é dada por (A.5).

$$
a_{k \ell}=\left\{\begin{array}{c}
1, \text { se o fluxo da linha } \ell \text { sai da barra } k \\
-1, \text { se o fluxo da linha } \ell \text { entra na barra } k \\
0, \text { se a linha } \ell \text { e a barra } k \text { não estão conectados }
\end{array}\right.
$$

Ainda das aproximações do fluxo de potência DC, para uma linha $k-m$ com reatância $x_{k m}$ e susceptância $b_{k m}=-1 / x_{k m}$, a igualdade $F_{k-m}=x_{k m}^{-1}$. $\left(\theta_{k}-\theta_{m}\right)=-b_{k m} \cdot\left(\theta_{k}-\theta_{m}\right)$ é verdadeira [48]. Aplicando a todas as linhas do sistema, a igualdade pode ser escrita matricialmente conforme (A.6)-(A.7).

$$
\begin{gathered}
{\left[\begin{array}{c}
F_{1-2} \\
F_{1-3} \\
\vdots \\
F_{k-m} \\
\vdots \\
F_{k-n}
\end{array}\right]=-\left[\begin{array}{cccccc}
b_{12} & 0 & \ldots & 0 & \ldots & 0 \\
0 & b_{13} & \ldots & 0 & \ldots & 0 \\
\vdots & \vdots & \ddots & \vdots & \vdots & \vdots \\
0 & 0 & \ldots & b_{k m} & \ldots & 0 \\
\vdots & \vdots & \vdots & \vdots & \ddots & \vdots \\
0 & 0 & \ldots & 0 & \ldots & b_{k n}
\end{array}\right] \cdot\left[\begin{array}{cccccc}
1 & -1 & \ldots & 0 & \ldots & 0 \\
1 & 0 & \ldots & -1 & \ldots & 0 \\
\vdots & \vdots & \vdots & \vdots & \vdots & \vdots \\
-1 & 0 & \cdots & 1 & \ldots & 0 \\
\vdots & \vdots & \vdots & \vdots & \vdots & \vdots \\
0 & 0 & \ldots & -1 & \ldots & 1
\end{array}\right] \cdot\left[\begin{array}{c}
\theta_{1} \\
\theta_{2} \\
\vdots \\
\theta_{k} \\
\vdots \\
\theta_{n}
\end{array}\right]} \\
\boldsymbol{F}=-\boldsymbol{b} \boldsymbol{A}^{t} \boldsymbol{\theta}
\end{gathered}
$$

Sendo $\boldsymbol{b}$ a matriz diagonal de dimensão $n_{L} \times n_{L}$ que contem elementos não nulos iguais a susceptância de cada linha, $\boldsymbol{A}^{t}$ a matriz de dimensão $n_{L} \times n_{B}$ que corresponde à transposta da matriz de incidência nodal $\boldsymbol{A}$ definida em (A.4), e $\boldsymbol{\theta}$ o vetor de dimensão $n_{B} \times 1$ que contem ângulos das barras do sistema. Da expressão (A.7), o vetor $\boldsymbol{\theta}$ é substituído por uma formulação equivalente que é função das injeções de potência nas barras do sistema. Assim a relação (A.8) é utilizada.

$$
\boldsymbol{P}=\boldsymbol{B}^{\prime} \boldsymbol{\theta} \rightarrow \boldsymbol{\theta}=\left(\boldsymbol{B}^{\prime}\right)^{-1} \boldsymbol{P}
$$

$\mathrm{O}$ vetor $\boldsymbol{P}$ de dimensão $n_{B} \times 1$ contém as injeções líquidas de potência em cada barra, e $\boldsymbol{B}^{\prime}$ de dimensão $n_{B} \times n_{B}$ é a matriz tipo admitância nodal, cujos elementos são calculados conforme (A.9). 
$B^{\prime}{ }_{k m}=\left\{\begin{array}{c}-x_{k m}^{-1} \text {, se } k \neq m \\ \sum_{m \in \Omega_{k}} x_{k m}^{-1}, \text { se } k=m \text { sendo } \Omega_{k} \text { o conjunto de barras conectadas à } k\end{array}\right.$

Substituindo (A.8) em (A.7):

$$
\boldsymbol{F}=-\boldsymbol{b} \boldsymbol{A}^{t}\left(\boldsymbol{B}^{\prime}\right)^{-1} \boldsymbol{P}
$$

Dado que a matriz $\boldsymbol{B}^{\prime}$ é singular, para que seja obtida a sua inversa são retiradas a linha e coluna referentes à barra de referência do sistema. Para que a igualdade em (A.10) seja válida, são retiradas também a linha do vetor $\boldsymbol{P}$ e a coluna na matriz $\boldsymbol{A}$ correspondentes à barra de referência. O sobrescrito ref indica a retirada de linhas e colunas associadas à barra de referência.

$$
F=-b\left(A^{r e f}\right)^{t}\left(B^{\prime r e f}\right)^{-1} P^{r e f}
$$

De (A.11), tem-se a relação $\boldsymbol{\beta}^{\text {ref }}$ entre fluxos e injeções de potência com exclusão da barra de referência (A.13). Assim a matriz $\boldsymbol{\beta}^{\text {ref }}$ possui dimensão $n_{L} \times n_{B}-1$.

$$
\begin{gathered}
F=\beta^{\text {ref }} P^{r e f} \\
\beta^{r e f}=-b\left(A^{r e f}\right)^{t}\left(B^{\prime r e f}\right)^{-1}
\end{gathered}
$$

Para incluir a barra de referência, uma coluna de zeros de dimensão $n_{L} \times 1$ é adicionada à $\boldsymbol{\beta}^{\text {ref }}$ na posição de tal barra, obtendo a matriz de sensibilidade $\boldsymbol{\beta}$ completa de dimensão $n_{L} \times n_{B}$. Conforme as demonstrações, a formulação da matriz depende apenas de parâmetros da rede.

Os elementos de $\boldsymbol{\beta}$ representam a sensibilidade dos fluxos nas linhas devido à injeção/extração de potência em uma barra $k$ e compensação na barra de referência. Assim, destaca-se que ao modificar a barra de referência nos cálculos, o valor dos termos de $\boldsymbol{\beta}$ também se modificam. No entanto, a matriz possui a característica de manter a diferença entre as suas colunas constantes, independente da escolha da barra de referência. Como exemplo, a diferença entre os elementos $\beta_{\ell i}-\beta_{\ell j}$ é independente da escolha da barra de referência. 


\section{Apêndice B \\ Métodos de alocação de tarifas}

Neste Apêndice são apresentados os métodos de alocação de tarifas utilizados para comparações e ilustrações de resultados na Seção 6.2.3 do Capítulo 6. As seções a seguir contém características gerais e o procedimento de cálculo das tarifas dos métodos Pro-rata [4,5], Zbus [34] e Equivalent Bilateral Exchanges (EBE) [32].

\section{B.1.}

\section{Pro rata}

O método Pro-rata, também conhecido por Selo Postal, possui metodologia simples e de fácil implementação em qualquer sistema. Aloca tarifas de transmissão sem considerar o uso efetivo das linhas de transmissão por parte dos fluxos de potência e de suas componentes. Como consequência, não fornece qualquer tipo de sinal econômico em suas tarifas. Desta forma, são definidos dois valores de tarifa: um atribuído a todos os geradores, e outro atribuído a todas as demandas. A formulação da tarifa para geradores $\left(t_{G i}^{P R O-R A T A}\right)$ e demandas $\left(t_{D j}^{P R O-R A T A}\right)$ é dada por $($ B.1) e (B.2) respectivamente. Em uma analogia às parcelas selo definidas para os métodos Nodal e TMA no Capítulo 4, o método Pro-rata consiste em parcelas selo quando todas as tarifas locacionais do sistema são nulas.

$$
\begin{aligned}
t_{G i}^{P R O-R A T A} & =\frac{\frac{C_{S I S T}^{T}}{2}}{\sum_{i \in \Omega_{\mathrm{G}}} P_{G i}}, \quad \forall i \in \Omega_{G} \\
t_{D j}^{P R O-R A T A} & =\frac{\frac{C_{S I S T}^{T}}{2}}{\sum_{j \in \Omega_{D}} P_{D j}}, \quad \forall j \in \Omega_{D}
\end{aligned}
$$




\section{B.2.}

\section{Zbus}

O método Zbus é fortemente baseado em parâmetros do sistema de transmissão. As tarifas são calculadas considerando injeções de corrente nas barras do sistema, a matriz de impedância $\boldsymbol{Z}_{\boldsymbol{b u s}}$ [62] e o resultado de um estudo de fluxo de potência AC [62]. O método é composto por três etapas gerais:

1. A potência ativa de cada linha de transmissão é associada a cada injeção nodal;

2. Baseado na repartição feita, o custo de uma linha é alocado para todos os geradores e cargas;

3. O processo é repetido para todas as linhas do sistema.

A característica principal da metodologia Zbus consiste no seu efeito de proximidade, que, baseado na teoria de circuitos elétricos, considera que um gerador/demanda usa principalmente as linhas da rede eletricamente próximas. Com estas premissas, considera-se a representação П equivalente de uma linha de transmissão $\ell$, delimitada pelas barras $p$ e $q$, conforme a Figura B.1.

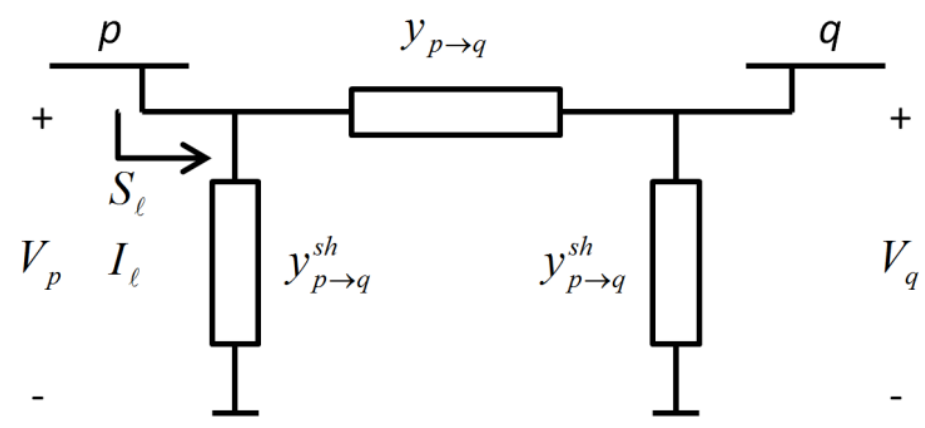

Figura B.1. Circuito П equivalente de uma linha de transmissão $\ell$.

Conhecido o resultado de um estudo de fluxo de potência AC do sistema, a potência complexa $S_{\ell}$ é conhecida, e pode ser formulada conforme (B.3).

$$
S_{\ell}=V_{p} \bar{I}_{\ell}, \quad \forall \ell \in \Omega_{L}
$$

Sendo $V_{p}$ a tensão da barra $p$, em V; e $\overline{I_{\ell}}$ o conjugado da corrente que flui pela linha $\ell$.

Considerando a corrente $I_{k}$, injetada em uma barra $k$ qualquer do sistema, tensão $V_{p}$ pode ser escrita conforme (B.4) utilizando o elemento $z_{p k}$ da matriz de impedância $\boldsymbol{Z}_{\text {bus }}$. A corrente $I_{\ell}$, por sua vez, pode ser escrita conforme (B.5) em 
função de $V_{p}$ e das admitâncias série $y_{p \rightarrow q}$ e paralelo $y_{p \rightarrow q}^{s h}$ do circuito da Figura B.1.

$$
\begin{gathered}
V_{p}=\sum_{k \in \Omega_{B}} z_{p k} I_{k} \\
I_{\ell}=\left(V_{p}-V_{q}\right) y_{p \rightarrow q}+V_{p} y_{p \rightarrow q}^{s h}
\end{gathered}
$$

Substituindo (B.4) em (B.5), tem-se uma nova expressão para a corrente $I_{\ell}$.

$$
\begin{gathered}
I_{\ell}=\sum_{k \in \Omega_{B}}\left[\left(z_{p k}-z_{q k}\right) y_{p \rightarrow q}+z_{p k} y_{p \rightarrow q}^{s h}\right] I_{k} \\
I_{\ell}=\sum_{k \in \Omega_{B}} a_{\ell}^{k} I_{k}
\end{gathered}
$$

O termo $a_{\ell}^{k}$ presente em (B.6) representa uma medida de distância elétrica entre a barra $k$ e a linha $\ell$, e ao ser considerado na formulação das tarifas garante o efeito de proximidade elétrica nas mesmas. A partir de $a_{\ell}^{k}$, a potência complexa $S_{\ell}$ pode ser reescrita substituindo (B.6) em (B.3).

$$
S_{\ell}=V_{p} \sum_{k \in \Omega_{B}}\left(\overline{a_{\ell}^{k} I_{k}}\right)=\sum_{k \in \Omega_{B}} V_{p} \overline{a_{\ell}^{k}} \overline{I_{k}}
$$

A partir de (B.7) é possível definir a expressão da potência ativa $P_{\ell}$ que flui pela linha de transmissão $\ell$, e a componente $P_{\ell}^{k}$ do fluxo $P_{\ell}$ associada a uma barra $k$ qualquer do sistema.

$$
\begin{gathered}
P_{\ell}=\sum_{k=1}^{n} \Re\left\{V_{p} \overline{a_{\ell}^{k}} \overline{I_{k}}\right\}, \quad \forall \ell \in \Omega_{L} \\
P_{\ell}^{k}=\Re\left\{V_{p} \overline{a_{\ell}^{k}} \bar{I}_{k}\right\}, \quad \forall \ell \in \Omega_{L}
\end{gathered}
$$

O termo $P_{\ell}^{k}$ definido em (B.9) corresponde a componente de fluxo atribuída a uma injeção de corrente por um usuário da rede em uma barra $k$. No método Zbus, é assumido que tanto componentes de fluxo como contrafluxo devem ser contabilizadas com custos positivos, ou seja, o efeito de alívio no fluxo total da linha proporcionado por contrafluxos não devem ser levado em conta na tarifa. Assim, é definida uma componente de uso $U_{\ell}^{k}$ de cada linha de transmissão por um usuário na barra $k$ conforme (B.10). 


$$
U_{\ell}^{k}=\left|P_{\ell}^{k}\right|, \quad \forall k \in \Omega_{B}, \forall \ell \in \Omega_{L}
$$

Para converter o uso de cada linha em tarifas de transmissão, é definido um custo unitário de uso, análogo ao termo $c_{\ell}$ definido em (4.1). A diferença está na divisão do custo $C_{\ell}^{T}$ pelo uso total da linha. Assim, o custo unitário $c_{\ell}^{Z B U S} \mathrm{em}$ \$MW é o custo pago por cada MW de uso da linha de transmissão $\ell$.

$$
c_{\ell}^{Z B U S}=\frac{C_{\ell}^{T}}{\sum_{k \in \Omega_{B}} U_{\ell}^{k}}, \quad \forall \ell \in \Omega_{L}
$$

Assim, os custos atribuídos a cada gerador localizado em uma barra $i$, e para cada demanda localizada em uma barra $j$ pelo uso de uma linha $\ell$ do sistema são dados por (B.12) e (B.13), respectivamente.

$$
\begin{aligned}
C_{G i}^{Z B U S}=\sum_{\ell \in \Omega_{L}} c_{\ell}^{Z B U S} \cdot U_{\ell}^{i}, & \forall i \in \Omega_{G} \\
C_{D j}^{Z B U S}=\sum_{\ell \in \Omega_{L}} c_{\ell}^{Z B U S} \cdot U_{\ell}^{j}, & \forall j \in \Omega_{D}
\end{aligned}
$$

A tarifa alocada para cada gerador $i$ e demanda $j$ é dada por:

$$
\begin{aligned}
& t_{G i}^{Z B U S}=\frac{C_{G i}^{Z B U S}}{P_{G i}}, \quad \forall i \in \Omega_{G} \\
& t_{D j}^{Z B U S}=\frac{C_{D j}^{Z B U S}}{P_{D j}}, \quad \forall j \in \Omega_{D}
\end{aligned}
$$

\section{B.3.}

\section{Equivalent Bilateral Exchanges}

O método Equivalent Bilateral Exchanges (EBE) [32] aloca tarifas de transmissão baseado na ideia de trocas bilaterais fictícias de potência entre geradores e demandas. É definida a quantidade de potência que um gerador fornece a uma carga, e a participação deste montante na composição dos fluxos das linhas de transmissão. Conforme mencionado na Seção 4.2.1 do Capítulo 4 deste documento, tal hipótese serviu de inspiração para o uso dos NEFs no método proposto neste trabalho. Como será visto a seguir, o método EBE define parcelas fixas e arbitrárias de trocas bilaterais de potência, enquanto o método 
proposto tais trocas são definidas em um problema de otimização para atender ao objetivo de máximo estresse do sistema sujeito à mínima amplitude tarifária.

Para formular as tarifas de transmissão via método EBE, primeiramente assume-se cada gerador alimenta obrigatoriamente todas as demandas do sistema, no percentual que cada uma ocupa na demanda total. De maneira semelhante, cada demanda do sistema é alimentada por todos os geradores no percentual que cada um ocupa na geração total. Assim, assumindo-se um estudo de fluxo de potência DC sem perdas, pode-se definir a parcela $G D_{i j}$, em MW, correspondente à quantidade de potência do gerador $i$ destinada a atender a demanda $j$. Para ressaltar as diferenças entre a formulação do método EBE e do método proposto, (B.16) pode ser comparada à (4.9).

$$
G D_{i j}=\frac{P_{D j}}{\sum_{j \in \Omega_{D}} P_{D j}} \cdot P_{G i}=\frac{P_{G i}}{\sum_{i \in \Omega_{G}} P_{G i}} \cdot P_{D j}, \quad \forall i \in \Omega_{G}, \forall j \in \Omega_{D}
$$

A partir do termo $G D_{i j}$, a componente de fluxo em uma linha de transmissão $\ell$ atribuída a um par $(i, j)$ de gerador e demanda pode ser definida utilizando o PTDF $\gamma_{i j \ell}$ definido na Seção 4.2.1 do Capítulo 4. Assim como para o método Zbus, no para o método EBE é assumida a premissa de que fluxos e contrafluxos são contabilizados com custos positivos nas tarifas. Desta forma, a componente de fluxo se converte em uma componente de uso de uma linha $\ell$ por uma par $(i, j)$ de gerador e demanda, conforme em (B.17). O operador módulo aplicado a $\gamma_{i j \ell}$ garante a premissa assumida.

$$
U_{\ell}^{i, j}=\left|\gamma_{i j \ell}\right| \cdot G D_{i j}
$$

Assim, o uso da linha de transmissão $\ell$ envolvendo o gerador $i$ pode ser obtido considerando o uso da linha por cada par $(i, j)$ do qual o gerador $i$ faz parte. O mesmo raciocínio pode ser utilizado para uma demanda $j$.

$$
\begin{aligned}
U_{\ell}^{G i}=\sum_{j \in \Omega_{D}}\left|\gamma_{i j \ell}\right| \cdot G D_{i j}, & \forall i \in \Omega_{G} \\
U_{\ell}^{D j}=\sum_{i \in \Omega_{G}}\left|\gamma_{i j \ell}\right| \cdot G D_{i j}, & \forall j \in \Omega_{D}
\end{aligned}
$$

Para converter o uso de cada linha em tarifas de transmissão, é definido um custo unitário de uso, assim como feito para o método Zbus na Seção B.2. Assim, 
o custo unitário $c_{\ell}^{E B E}$ em $\$ / M W$ é o custo pago por cada MW de uso da linha de transmissão $\ell$.

$$
c_{\ell}^{E B E}=\frac{C_{\ell}^{T}}{\sum_{i \in \Omega_{G}} \sum_{j \in \Omega_{D}} U_{\ell}^{i, j}}, \quad \forall \ell \in \Omega_{L}
$$

Considerando que geradores e demandas são responsáveis por metade do custo total $C_{S I S T}^{T}$ cada, o custo de cada gerador e de cada carga do sistema de transmissão é:

$$
\begin{aligned}
C_{G i}^{E B E}=\sum_{\ell \in \Omega_{L}} \sum_{j \in \Omega_{D}} \frac{c_{\ell}^{E B E}}{2} \cdot\left|\gamma_{i j \ell}\right| \cdot G D_{i j}, & \forall i \in \Omega_{G} \\
C_{D j}^{E B E}=\sum_{\ell \in \Omega_{L}} \sum_{i \in \Omega_{G}} \frac{c_{\ell}^{E B E}}{2} \cdot\left|\gamma_{i j \ell}\right| \cdot G D_{i j}, & \forall j \in \Omega_{D}
\end{aligned}
$$

A tarifa alocada para cada gerador $i$ e demanda $j$ é dada por:

$$
\begin{aligned}
& t_{G i}^{E B E}=\frac{C_{G i}^{E B E}}{P_{G i}}, \quad \forall i \in \Omega_{G} \\
& t_{D j}^{E B E}=\frac{C_{D j}^{E B E}}{P_{D j}}, \quad \forall j \in \Omega_{D}
\end{aligned}
$$




\section{Apêndice C Linearização do modelo ABTT via expansão binária}

Neste Apêndice é apresentado o modelo de Alocação Binível de Tarifas de Transmissão (ABTT) linearizado via método de Expansão Binária. Este modelo linearizado é utilizado na Seção 6.2.4 do Capítulo 6 para avaliar a performance do solver não-linear CONOPT tanto em tempo computacional de solução como em capacidade de atingir o ótimo global do problema. Conforme mencionado anteriormente no Capítulo 6, o modelo linearizado por Expansão Binária é um problema de otimização do tipo linear inteiro misto (LIM) no qual ótimo global é matematicamente garantido. Em contrapartida, a necessidade de grande quantidade de variáveis binárias comprometeria a utilização do modelo ABTT em sistemas de grande porte. Assim, o modelo linearizado é aqui apresentado apenas para possibilitar a reprodutibilidade dos resultados apresentados na Seção 6.2.4.

De acordo com o Capítulo 5 deste documento, o modelo ABTT é não-linear devido aos produtos de variáveis de decisão reais em suas restrições. Dado um destes produtos, a aplicação da Expansão Binária [54] consiste em transformar o intervalo contínuo viável de uma das variáveis em um intervalo discreto de valores, representado em função de variáveis binárias. Os componentes deste intervalo discreto são espaçados por um intervalo $\delta$ constante. Desta forma, o produto entre variáveis reais é substituído por produtos entre uma variável real e variáveis binárias, o que pode ser tratado por restrições lineares de forma que o problema final seja do tipo Linear Inteiro Misto (LIM). Como exemplo, a discretização da variável de despacho de geração $P_{G i}$ é dada por (C.1)-(C.2).

$$
\begin{gathered}
P_{G i}=P_{G i}^{M I N}+\delta_{G i} \cdot \sum_{k=0}^{K_{i}} 2^{k} \cdot x_{k i}, \quad \forall i \in \Omega_{G} \\
\delta_{G i}=\frac{\left(P_{G i}^{M A X}-P_{G i}^{M I N}\right)}{B_{i}}, \quad \forall i \in \Omega_{G}
\end{gathered}
$$

Sendo $K_{i}$ um número inteiro não-negativo de forma que a discretização de $P_{G i}$ é representada por $\left\{P_{G i}^{\varepsilon}, \varepsilon=0,1, \ldots, B_{i}\right\}$ com $B_{i}=2^{K_{i}} ; \delta_{G i}$ o intervalo entre os 
valores da discretização; e $x_{k i}$ uma variável binária. A acurácia da discretização depende do valor de $B_{i}$ : quanto maior é $B_{i}$, menor é $\delta_{G i}$ e mais precisa é a aproximação ao intervalo contínuo original. No entanto, maior precisão acarreta maior quantidade de variáveis binárias.

A partir da discretização (C.1)-(C.2),o produto de variáveis pode ser linearizado. Ainda como exemplo, para o produto de variáveis $P_{G i} \cdot \alpha_{G i j}$, pode-se escrever:

$$
\begin{gathered}
P_{G i} \cdot \alpha_{G i j}=P_{G i}^{M I N} \cdot \alpha_{G i j}+\delta_{G i} \cdot \sum_{k=0}^{K_{i}} 2^{k} \cdot y_{k i j}, \quad \forall i \in \Omega_{G}, \forall j \in \Omega_{D} \\
y_{k i j}=\alpha_{G i j} \cdot x_{k i}, \quad \forall i \in \Omega_{G}, \forall j \in \Omega_{D}, \forall k \in\left\{0, \ldots, K_{i}\right\}
\end{gathered}
$$

Para que $y_{k i j}$ seja capaz de reproduzir o produto $\alpha_{G i j} \cdot x_{k i}$, as restrições (C.5) e (C.6) devem ser respeitadas, sendo $G$ um valor capaz de relaxar a restrição (C.5) quando $x_{k i}=0$, e a restrição (C.6) quando $x_{k i}=1$. Dado que $x_{k i} \in\{0,1\}$, o objetivo é reproduzir o resultado $y_{k i j}=0$ se $x_{k i}=0$, e $y_{k i j}=\alpha_{G i j}$ se $x_{k i}=1$. Para aplicar o método a todo o modelo ABTT, a formulação (C.1), (C.3) e (C.5)(C.6) deve ser aplicada a todos os produtos de variáveis. Como no modelo todos os produtos de variáveis envolvem o despacho $P_{G i}$, não é necessário discretizar outras variáveis.

$$
\begin{array}{r}
0 \leq \alpha_{G i j}-y_{k i j} \leq\left(1-x_{k i}\right) \cdot G, \quad \forall i \in \Omega_{G}, \forall j \in \Omega_{D}, \forall k \in\left\{0, \ldots, K_{i}\right\} \\
0 \leq y_{k i j} \leq x_{k i} \cdot G, \quad \forall i \in \Omega_{G}, \forall j \in \Omega_{D}, \forall k \in\left\{0, \ldots, K_{i}\right\}
\end{array}
$$

Assim, o modelo ABTT linear inteiro misto obtido via a utilização do método de Expansão Binária é apresentado em (C.7)-(C.52).

\section{Alocação Binível de Tarifas de Transmissão - Modelo Linear Inteiro Misto}

$$
\text { maximizar } y_{A B T T}=\sum_{\ell \in \Omega_{L}} F_{\ell}
$$

s.a.:

$$
F_{\ell}=\sum_{\substack{i \in \Omega_{G} \\ j \in \Omega_{D}}} \gamma_{\ell i j}\left(P_{G i}^{M I N} \alpha_{G i j}+\delta_{G i} \sum_{k=0}^{K_{i}} 2^{k} y_{k i j}\right), \quad \forall \ell \in \Omega_{L}
$$




$$
\begin{aligned}
& \sum_{i \in \Omega_{G}}\left(P_{G i}^{M I N} \alpha_{G i j}+\delta_{G i} \sum_{k=0}^{K_{i}} 2^{k} y_{k i j}\right)=P_{D j}, \quad \forall j \in \Omega_{D} \\
& 0 \leq F_{\ell} \leq \operatorname{Cap}_{\ell}, \quad \forall \ell \in \Omega_{L} \\
& P_{G i}^{M I N} \leq P_{G i} \leq P_{G i}^{M A X}, \quad \forall i \in \Omega_{G} \\
& \sum_{\substack{\ell \in \Omega_{L} \\
j \in \Omega_{D}}} \frac{c_{\ell} \gamma_{\ell i j}}{2 \operatorname{Cap}_{\ell}}\left[\beta_{\ell i}\left(P_{G i}^{M I N} \alpha_{G i j}+\delta_{G i} \sum_{k=0}^{K_{i}} 2^{k} y_{k i j}\right)-\alpha_{G i j} \beta_{\ell j} P_{D j}\right] \leq z, \quad \forall i \in \Omega_{G} \\
& \sum_{\substack{\ell \in \Omega_{L} \\
j \in \Omega_{D}}} \frac{c_{\ell} \gamma_{\ell i j}}{2 \operatorname{Cap}_{\ell}}\left[\beta_{\ell i}\left(P_{G i}^{M I N} \alpha_{D i j}+\delta_{G i} \sum_{k=0}^{K_{i}} 2^{k} t_{k i j}\right)-\alpha_{D i j} \beta_{\ell j} P_{D j}\right] \leq z, \\
& \forall j \in \Omega_{D} \\
& \sum_{\substack{\ell \in \Omega_{L} \\
j \in \Omega_{D}}} \frac{c_{\ell} \gamma_{\ell i j}}{2 \operatorname{Cap}_{\ell}}\left[\beta_{\ell i}\left(P_{G i}^{M I N} \alpha_{G i j}+\delta_{G i} \sum_{k=0}^{K_{i}} 2^{k} y_{k i j}\right)-\alpha_{G i j} \beta_{\ell j} P_{D j}\right] \geq w, \\
& \forall i \in \Omega_{G} \\
& \sum_{\substack{\ell \in \Omega_{L} \\
j \in \Omega_{D}}} \frac{c_{\ell} \gamma_{\ell i j}}{2 \operatorname{Cap}_{\ell}}\left[\beta_{\ell i}\left(P_{G i}^{M I N} \alpha_{D i j}+\delta_{G i} \sum_{k=0}^{K_{i}} 2^{k} t_{k i j}\right)-\alpha_{D i j} \beta_{\ell j} P_{D j}\right] \geq w, \\
& \forall j \in \Omega_{D} \\
& z \leq z^{M A X} \\
& w \geq w^{M I N} \\
& \sum_{j \in \Omega_{D}} \alpha_{G i j}=1, \quad \forall i \in \Omega_{G} \\
& \sum_{i \in \Omega_{G}} \alpha_{D j i}=1, \quad \forall j \in \Omega_{D} \\
& P_{G i}^{M I N} \cdot \alpha_{G i j}+\delta_{G i} \cdot \sum_{k=0}^{K_{i}} 2^{k} \cdot y_{k i j}=\alpha_{D j i} \cdot P_{D j}, \quad \forall i \in \Omega_{G}, \forall j \in \Omega_{D}
\end{aligned}
$$




$$
\begin{aligned}
& \varepsilon_{i}^{G}+\left(P_{G i}^{M I N} \tau_{i j}+\delta_{G i} \sum_{k=0}^{K_{i}} 2^{k} u_{k i j}\right) \\
& +\sum_{\ell \in \Omega_{L}}\left\{\frac { c _ { \ell } \gamma _ { \ell i j } } { 2 \operatorname { C a p } _ { \ell } } \left[\beta_{\ell i}\left(P_{G i}^{M I N}\left(\theta_{i}^{L}-\theta_{i}^{U}\right)+\delta_{G i} \sum_{k=0}^{K_{i}} 2^{k}\left(q_{k i}-v_{k i}\right)\right\}\right.\right. \\
& \left.\left.+\beta_{\ell j} P_{D j}\left(\theta_{i}^{U}-\theta_{i}^{L}\right)\right]\right\} \leq 0, \quad \forall i \in \Omega_{G}, \forall j \in \Omega_{D} \\
& \varepsilon_{j}^{D}-\tau_{i j} P_{D j}+\sum_{\ell \in \Omega_{L}}\left\{\frac { c _ { \ell } \gamma _ { \ell i j } } { 2 \operatorname { C a p } _ { \ell } } \left[\beta_{\ell i}\left(P_{G i}^{M I N}\left(\varphi_{j}^{L}-\varphi_{j}^{U}\right)+\delta_{G i} \sum_{k=0}^{K_{i}} 2^{k}\left(s_{k i j}-h_{k i j}\right)\right)\right.\right. \\
& \left.\left.+\beta_{\ell j} P_{D j}\left(\varphi_{j}^{U}-\varphi_{j}^{L}\right)\right]\right\} \leq 0 ; \quad \forall i \in \Omega_{G}, \forall j \in \Omega_{D} \\
& \sum_{i \in \Omega_{G}} \theta_{i}^{U}+\sum_{j \in \Omega_{D}} \varphi_{j}^{U}-\rho^{U}=1 \\
& \sum_{i \in \Omega_{G}}-\theta_{i}^{L}+\sum_{j \in \Omega_{D}}-\varphi_{j}^{L}+\rho^{L}=-1 \\
& \sum_{i \in \Omega_{G}} \varepsilon_{i}^{G}+\sum_{j \in \Omega_{D}} \varepsilon_{j}^{D}-\rho^{U} \cdot z^{M A X}+\rho^{L} \cdot w^{M I N}=z-w \\
& P_{G i}=P_{G i}^{M I N}+\delta_{G i} \cdot \sum_{k=0}^{K_{i}} 2^{k} \cdot x_{k i}, \quad \forall i \in \Omega_{G} \\
& 0 \leq \alpha_{G i j}-y_{k i j} \leq\left(1-x_{k i}\right) \cdot G, \quad \forall i \in \Omega_{G}, \forall j \in \Omega_{D}, \forall k \in\left\{0, \ldots, K_{i}\right\} \\
& 0 \leq y_{k i j} \leq x_{k i} \cdot G, \quad \forall i \in \Omega_{G}, \forall j \in \Omega_{D}, \forall k \in\left\{0, \ldots, K_{i}\right\} \\
& 0 \leq \alpha_{D j i}-t_{k i j} \leq\left(1-x_{k i}\right) \cdot G, \quad \forall i \in \Omega_{G}, \forall j \in \Omega_{D}, \forall k \in\left\{0, \ldots, K_{i}\right\} \\
& 0 \leq t_{k i j} \leq x_{k i} \cdot G, \quad \forall i \in \Omega_{G}, \forall j \in \Omega_{D}, \forall k \in\left\{0, \ldots, K_{i}\right\} \\
& 0 \leq \tau_{i j}-u_{k i j} \leq\left(1-x_{k i}\right) \cdot G, \quad \forall i \in \Omega_{G}, \forall j \in \Omega_{D}, \forall k \in\left\{0, \ldots, K_{i}\right\} \\
& -x_{k i} \cdot G \leq u_{k i j} \leq x_{k i} \cdot G, \quad \forall i \in \Omega_{G}, \forall j \in \Omega_{D}, \forall k \in\left\{0, \ldots, K_{i}\right\} \\
& 0 \leq \varphi_{j}^{U}-h_{k i j} \leq\left(1-x_{k i}\right) \cdot G, \quad \forall i \in \Omega_{G}, \forall j \in \Omega_{D}, \forall k \in\left\{0, \ldots, K_{i}\right\}
\end{aligned}
$$




$$
\begin{aligned}
& 0 \leq h_{k i j} \leq x_{k i} \cdot G, \quad \forall i \in \Omega_{G}, \forall j \in \Omega_{D}, \forall k \in\left\{0, \ldots, K_{i}\right\} \\
& 0 \leq \varphi_{j}^{L}-s_{k i j} \leq\left(1-x_{k i}\right) \cdot G, \quad \forall i \in \Omega_{G}, \forall j \in \Omega_{D}, \forall k \in\left\{0, \ldots, K_{i}\right\} \\
& 0 \leq s_{k i j} \leq x_{k i} \cdot G, \quad \forall i \in \Omega_{G}, \forall j \in \Omega_{D}, \forall k \in\left\{0, \ldots, K_{i}\right\} \\
& 0 \leq \theta_{i}^{U}-v_{k i} \leq\left(1-x_{k i}\right) \cdot G, \quad \forall i \in \Omega_{G}, \forall k \in\left\{0, \ldots, K_{i}\right\} \\
& 0 \leq v_{k i} \leq x_{k i} \cdot G, \quad \forall i \in \Omega_{G}, \forall k \in\left\{0, \ldots, K_{i}\right\} \\
& 0 \leq \theta_{i}^{L}-q_{k i} \leq\left(1-x_{k i}\right) \cdot G, \quad \forall i \in \Omega_{G}, \forall k \in\left\{0, \ldots, K_{i}\right\} \\
& 0 \leq q_{k i} \leq x_{k i} \cdot G, \quad \forall i \in \Omega_{G}, \forall k \in\left\{0, \ldots, K_{i}\right\} \\
& y_{k i j}, t_{k i j}, u_{k i j}, h_{k i j}, s_{k i j} \in \mathbb{R}, \quad \forall i \in \Omega_{G}, \forall j \in \Omega_{D}, \forall k \in\left\{0, \ldots, K_{i}\right\} \\
& v_{k i}, q_{k i} \in \mathbb{R}, \quad \forall i \in \Omega_{G}, \forall k \in\left\{0, \ldots, K_{i}\right\} \\
& F_{\ell} \in \mathbb{R}, \quad \forall \ell \in \Omega_{L} \\
& P_{G i} \in \mathbb{R}, \quad \forall i \in \Omega_{G} \\
& \alpha_{G i j}, \alpha_{D j i} \in \mathbb{R}_{+}, \quad \forall i \in \Omega_{G}, \forall j \in \Omega_{D} \\
& z, w \in \mathbb{R} \\
& \theta_{i}^{U}, \theta_{i}^{L} \in \mathbb{R}_{+}, \quad \forall i \in \Omega_{G} \\
& \varphi_{j}^{U}, \varphi_{j}^{L} \in \mathbb{R}_{+}, \quad \forall j \in \Omega_{D} \\
& \rho^{U}, \rho^{L} \in \mathbb{R}_{+} \\
& \varepsilon_{i}^{G} \in \mathbb{R}, \quad \forall i \in \Omega_{G} \\
& \varepsilon_{j}^{D} \in \mathbb{R}, \quad \forall j \in \Omega_{D} \\
& \tau_{i j} \in \mathbb{R}, \quad \forall i \in \Omega_{G}, \forall j \in \Omega_{D}
\end{aligned}
$$




\section{Apêndice D}

\section{Dados de Simulação}

Neste Apêndice são apresentados os dados dos sistemas de 6 barras e de 118 barras utilizados no Capítulo 6 para as simulações e apresentação de resultados.

\section{D.1.}

\section{Sistema 6 barras}

Tabela D.1. Dados de barra para o sistema de 6 barras

\begin{tabular}{|c|c|c|c|}
\hline Barra & Demanda (MW) & Geração máxima (MW) & Geração mínima (MW) \\
\hline $1^{*}$ & - & 70 & 7 \\
\hline 2 & 240 & - & 32 \\
\hline 3 & - & 320 & - \\
\hline 4 & 160 & - & 60 \\
\hline 5 & - & 600 & - \\
\hline 6 & 240 & - & \multicolumn{2}{|c|}{} \\
\hline
\end{tabular}

* Barra de referência

Tabela D.2. Dados de linha para o sistema de 6 barras

\begin{tabular}{|c|c|c|c|c|}
\hline Barra "de" & Barra "para" & Reatância (p.u.) & Custo (\$) & Capacidade(MW) \\
\hline 1 & 2 & 0,400 & 1500 & 150 \\
\hline 3 & 2 & 0,600 & 2000 & 170 \\
\hline 3 & 6 & 0,200 & 4000 & 200 \\
\hline 4 & 1 & 0,200 & 750 & 80 \\
\hline 4 & 3 & 0,400 & 1000 & 100 \\
\hline 5 & 4 & 0,100 & 6000 & 400 \\
\hline 5 & 6 & 0,075 & 4000 & 200 \\
\hline 6 & 1 & 0,150 & 4000 & 200 \\
\hline
\end{tabular}

\section{D.2.}

\section{Sistema 118 barras}

Tabela D.3. Dados de barra para o sistema de 118 barras

\begin{tabular}{|c|c|c|c|c|c|}
\hline Barra & Área & $\begin{array}{c}\text { Demanda original } \\
(\mathrm{MW})\end{array}$ & $\begin{array}{c}\text { Demanda } \\
\text { incrementada }(\mathrm{MW})\end{array}$ & $\begin{array}{c}\text { Geração máxima } \\
(\mathrm{MW})\end{array}$ & $\begin{array}{c}\text { Geração mínima } \\
(\mathrm{MW})\end{array}$ \\
\hline 1 & I & 51,00 & 61,20 & - & - \\
\hline 2 & I & 20,00 & 24,00 & - & - \\
\hline 3 & I & 39,00 & 46,80 & - & - \\
\hline 4 & I & 39,00 & 46,80 & - & - \\
\hline 5 & I & - & - & - & - \\
\hline 6 & I & 52,00 & 62,40 & - & - \\
\hline 7 & I & 19,00 & 22,80 & - & - \\
\hline 8 & I & 28,00 & 33,60 & - & - \\
\hline 9 & I & - & - & - & 55,00 \\
\hline 10 & I & - & - & 550,00 & - \\
\hline 11 & I & 70,00 & 84,00 & - & \\
\hline
\end{tabular}




\begin{tabular}{|c|c|c|c|c|c|}
\hline 12 & I & - & - & 138,00 & 13,80 \\
\hline 13 & I & 34,00 & 40,80 & - & - \\
\hline 14 & I & 14,00 & 16,80 & - & - \\
\hline 15 & I & 90,00 & 108,00 & - & - \\
\hline 16 & I & 25,00 & 30,00 & - & - \\
\hline 17 & $\mathrm{I}$ & 11,00 & 13,20 & - & - \\
\hline 18 & I & 60,00 & 72,00 & - & - \\
\hline 19 & I & 45,00 & 54,00 & - & - \\
\hline 20 & I & 18,00 & 21,60 & - & - \\
\hline 21 & I & 14,00 & 16,80 & - & - \\
\hline 22 & I & 10,00 & 12,00 & - & - \\
\hline 23 & $\mathrm{I}$ & 7,00 & 8,40 & - & - \\
\hline 24 & III & 13,00 & 15,60 & - & - \\
\hline 25 & $\mathrm{I}$ & - & - & 320,00 & 32,00 \\
\hline 26 & $\mathrm{I}$ & - & - & 414,00 & 41,40 \\
\hline 27 & I & 71,00 & 85,20 & - & - \\
\hline 28 & I & 17,00 & 20,40 & - & - \\
\hline 29 & I & 24,00 & 28,80 & - & - \\
\hline 30 & I & - & - & - & - \\
\hline 31 & I & - & - & 64,00 & 6,40 \\
\hline 32 & I & 59,00 & 70,80 & - & - \\
\hline 33 & I & 23,00 & 33,12 & - & - \\
\hline 34 & II & 59,00 & 84,96 & - & - \\
\hline 35 & II & 33,00 & 47,52 & - & - \\
\hline 36 & II & 31,00 & 44,64 & - & - \\
\hline 37 & II & - & - & - & - \\
\hline 38 & II & - & - & - & - \\
\hline 39 & II & 27,00 & 38,88 & - & - \\
\hline 40 & II & 66,00 & 95,04 & - & - \\
\hline 41 & II & 37,00 & 53,28 & - & - \\
\hline 42 & II & 96,00 & 138,24 & - & - \\
\hline 43 & II & 18,00 & 25,92 & - & - \\
\hline 44 & II & 16,00 & 23,04 & - & - \\
\hline 45 & II & 53,00 & 76,32 & - & - \\
\hline 46 & II & - & - & 91,00 & 9,10 \\
\hline 47 & II & 34,00 & 48,96 & - & - \\
\hline 48 & II & 20,00 & 28,80 & - & - \\
\hline 49 & II & - & - & 217,00 & 21,70 \\
\hline 50 & II & 17,00 & 24,48 & - & - \\
\hline 51 & II & 17,00 & 24,48 & - & - \\
\hline 52 & II & 18,00 & 25,92 & - & - \\
\hline 53 & II & 23,00 & 33,12 & - & - \\
\hline 54 & II & - & - & 179,25 & 17,93 \\
\hline 55 & II & 63,00 & 90,72 & - & - \\
\hline 56 & II & 84,00 & 120,96 & - & - \\
\hline 57 & II & 12,00 & 17,28 & - & - \\
\hline 58 & II & 12,00 & 17,28 & - & - \\
\hline 59 & II & - & - & 620,00 & 62,00 \\
\hline 60 & II & 78,00 & 112,32 & - & - \\
\hline 61 & II & - & - & 436,00 & 43,60 \\
\hline 62 & II & 77,00 & 110,88 & - & - \\
\hline 63 & II & - & - & - & - \\
\hline
\end{tabular}




\begin{tabular}{|c|c|c|c|c|c|}
\hline 64 & II & - & - & - & - \\
\hline 65 & II & - & - & 491,00 & 49,10 \\
\hline 66 & II & - & - & 453,00 & 45,30 \\
\hline 67 & II & 28,00 & 40,32 & - & - \\
\hline 68 & II & - & - & - & - \\
\hline $69^{*}$ & III & - & - & 805,20 & 80,52 \\
\hline 70 & III & 66,00 & 79,20 & - & - \\
\hline 71 & III & - & - & - & - \\
\hline 72 & III & 12,00 & 14,40 & - & - \\
\hline 73 & III & 6,00 & 7,20 & - & - \\
\hline 74 & III & 68,00 & 81,60 & - & - \\
\hline 75 & III & 47,00 & 56,40 & - & - \\
\hline 76 & III & 68,00 & 97,92 & - & - \\
\hline 77 & III & 61,00 & 87,84 & - & - \\
\hline 78 & III & 71,00 & 102,24 & - & - \\
\hline 79 & III & 39,00 & 56,16 & - & - \\
\hline 80 & III & - & - & 14,25 & 1,43 \\
\hline 81 & III & - & - & - & - \\
\hline 82 & IV & 54,00 & 54,00 & - & - \\
\hline 83 & IV & 20,00 & 20,00 & - & - \\
\hline 84 & IV & 11,00 & 11,00 & - & - \\
\hline 85 & IV & 24,00 & 24,00 & - & - \\
\hline 86 & IV & 21,00 & 21,00 & - & - \\
\hline 87 & IV & - & - & 104,00 & 10,40 \\
\hline 88 & IV & 48,00 & 48,00 & - & - \\
\hline 89 & IV & - & - & 353,50 & 35,35 \\
\hline 90 & IV & 163,00 & 163,00 & - & - \\
\hline 91 & IV & 10,00 & 10,00 & - & - \\
\hline 92 & IV & 65,00 & 65,00 & - & - \\
\hline 93 & IV & 12,00 & 12,00 & - & - \\
\hline 94 & IV & 30,00 & 30,00 & - & - \\
\hline 95 & IV & 42,00 & 42,00 & - & - \\
\hline 96 & IV & 38,00 & 38,00 & - & - \\
\hline 97 & III & 15,00 & 21,60 & - & - \\
\hline 98 & III & 34,00 & 48,96 & - & - \\
\hline 99 & III & 42,00 & 60,48 & - & - \\
\hline 100 & IV & - & - & 139,00 & 13,90 \\
\hline 101 & IV & 22,00 & 22,00 & - & - \\
\hline 102 & IV & 5,00 & 5,00 & - & - \\
\hline 103 & $\mathrm{~V}$ & - & - & 117,00 & 11,70 \\
\hline 104 & $\mathrm{~V}$ & 38,00 & 38,00 & - & - \\
\hline 105 & $\mathrm{~V}$ & 31,00 & 31,00 & - & - \\
\hline 106 & $\mathrm{~V}$ & 43,00 & 43,00 & - & - \\
\hline 107 & $\mathrm{~V}$ & 50,00 & 50,00 & - & - \\
\hline 108 & $\mathrm{~V}$ & 2,00 & 2,00 & - & - \\
\hline 109 & $\mathrm{~V}$ & 8,00 & 8,00 & - & - \\
\hline 110 & V & 39,00 & 39,00 & - & - \\
\hline 111 & V & - & - & 136,00 & 13,60 \\
\hline 112 & V & 68,00 & 68,00 & - & - \\
\hline 113 & I & 6,00 & 7,20 & - & - \\
\hline 114 & I & 8,00 & 9,60 & - & - \\
\hline 115 & I & 22,00 & 26,40 & - & - \\
\hline
\end{tabular}




\begin{tabular}{|c|c|c|c|c|c|}
\hline 116 & II & 184,00 & 184,00 & - & - \\
\hline 117 & I & 20,00 & 24,00 & - & - \\
\hline 118 & III & 33,00 & 47,52 & - & - \\
\hline
\end{tabular}

* Barra de referência

Tabela D.4. Dados de linha para o sistema de 118 barras

\begin{tabular}{|c|c|c|c|c|}
\hline Barra "de" & Barra "para" & Reatância (p.u.) & Custo (\$) & Capacidade (MW) \\
\hline 1 & 2 & 0,10 & 699,30 & 70,00 \\
\hline 1 & 3 & 0,04 & 296,80 & 70,00 \\
\hline 2 & 12 & 0,06 & 431,20 & 70,00 \\
\hline 3 & 5 & 0,11 & 1890,00 & 175,00 \\
\hline 3 & 12 & 0,16 & 1120,00 & 70,00 \\
\hline 4 & 5 & 0,01 & 159,60 & 200,00 \\
\hline 4 & 11 & 0,07 & 1204,00 & 175,00 \\
\hline 5 & 6 & 0,05 & 945,00 & 175,00 \\
\hline 5 & 11 & 0,07 & 1193,50 & 175,00 \\
\hline 6 & 7 & 0,02 & 145,60 & 70,00 \\
\hline 7 & 12 & 0,03 & 238,00 & 70,00 \\
\hline 8 & 9 & 0,03 & 5032,50 & 550,00 \\
\hline 8 & 5 & 0,03 & 4005,00 & 500,00 \\
\hline 8 & 30 & 0,05 & 882,00 & 175,00 \\
\hline 9 & 10 & 0,03 & 5313,00 & 550,00 \\
\hline 11 & 12 & 0,02 & 137,20 & 70,00 \\
\hline 11 & 13 & 0,07 & 511,70 & 70,00 \\
\hline 12 & 14 & 0,07 & 494,90 & 70,00 \\
\hline 12 & 16 & 0,08 & 583,80 & 70,00 \\
\hline 12 & 117 & 0,14 & 980,00 & 70,00 \\
\hline 13 & 15 & 0,24 & 1710,80 & 70,00 \\
\hline 14 & 15 & 0,20 & 1365,00 & 70,00 \\
\hline 15 & 17 & 0,04 & 874,00 & 200,00 \\
\hline 15 & 19 & 0,04 & 275,80 & 70,00 \\
\hline 15 & 33 & 0,12 & 870,80 & 70,00 \\
\hline 16 & 17 & 0,18 & 1260,70 & 70,00 \\
\hline 17 & 18 & 0,05 & 883,75 & 175,00 \\
\hline 17 & 31 & 0,16 & 1094,10 & 70,00 \\
\hline 17 & 113 & 0,03 & 210,70 & 70,00 \\
\hline 18 & 19 & 0,05 & 345,10 & 70,00 \\
\hline 19 & 20 & 0,12 & 819,00 & 70,00 \\
\hline 19 & 34 & 0,25 & 1729,00 & 70,00 \\
\hline 20 & 21 & 0,08 & 594,30 & 70,00 \\
\hline 21 & 22 & 0,10 & 679,00 & 70,00 \\
\hline 22 & 23 & 0,16 & 1113,00 & 70,00 \\
\hline 23 & 24 & 0,05 & 861,00 & 175,00 \\
\hline 23 & 25 & 0,08 & 7200,00 & 300,00 \\
\hline 23 & 32 & 0,12 & 1614,20 & 140,00 \\
\hline 24 & 70 & 0,41 & 2880,50 & 70,00 \\
\hline 24 & 72 & 0,20 & 1372,00 & 70,00 \\
\hline 25 & 27 & 0,16 & 3260,00 & 200,00 \\
\hline 26 & 25 & 0,04 & 764,00 & 200,00 \\
\hline 26 & 30 & 0,09 & 7740,00 & 300,00 \\
\hline 27 & 28 & 0,09 & 598,50 & 70,00 \\
\hline 27 & 32 & 0,08 & 528,50 & 70,00 \\
\hline
\end{tabular}




\begin{tabular}{|c|c|c|c|c|}
\hline 27 & 115 & 0,07 & 518,70 & 70,00 \\
\hline 28 & 29 & 0,09 & 660,10 & 70,00 \\
\hline 29 & 31 & 0,03 & 231,70 & 70,00 \\
\hline 30 & 17 & 0,04 & 3492,00 & 300,00 \\
\hline 30 & 38 & 0,05 & 945,00 & 175,00 \\
\hline 31 & 32 & 0,10 & 689,50 & 70,00 \\
\hline 32 & 113 & 0,20 & 4060,00 & 200,00 \\
\hline 32 & 114 & 0,06 & 428,40 & 70,00 \\
\hline 33 & 37 & 0,14 & 994,00 & 70,00 \\
\hline 34 & 36 & 0,03 & 187,60 & 70,00 \\
\hline 34 & 37 & 0,01 & 188,00 & 200,00 \\
\hline 34 & 43 & 0,17 & 1176,70 & 70,00 \\
\hline 35 & 36 & 0,01 & 71,40 & 70,00 \\
\hline 35 & 37 & 0,05 & 347,90 & 70,00 \\
\hline 37 & 39 & 0,11 & 742,00 & 70,00 \\
\hline 37 & 40 & 0,17 & 1176,00 & 70,00 \\
\hline 38 & 37 & 0,04 & 3375,00 & 300,00 \\
\hline 38 & 65 & 0,10 & 1972,00 & 200,00 \\
\hline 39 & 40 & 0,06 & 423,50 & 70,00 \\
\hline 40 & 41 & 0,05 & 340,90 & 70,00 \\
\hline 40 & 42 & 0,18 & 1281,00 & 70,00 \\
\hline 41 & 42 & 0,14 & 945,00 & 70,00 \\
\hline 42 & 49 & 0,32 & 2261,00 & 70,00 \\
\hline 42 & 49 & 0,32 & 2261,00 & 70,00 \\
\hline 43 & 44 & 0,25 & 1717,80 & 70,00 \\
\hline 44 & 45 & 0,09 & 630,70 & 70,00 \\
\hline 45 & 46 & 0,14 & 949,20 & 70,00 \\
\hline 45 & 49 & 0,19 & 1302,00 & 70,00 \\
\hline 46 & 47 & 0,13 & 889,00 & 70,00 \\
\hline 46 & 48 & 0,19 & 1323,00 & 70,00 \\
\hline 47 & 49 & 0,06 & 437,50 & 70,00 \\
\hline 47 & 69 & 0,28 & 1944,60 & 70,00 \\
\hline 48 & 49 & 0,05 & 353,50 & 70,00 \\
\hline 49 & 50 & 0,08 & 526,40 & 70,00 \\
\hline 49 & 51 & 0,14 & 959,00 & 70,00 \\
\hline 49 & 54 & 0,29 & 2023,00 & 70,00 \\
\hline 49 & 54 & 0,29 & 2037,00 & 70,00 \\
\hline 49 & 66 & 0,09 & 1838,00 & 200,00 \\
\hline 49 & 66 & 0,09 & 1838,00 & 200,00 \\
\hline 49 & 69 & 0,32 & 2268,00 & 70,00 \\
\hline 50 & 57 & 0,13 & 938,00 & 70,00 \\
\hline 51 & 52 & 0,06 & 411,60 & 70,00 \\
\hline 51 & 58 & 0,07 & 503,30 & 70,00 \\
\hline 52 & 53 & 0,16 & 1144,50 & 70,00 \\
\hline 53 & 54 & 0,12 & 854,00 & 70,00 \\
\hline 54 & 55 & 0,07 & 494,90 & 70,00 \\
\hline 54 & 56 & 0,01 & 167,13 & 175,00 \\
\hline 54 & 59 & 0,23 & 1605,10 & 70,00 \\
\hline 55 & 56 & 0,02 & 105,70 & 70,00 \\
\hline 55 & 59 & 0,22 & 1510,60 & 70,00 \\
\hline 56 & 57 & 0,10 & 676,20 & 70,00 \\
\hline 56 & 58 & 0,10 & 676,20 & 70,00 \\
\hline
\end{tabular}




\begin{tabular}{|c|c|c|c|c|}
\hline 56 & 59 & 0,25 & 1757,00 & 70,00 \\
\hline 56 & 59 & 0,24 & 1673,00 & 70,00 \\
\hline 59 & 60 & 0,15 & 2537,50 & 175,00 \\
\hline 59 & 61 & 0,15 & 1050,00 & 70,00 \\
\hline 60 & 61 & 0,01 & 270,00 & 200,00 \\
\hline 60 & 62 & 0,06 & 392,70 & 70,00 \\
\hline 61 & 62 & 0,04 & 658,00 & 175,00 \\
\hline 62 & 66 & 0,22 & 1526,00 & 70,00 \\
\hline 62 & 67 & 0,12 & 819,00 & 70,00 \\
\hline 63 & 59 & 0,04 & 3474,00 & 300,00 \\
\hline 63 & 64 & 0,02 & 1800,00 & 300,00 \\
\hline 64 & 61 & 0,03 & 536,00 & 200,00 \\
\hline 64 & 65 & 0,03 & 4530,00 & 500,00 \\
\hline 65 & 66 & 0,04 & 740,00 & 200,00 \\
\hline 65 & 68 & 0,02 & 2400,00 & 500,00 \\
\hline 66 & 67 & 0,10 & 710,50 & 70,00 \\
\hline 68 & 69 & 0,04 & 740,00 & 200,00 \\
\hline 68 & 81 & 0,02 & 3030,00 & 500,00 \\
\hline 68 & 116 & 0,00 & 81,00 & 200,00 \\
\hline 69 & 70 & 0,13 & 2540,00 & 200,00 \\
\hline 69 & 75 & 0,12 & 2440,00 & 200,00 \\
\hline 69 & 77 & 0,10 & 1767,50 & 175,00 \\
\hline 70 & 71 & 0,04 & 248,50 & 70,00 \\
\hline 70 & 74 & 0,13 & 926,10 & 70,00 \\
\hline 70 & 75 & 0,14 & 987,00 & 70,00 \\
\hline 71 & 72 & 0,18 & 1260,00 & 70,00 \\
\hline 71 & 73 & 0,05 & 317,80 & 70,00 \\
\hline 74 & 75 & 0,04 & 284,20 & 70,00 \\
\hline 75 & 77 & 0,20 & 1399,30 & 70,00 \\
\hline 75 & 118 & 0,05 & 841,75 & 175,00 \\
\hline 76 & 77 & 0,15 & 1036,00 & 70,00 \\
\hline 76 & 118 & 0,05 & 380,80 & 70,00 \\
\hline 77 & 78 & 0,01 & 217,00 & 175,00 \\
\hline 77 & 80 & 0,05 & 970,00 & 200,00 \\
\hline 77 & 80 & 0,11 & 2100,00 & 200,00 \\
\hline 77 & 82 & 0,09 & 682,40 & 80,00 \\
\hline 78 & 79 & 0,02 & 170,80 & 70,00 \\
\hline 79 & 80 & 0,07 & 492,80 & 70,00 \\
\hline 80 & 96 & 0,18 & 1274,00 & 70,00 \\
\hline 80 & 97 & 0,09 & 653,80 & 70,00 \\
\hline 80 & 98 & 0,11 & 1890,00 & 175,00 \\
\hline 80 & 99 & 0,21 & 1648,00 & 80,00 \\
\hline 81 & 80 & 0,04 & 5550,00 & 500,00 \\
\hline 82 & 83 & 0,04 & 293,20 & 80,00 \\
\hline 82 & 96 & 0,05 & 371,00 & 70,00 \\
\hline 83 & 84 & 0,13 & 924,00 & 70,00 \\
\hline 83 & 85 & 0,15 & 1036,00 & 70,00 \\
\hline 84 & 85 & 0,06 & 448,70 & 70,00 \\
\hline 85 & 86 & 0,12 & 2460,00 & 200,00 \\
\hline 85 & 88 & 0,10 & 714,00 & 70,00 \\
\hline 85 & 89 & 0,17 & 1211,00 & 70,00 \\
\hline 86 & 87 & 0,21 & 4148,00 & 200,00 \\
\hline
\end{tabular}




\begin{tabular}{|c|c|c|c|c|}
\hline 88 & 89 & 0,07 & 1424,00 & 200,00 \\
\hline 89 & 90 & 0,19 & 3760,00 & 200,00 \\
\hline 89 & 90 & 0,10 & 1994,00 & 200,00 \\
\hline 89 & 92 & 0,05 & 1010,00 & 200,00 \\
\hline 89 & 92 & 0,16 & 3162,00 & 200,00 \\
\hline 90 & 91 & 0,08 & 585,20 & 70,00 \\
\hline 91 & 92 & 0,13 & 890,40 & 70,00 \\
\hline 92 & 93 & 0,08 & 593,60 & 70,00 \\
\hline 92 & 94 & 0,16 & 1106,00 & 70,00 \\
\hline 92 & 100 & 0,30 & 2065,00 & 70,00 \\
\hline 92 & 102 & 0,06 & 391,30 & 70,00 \\
\hline 93 & 94 & 0,07 & 512,40 & 70,00 \\
\hline 94 & 95 & 0,04 & 303,80 & 70,00 \\
\hline 94 & 96 & 0,09 & 608,30 & 70,00 \\
\hline 94 & 100 & 0,06 & 406,00 & 70,00 \\
\hline 95 & 96 & 0,05 & 382,90 & 70,00 \\
\hline 96 & 97 & 0,09 & 619,50 & 70,00 \\
\hline 98 & 100 & 0,18 & 1253,00 & 70,00 \\
\hline 99 & 100 & 0,08 & 569,10 & 70,00 \\
\hline 100 & 101 & 0,13 & 883,40 & 70,00 \\
\hline 100 & 103 & 0,05 & 1050,00 & 200,00 \\
\hline 100 & 104 & 0,20 & 1428,00 & 70,00 \\
\hline 100 & 106 & 0,23 & 1603,00 & 70,00 \\
\hline 101 & 102 & 0,11 & 784,00 & 70,00 \\
\hline 103 & 104 & 0,16 & 1108,80 & 70,00 \\
\hline 103 & 105 & 0,16 & 1137,50 & 70,00 \\
\hline 103 & 110 & 0,18 & 3172,75 & 175,00 \\
\hline 104 & 105 & 0,04 & 264,60 & 70,00 \\
\hline 105 & 106 & 0,05 & 382,90 & 70,00 \\
\hline 105 & 107 & 0,18 & 1281,00 & 70,00 \\
\hline 105 & 108 & 0,07 & 492,10 & 70,00 \\
\hline 106 & 107 & 0,18 & 1281,00 & 70,00 \\
\hline 108 & 109 & 0,03 & 201,60 & 70,00 \\
\hline 109 & 110 & 0,08 & 533,40 & 70,00 \\
\hline 110 & 111 & 0,08 & 1321,25 & 175,00 \\
\hline 110 & 112 & 0,06 & 1120,00 & 175,00 \\
\hline 114 & 115 & 0,01 & 72,80 & 70,00 \\
\hline
\end{tabular}

